\title{
AN OILSPILL RISK ANALYSIS FOR THE EASTERN GULF OF MEXICO (Proposed Sale 65) OUTER CONTINENTAL SHELF LEASE AREA
}

U.S. GEOLOGICAL SURVEY

Open-File Report 78-132

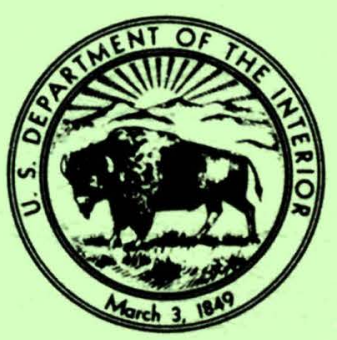




\section{AN OILSPILL RISK ANALYSIS FOR}

THE EASTERN GULF OF MEXICO

(Proposed Sale 65)

OUTER CONTINENTAL SHELF LEASE AREA

By TIMOTHY WYANT and JAMES R. SLACK

U.S. GEOLOGICAL SURVEY

Open-File Report 78-132

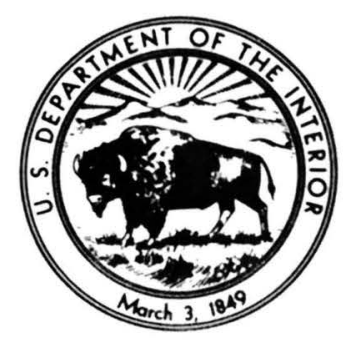




\title{
U.S. DEPARTMENT OF THE INTERIOR \\ CECIL D. ANDRUS, Secretary
}

\author{
GEOLOGICAL SURVEY \\ W.A. Radlinski, Acting Director
}

For additional information write to:

Chief Hydrologist

U.S. Geological Survey, WRD

410 National Center

Reston, Virginia 22092 


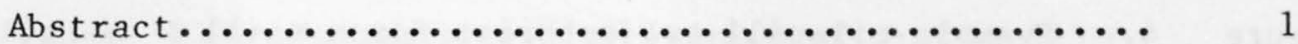

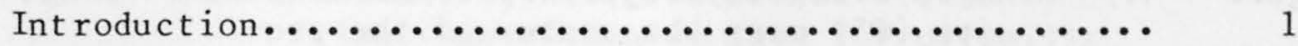

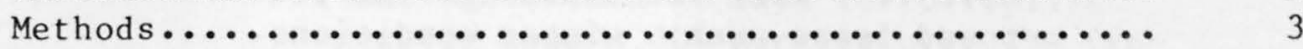

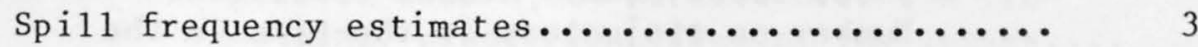

Oispil1 trajectory simulations............... 7

Locations of biological and recreational resources 9

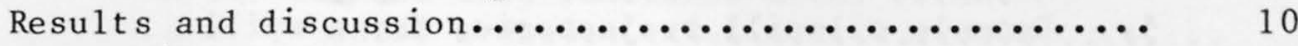

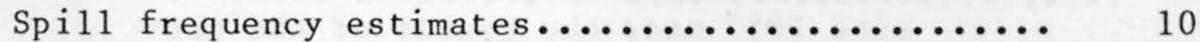

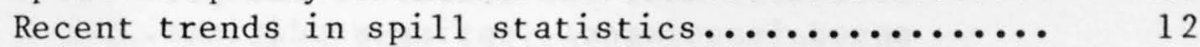

0ilspil1 trajectories...................... 13

Oilspill trajectories in relation to biological resources and recreation areas............... 18

Estimates of weathering rates and slick dispersion 28

Combined analysis: spill frequency estimates and

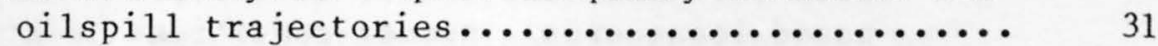

Relative risks of leasing in different parts of

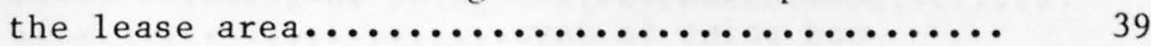

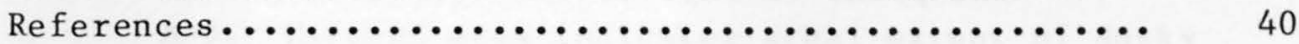

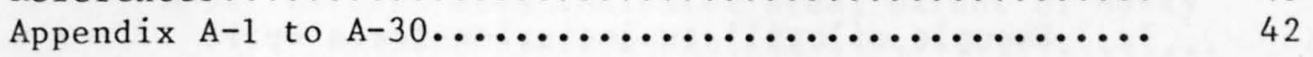

\section{ILLUSTRATIONS}

Page

Figure 1A. Map showing the subdivisions of the

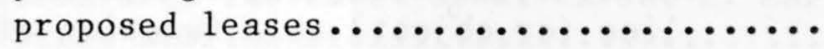

1B. Map showing the subdivisions of the

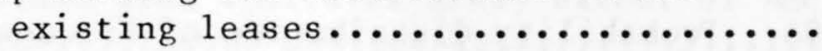

2. Map showing potential starting points for spills from proposed leases (P1-P14), existing leases (E1-E12), and transportation $(\mathrm{T} 1-\mathrm{T} 3)$

3. Spill frequency distributions for spills greater than $1,000 \mathrm{barrels}$ during the (remaining) production 1 ives of the

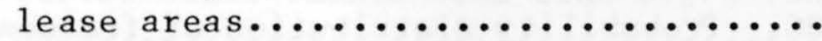


Page

Figure 4. Example oilspill trajectories for a spil1 site (P5) near the center of the proposed lease area: winter conditions. Number on trajectory is the time to the

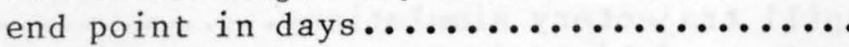

5. Example oilspill trajectories for a spill site (P5) near the center of the proposed lease area: spring conditions. Number on trajectory is the time to the

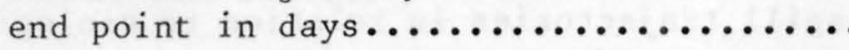

6. Example oilspill trajectories for a spill site (P5) near the center of the proposed lease area: summer conditions. Number on trajectory is the time to the

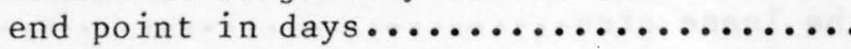

7. Example oilspill trajectories for a spill site $(\mathrm{P}-5)$ near the center of the proposed lease area: autumn conditions. Number on trajectory is the time to the

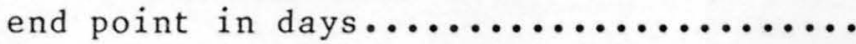

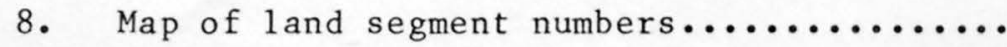

9. Density of oil reaching an idealized shoreline (or object) as a function of travel

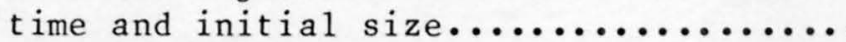

10A. Probability distribution of frequency of 1 andings within 3 days for oilspills greater than 1,000 barrels over the (remaining) production lives of the leases..

10B. Probability distribution of frequency of landings within 10 days for oilspills greater than 1,000 barrels over the (remaining) production lives of the leases..

10C. Probability distribution of frequency of 1 andings within 30 days for oilspills greater than 1,000 barrels over the (remaining) production lives of the leases.. 
Page

Figure 10D. Probability distribution of frequency of

landings within 60 days for oilspills greater than 1,000 barrels over the (remaining) production lives of the leases....

A-1. Hatched area indicates areal extent of

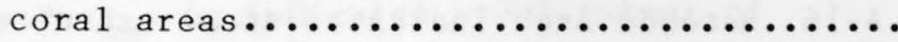

A-2. Hatched area indicates areal extent of

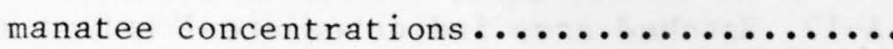

A-3. Hatched area indicates areal extent of brown

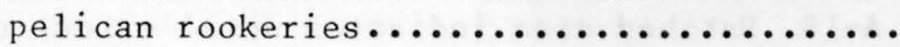

A-4. Hatched area indicates areal extent of wading or pelagic bird rookeries..........

A-5. Hatched area indicates areal extent of dusky

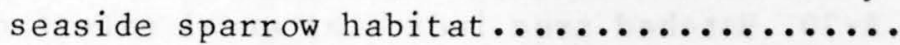

A-6. Hatched area indicates areal extent of bald

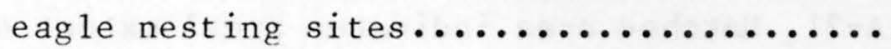

A-7. Hatched area indicates areal extent of Mississippi sandhil1 crane habitat........

A-8. Hatched area indicates areal extent of marine

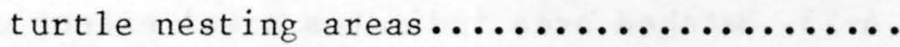

A-9. Hatched area indicates areal extent of Ameri-

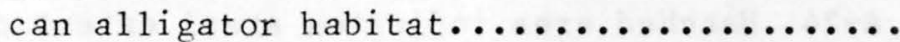

$A-10$. Hatched area indicates areal extent of mangroves or tidal marsh................

A-11. Hatched area indicates areal extent of estua-

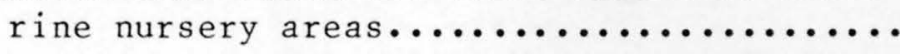

$A-12$. Hatched area indicates areal extent of West F1orida adult female blue crab migration

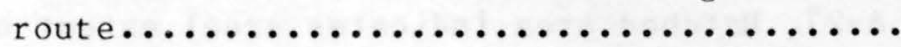

A-13. Hatched area indicates areal extent of West Florida blue crab larval transport route... 
Figure A-14. Hatched area indicates areal extent of

Tortugas pink shrimp nursery grounds......

A-15. Hatched area indicates areal extent of stone

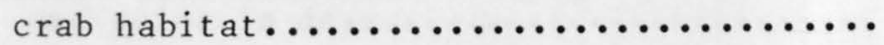

A-16. Hatched area indicates areal extent of

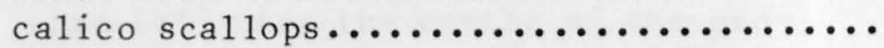

A-17. Hatched area indicates areal extent of

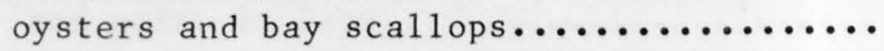

A-18. Hatched area indicates areal extent of sea-

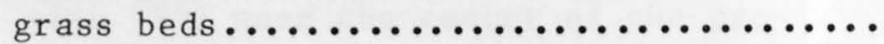

A-19. Hatched area indicates areal extent of spiny

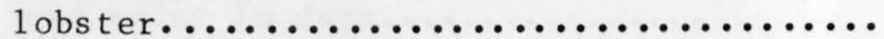

A-20. Hatched area indicates areal extent of sandy

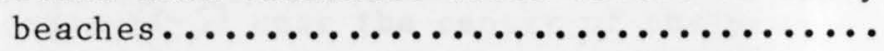

$A-21$. Hatched area indicates areal extent of

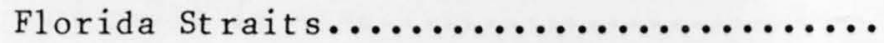

A-22. Hatched area indicates areal extent of high density use shoreline.................

A-23. Hatched area indicates areal extent of

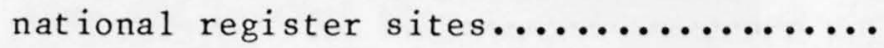

A-24. Hatched area indicates areal extent of designated wildlife, natural, and conser-

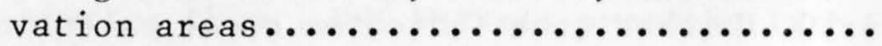

A-25. Hatched area indicates areal extent of designated national wilderness areas......

A-26. Hatched area indicates areal extent of national marine and estuarine sanctuaries.

A-27. Hatched area indicates areal extent of

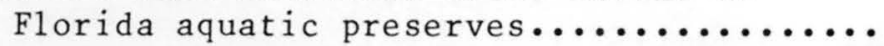


Figure A-28. Hatched area indicates areal extent of designated shoreline, national, and state

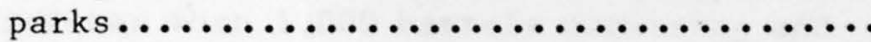

A-29. Hatched area indicates areal extent of ports

A-30. Hatched area indicates areal extent of

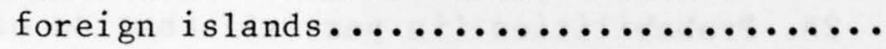


Table 1. Oilspill probability estimates for the

Eastern Gulf of Mexico lease area.........

2A. Probabilities (in percent) that an oilspill starting at a particular location will reach a certain land segment in 3 days....

2B. Probabilities (in percent) that an oilspill starting at a particular location will reach a certain 1 and segment in 10 days...

2C. Probabilities (in percent) that an oilspill starting at a particular location will reach a certain land segment in 30 days...

2D. Probabilities (in percent) that an oilspill starting at a particular location will reach a certain land segment in 60 days...

3A. Probabilities (in percent) that an oilspill starting at a particular location will reach a certain object in 3 days...........

3B. Probabilities (in percent) that an oilspill starting at a particular location will reach a certain object in 10 days.........

3C. Probabilities (in percent) that an oilspill starting at a particular location will reach a certain object in 30 days.........

3D. Probabilities (in percent) that an oilspill starting at a particular location will reach a certain object in 60 days.........

4. Probabilities (in percent) of one or more spills and most likely number of spills greater than 1,000 barrels occurring and contacting objects over the (remaining) production 1 ife of the lease area......... 
Page

Table 5. Probabilities (in percent) of one or more spills and most likely number of spills greater than 1,000 barrels occurring and contacting land segments over the (remaining) production 1 ife of the lease area.... 

An oilspill risk analysis was conducted to determine the relative environmental hazards of developing oil in different regions of the Eastern Gulf of Mexico Outer Continental Shelf lease area. The study analyzed the probability of spill occurrence, likely paths of the spills, and locations in space and time of such objects as recreational and biological resources likely to be vulnerable. These results combined to yield estimates of the overall oilspill risk associated with development of the proposed lease area. This risk is compared to the existing oilspill risk from existing leases in the area. The analysis implicitly includes estimates of weathering rates and slick dispersion and an indication of the possible mitigating effects of cleanups.

\section{INTRODUCTION}

The Federal Government has proposed to lease 667 thousand acres of Outer Continental Shelf (OCS) lands in the Eastern Gulf of Mexico for oil and gas development. Estimated recoverable petroleum resources for the proposed $116 \mathrm{tracts}$ in the sale area range from 15 million to 150 million barrels. Contingent upon actual discovery of this quantity of oil, production is expected to span a period of about 25 years. There is already existing production of petroleum in this area (largely in the western portion) which, it is estimated, has yet to yield on the order of 1.5 to 2 billion barrels of oil.

Oilspills are one of the major concerns associated with offshore oil and gas development in the Eastern Gulf of Mexico. An important fact that stands out when one attempts to evaluate the significance of accidental oil spillage for this, or any proposed lease area, is that the problem is fundamentally probabilistic. A great deal of uncertainty exists, for example, about the number and size of spills that might occur during the course of development, as well as the wind and current 
conditions that would exist and give direction to the oil slick at the specifictimes spills do occur. While some of the uncertainty reflects incomplete and imperfect data, considerable uncertainty is simply inherent in the problem.

In view of this inability to predict with certainty future oilspill effects, it is important to consider the range of possible effects that could accompany oil and gas development. It is equally important, however, in attempting to maintain perspective on the problem, to associate these potential effects with quantitative estimates of the probability of their occurrence.

This report summarizes results of an oilspill risk analysis conducted for the proposed Eastern Gulf of Mexico (Sale 65) OCS lease sale. The study had the objective of determining relative risks associated with additional oil and gas development in different regions of the proposed lease area and was undertaken to facilitate final selection of tracts to be offered for sale. The analysis was conducted in three more or less independent parts corresponding to different aspects of the overall problem. The first part dealt with the probability of spill occurrence, the second with likely spill trajectories for the times and places spills might occur, and the third part with the spatial and temporal location of specific objects, such as biological and recreation resources thought to be vulnerable to oil spills. Results of the individual parts of the analysis were then combined to give estimates of the overall oilspill risk associated with oil and gas development in the lease area. This analysis was done seperately for the proposed leases and the existing leases and the results combined to determine the cumulative or incremental risk due to the proposed sale.

Much of the data and information used in the analysis were compiled by the U.S. Bureau of Land Management in the course of preparing the environmental impact statement for the proposed lease sale. These results, then, represent synthesis and analysis of existing information rather than presentation of new material.

We would like to express special appreciation to David Amstutz, John Meier, and Robert Moore of the U.S. Bureau of Land Management for their assistance in gathering the necessary data and information for the study; and to the Conservation Division of the Geological Survey for providing the estimates of petroleum. 
Statistical distributions for estimating probabilities of oilspill occurrence were taken from Devanney and Stewart (1974) and Stewart (1975, 1976). In addition to the fundamental assumption that realistic estimates of future spill frequency can be based on past ocs experience, use of these distributions requires the further specific assumptions that spills occur independently of each other (as a Poisson process), and that spill rate is dependent on volume of oil produced and handled. Each of these assumptions is open to dispute. The first assumption - that past spill rates are indicative of future spill rates - might be modified either by assuming a decrease in future spill rate owing to experience and improved standards or by assuming an increase in future spill rate owing to unknown conditions in new territory. The second assumption - that spills occur independently of each other - might be modified either by assuming a positive correlation (if a spill occurs, the time is ripe for more) or by assuming a negative correlation (if a spill occurs, extra precautions are immediately thereaftertaken). The third assumption-that the spill rate is soley a function of the volume of oil handled-might be modified on the basis of size, extent, frequency and duration of the handing. This analysis takes the middle ground through these assumptions. Any changes in the results due to variations of the assumptions apply across the board so that relative merits are not altered.

Spill frequency estimates were calculated separately for each of the 14 subdivisions of the proposed lease area (figure 1A) and the 12 subdivisions of the existing leases (figure 1B) based on estimated petroleum resources for the areas (U.S. Ceological Survey, proprietary data). Use of the Devanney and Stewart distributions permitted separate estimates of platform, pipeline, and tanker spill frequencies; which could then be combined to estimate the risk from production, transport of crude to shore, and trans-shipment of some of the crude within the Gulf of Mexico. Spill frequency estimates ( $t a b l e ~ 1)$ were made for spills less than 50 barrels, between 50 and 1,000 barrels, and greater than $1,000 \mathrm{barrels}$ in size. The size grouping is somewhat arbitrary but, as discussed below, is important in considering the significance of weathering in reducing oilspill impacts. 


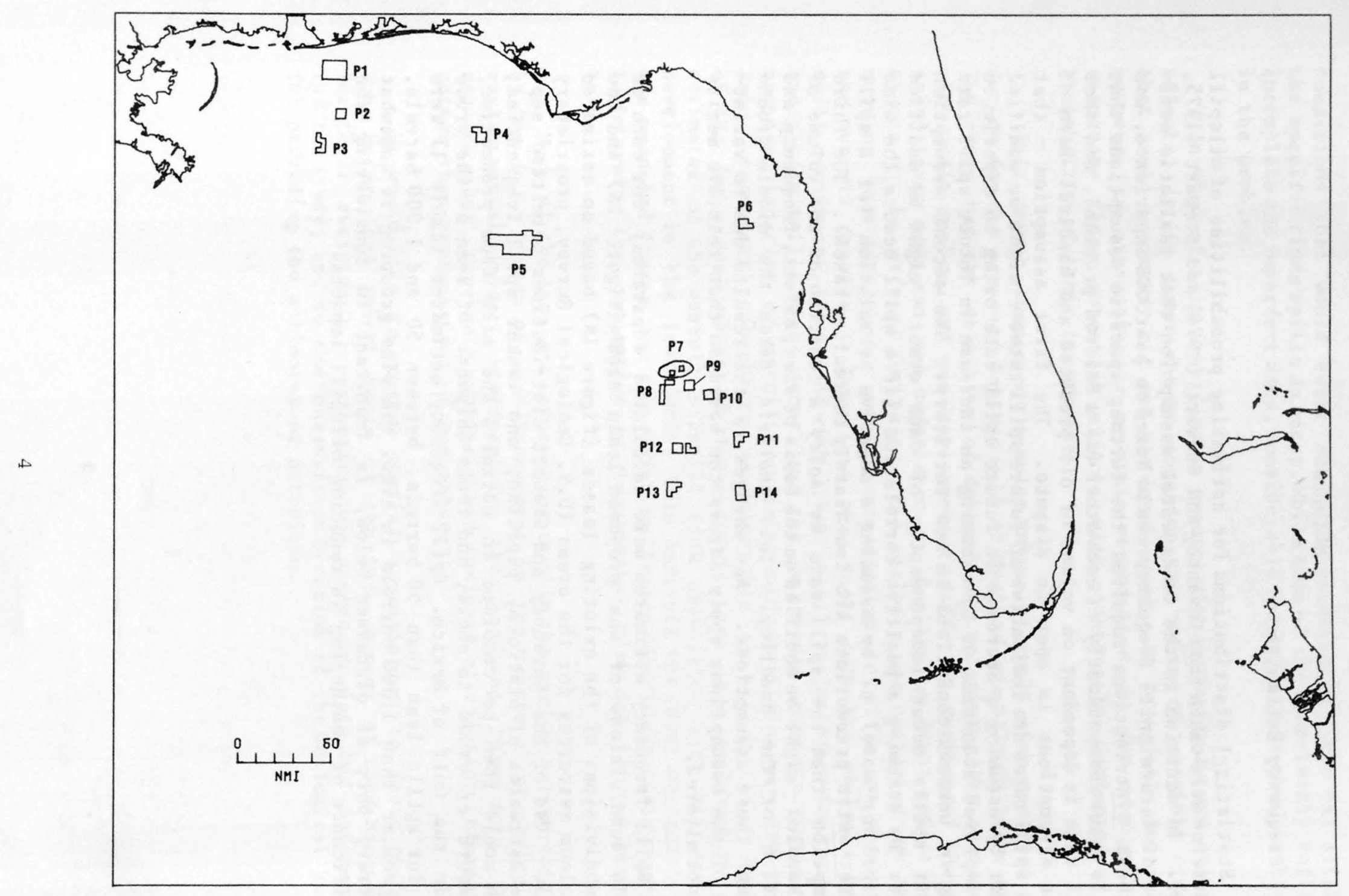

Figure 1A.--Map showing the subdivisions of the proposed leases. 


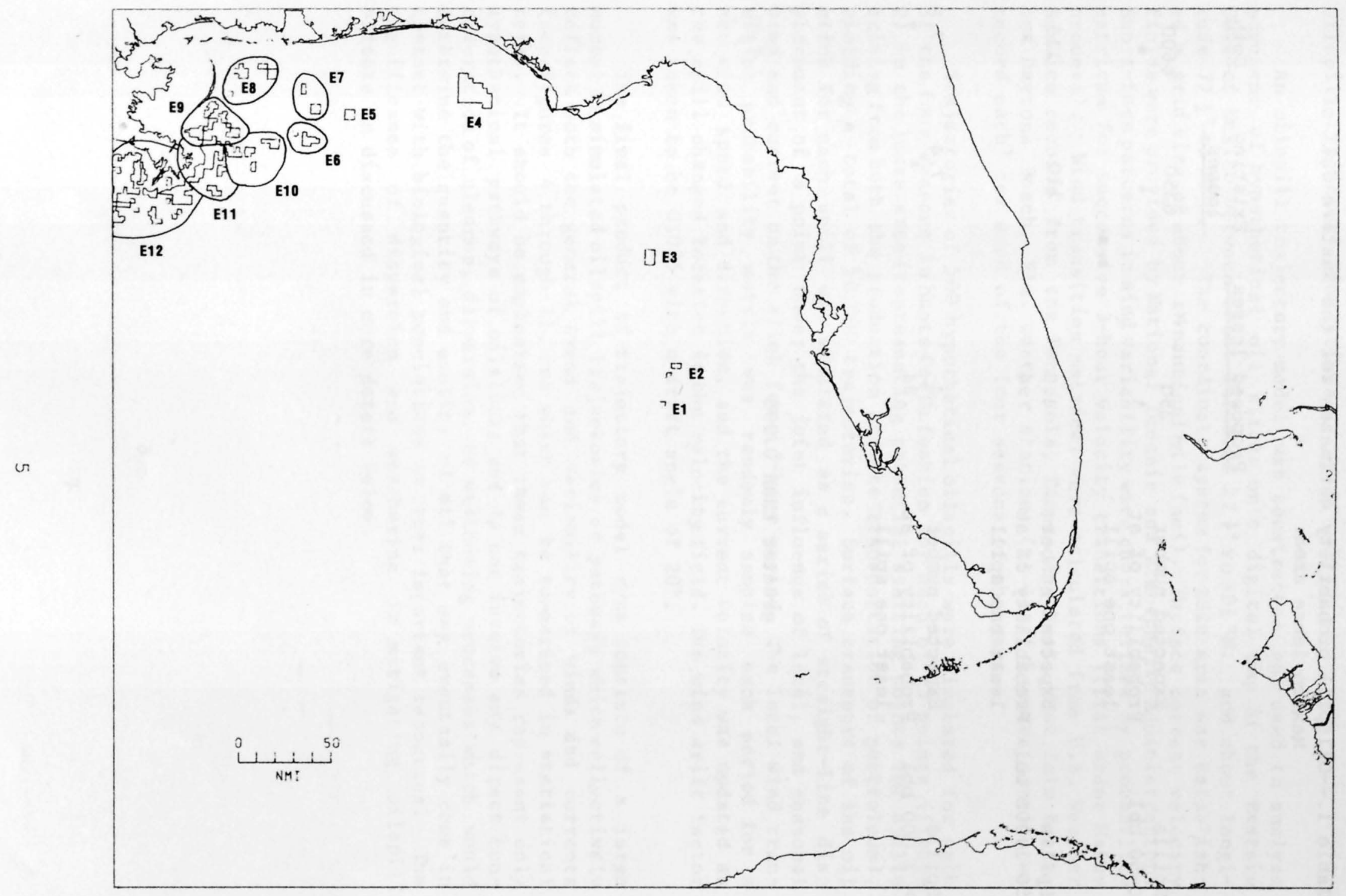

Figure 1B--Map showing the subdivisions of the existing leases. 
Table 1.--Oilspill probability estimates for the Eastern Gulf of Mexico lease area.

\begin{tabular}{|c|c|c|c|c|}
\hline & & Proposed leases & $\begin{array}{l}\text { Existing } \\
\text { leases } \\
\end{array}$ & Both \\
\hline Spills & Expected number & 250 & 6350 & 6600 \\
\hline $0-50 \mathrm{bbl}$ & $\begin{array}{l}\text { Probability of at } \\
\text { least one spill }\end{array}$ & * & * & * \\
\hline Spills & Expected number & 4.8 & 110 & 115 \\
\hline $50-1,000 \mathrm{bbl}$ & $\begin{array}{l}\text { Brobability of at } \\
\text { least one spill }\end{array}$ & .47 & * & * \\
\hline Spills & Expected number & .4 & 7.4 & 7.8 \\
\hline$>1,000 \mathrm{bbl}$ & $\begin{array}{l}\text { Probability of at } \\
\text { least one spill }\end{array}$ & .34 & * & $\star$ \\
\hline
\end{tabular}


An oilspill trajectory model was constructed and used to analyze movement of hypothetical oil slicks on a digital map of the Eastern Gulf of Mexico between about latitude $22 \frac{1}{2}^{\circ}$ to $30 \frac{1}{2}^{\circ} \mathrm{N}$. and about longitude $77 \frac{1}{2}^{\circ}$ to $90^{\circ} \mathrm{W}$. The coordinate system for this area was establish-

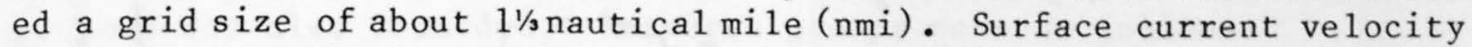
fields were provided by National Oceanic and Atmospheric Administration. Short-term patterns in wind variability were characterized by probability matrices for successive 3-hour velocity transitions (first order Makov process). Wind transition matrices were calculated from U.S. Weather Service records from the Pensacola, Tampa, Key West, West Palm Beach, and Daytona Beach, Fla. weather stations (at least 5 years continuous record each) for each of the four seasons of the year.

Trajectories of 500 hypothetical oilspills were simulated for each of the four seasons in Monte Carlo fashion for each of 25 points (figure 2) in the lease area (representing potential starting points for spills arising fromboth the production and the transportation of pertroleum), yielding a total of 50,000 trajectories. Surface transport of the oil slick for each spill was simulated as a series of straight-line displacement of a point under the joint influence of local, and seasonal wind and current on the slick for a 3-hour period. The local wind transition probability matrix was randomly sampled each period for a new wind speed and direction, and the current velocity was updated as the spill changed location in the velocity field. The wind drift factor was taken to be 0.035 with a drift angle of $20^{\circ}$.

The final product of trajectory model runs consists of a large number of simulated oilspill trajectories or pathways which collectively reflect both the general trend and variability of winds and currents (see figures 4 through 7 ), and which can be summarized in statistical terms. It should be emphasized that these trajectories represent only hypothetical pathways of oilslicks and do not involve any direct consideration of cleanup, dispersion, or weathering processes which would determine the quantity and quality of oil that may eventually come in contact with biological populations or other important resources. The significance of dispersion and weathering in mitigating oilspill effects is discussed in more detail below. 


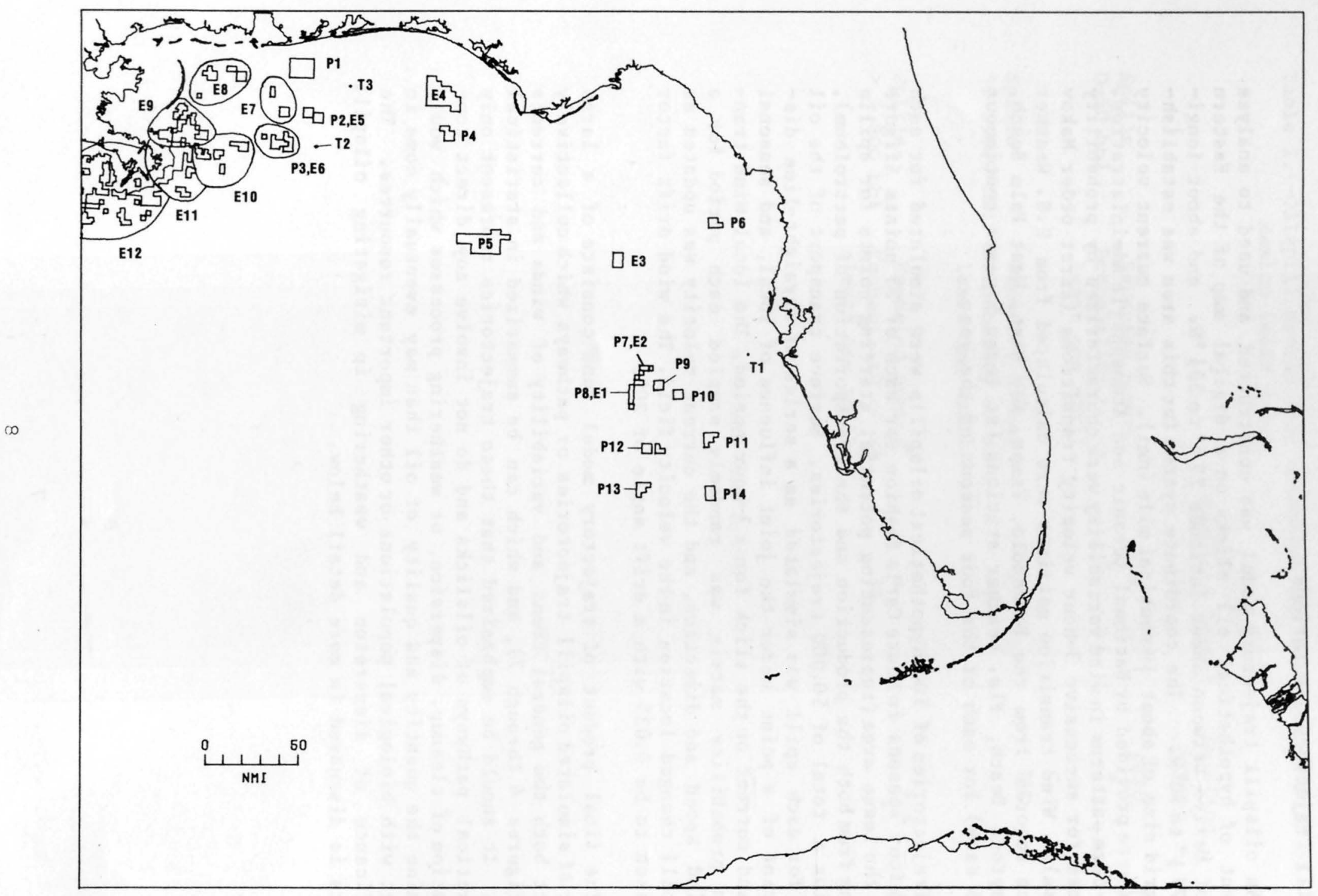

Figure 2.--Map showing potential starting points for spills from proposed leases (P1-P14), existing leases (El-El2), and transportation (T $1-\mathrm{T} 3$ ). 
Locations of Biological and Recreational Resources

The locations of 30 categories of biological, recreational, and other resources were digitized in the same coordinate system as that used in trajectory simulations (see Appendix A, figures Al-30). The monthly sensitivity of these resources (for example spawning period or migration period) was also recorded, Resource groups were as follows:

1 Coral areas

2 Manatee concentrations

3 Brown pelican rookeries

4 Wading or pelagic bird rookeries

5 Dusky seaside sparrow habitat

6 Bald eagle nesting sites

7 Mississippi sandhill crane habitat

8 Marine turtle nesting areas

9 Ame rican alligator habitat

10 Mangroves or tidal marsh

11 Estuarine nursery areas

12 West Florida adult female blue crab migration route

13 West Florida blue crab larval transport route

14 Tortugas pink shrimp nursery grounds

15 Stone crab habitat

16 Calico scallops

17 Oysters and bay scallops

18 Seagrass beds 
19 Spiny lobster

20 Sandy beaches

21 Florida Straits

22 High density use shoreline

23 National register sites

24 Designated wildlife, natura1, and conservation areas

25 Designated national wilderness areas

26 National marine and estuarine sanctuaries

27 Florida aquatic preserves

28 Designated shoreline, national, and state parks

29 Ports

30 Foreign islands

RESULTS AND DISCUSSION

\section{Spi11 Frequency Estimates}

The probabilitydistributions on the frequency of oilspills greater than 1,000 barrels in size during the production life of the proposed lease area and the remaining production life of the existing leases are given in figure 3. Probabilities apply to the total of production platform spills and pipeline spills assuming transport of the total product to shore via pipeline plus some trans-shipment by tanker. Petroleum from the western portion of the area (proposed lease areas P1-P5 and existing lease areas E4-E12) would be piped directly to shore in that area, while petroleum from the eastern portion (P6-P14 and E1-E2) would be piped to storage facilities at the mouth of Tampa Bay. It is expected that any crude oil transported by pipeline from the lease area to storage facilities at Tampa Bay would be subsequently carried by tanker from such terminals to existing refineries either around Pensacola or the 


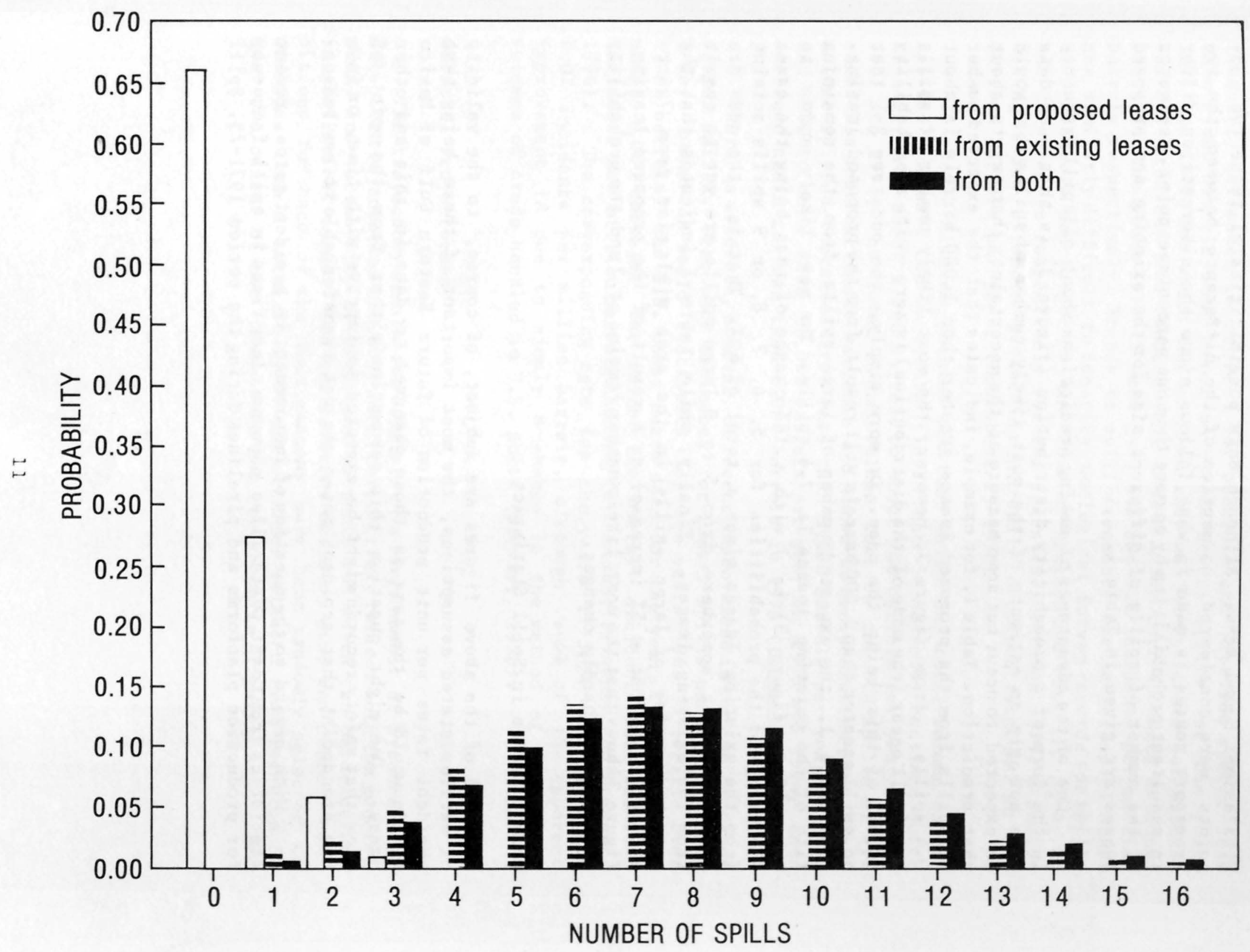

Figure 3.--Spill frequency distributions for spills greater than 1,000 barrels during the (remaining) production lives of the lease areas. 
Mississippi Sound area. Although both possibilities of these two endpoints were considered, no mention of the difference between the two transport routes is made in what follows since the alternatives differ in resultant probabilities by nomore than one percentage point. Estimates of the number of spills of different size for the existing and proposed leases are given in Table 1 .

One of the advantages of making predictions about oilspill frequency in the form of a probability distribution (figure 3 ) is that such data give not only an estimate of the most likely number of spills that would be expected to occur but some measure of the uncertainty that exists about that prediction. Table 1 , for example, indicates that the expected number of spills from the proposed leases greater than 1,000 barrels is about 0.4 spills. From figure 3, however, the most 1 ikely number of spills that will occur (the mode of the distribution) is zero-with a probability of $66 \%$ of this being the case. Or more simply, the odds are 2-1 that no spill greater than 1,000 barrels will result from the proposed leasing . From table 1, the expected number of large spills from the remaining life of the existing leases is $7.4 \mathrm{spills}$. The most 1 ikely number to occur (from figure 3 ) is 7 with a $14 \%$ chance of that being the case. A summing of the probabilities for $5,6,7,8$, or 9 spills arising from the existing leases gives a total of $62 \%$. That is, the odds are almost 2-1 that somewhere from 5 to 9 large spills are yet to result from the existing leases. Finally, while table 1 indicates that the expected number of large spills in the area will rise from 7.4 to $7.8 \mathrm{spills}$ (about a $5 \%$ increase) as a result of the proposed leasing, figure 3 shows that the most 1 ikely number remains at 7 and the probability distribution hardly changes.

\section{Recent Trends in Spil1 Statistics}

A11 of the above figures are subject, of course, to the validity of earlier stated assumptions, the most important of these being that accident rates per unit production of future Eastern Culf of Mexico fields would be the same as those observed to date in this and other areas. One might question this assumption either from the point of view that safety records might be expected to improve with time, or from the standpoint that accident rates are not transferrable to new leases.

With regard to the question of improvement in accident rates, recent statistics from Coast Guard files show no cleartrend in spill frequency for production platforms and pipelines during the period 1971-75. Spil1 
frequency estimates in table 1 for platform and pipeline spills less than 1,000 barrels were based on United States spills for the years 1971 and 1972, for which the accident rate was 3.6 incidents per million barrels produced and handled (a11 sizes). The corresponding accident rates for the years $1973-75$ were $3.9,4.2$ and 3.2 incidents per million barrels respectively. Trends in spill frequency for larger spill sizes are similarlydifficult to identify. Geological Survey records for spills of 50 barrels and larger in the Gulf of Mexico OCS 1 ist 11, 2, 4, 8, and 2 incidents respectively for the years 1971 through 1975, a period during which offshore production gradually declined from 387 to 315 million barrels per year, (Danenberger, 1976)

It should also be pointed out that while the total volume of oil spilled in sma11 OCS incidents (less than 50 barrels) declined quite steadily from about 1,500 barrels to about 700 barrels per year between 1971 and 1975, the total annual volume lost in the OCS spills of all sizes has been extremely variable and shows no decipherable trend. Total volume spilled increased from less than 3,000 barrels per year in 1971 and 1972 to more than 23,000 barrels per year in 1973 and 1974, then declined again to less than 1,000 barrels in 1975 (Danenberger, 1976).

There is evidence, however, of recent improvement in the incidence of tanker spills. Frequency estimates for tanker spills underlying table 1 were based on world statistics for the years 1969-75 (spills over 1,000 barrels) and U.S. Coast Guard data for the years 1971-72 (spil1s under 1,000 barre1s) for which the overall accident rate was 0.45 incidents per million barrels handled (a11 sizes; Devanney and Stewart, 1974). The corresponding rate for the years 1973-74 was only about 0.07 incidents per million barrels, although some of the apparent improvement is due to simply a change in the method of estimating volumes of crude handled in U.S. ports (Stewart, 1976).

\section{Oilspill Trajectories}

The trajectory simulation consists of a large number of hypothetical oilspill trajectories $(50,000)$ which collectively reflect both the general trend and variability of winds and currents and which can be described in statistical terms. Ten trajectories based on wind and current conditions for each of the four seasons have been randomly selected as examples from a total of 2,000 trajectories released from location $\mathrm{P} 5$ near the center of the lease area and are shown in figures 4-7. The 


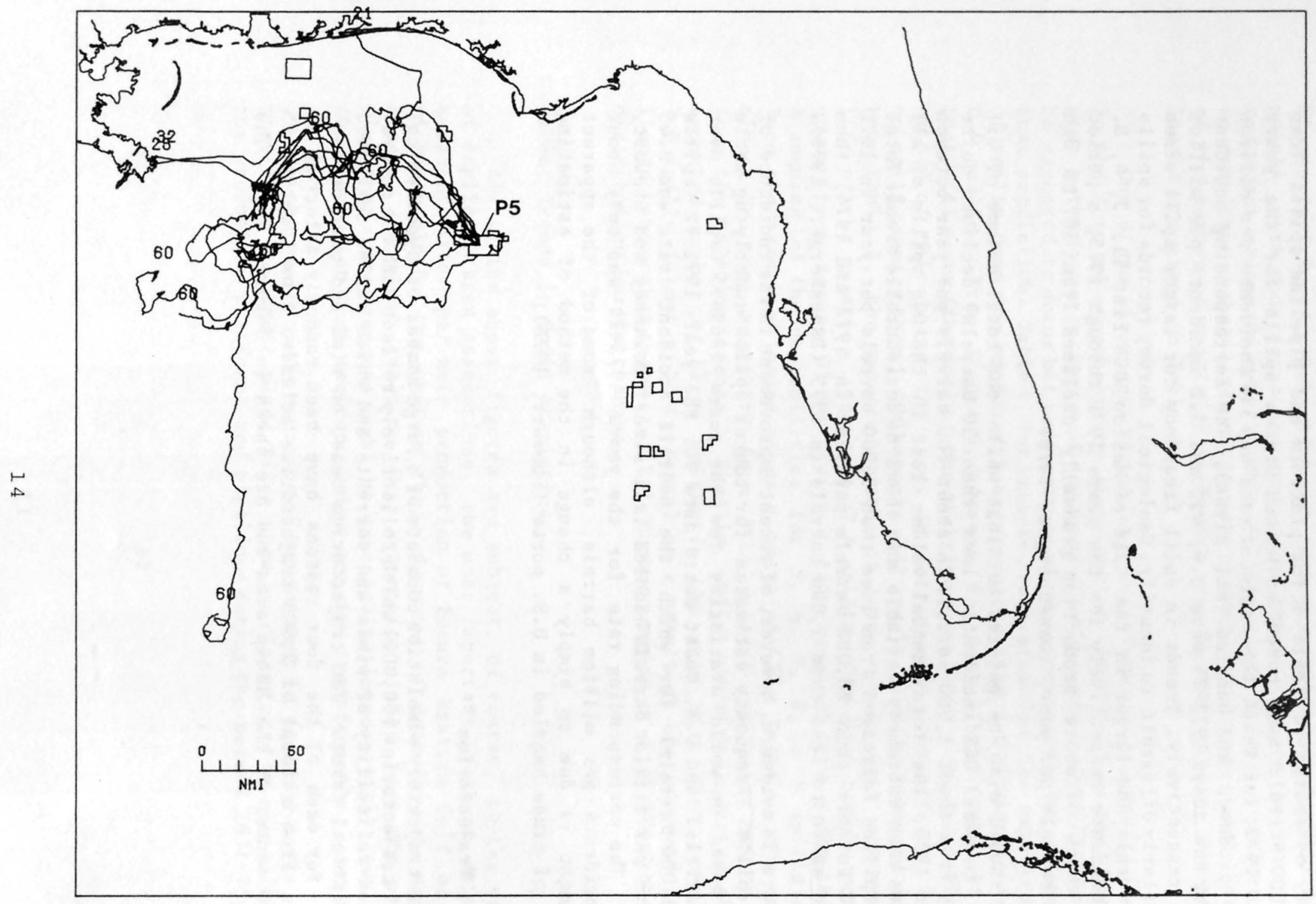

Figure 4.--Example oilspill trajectories for a spill site (P5) near the center of the proposed lease area: winter conditions. Number on trajectory is the time to the end point in days. 


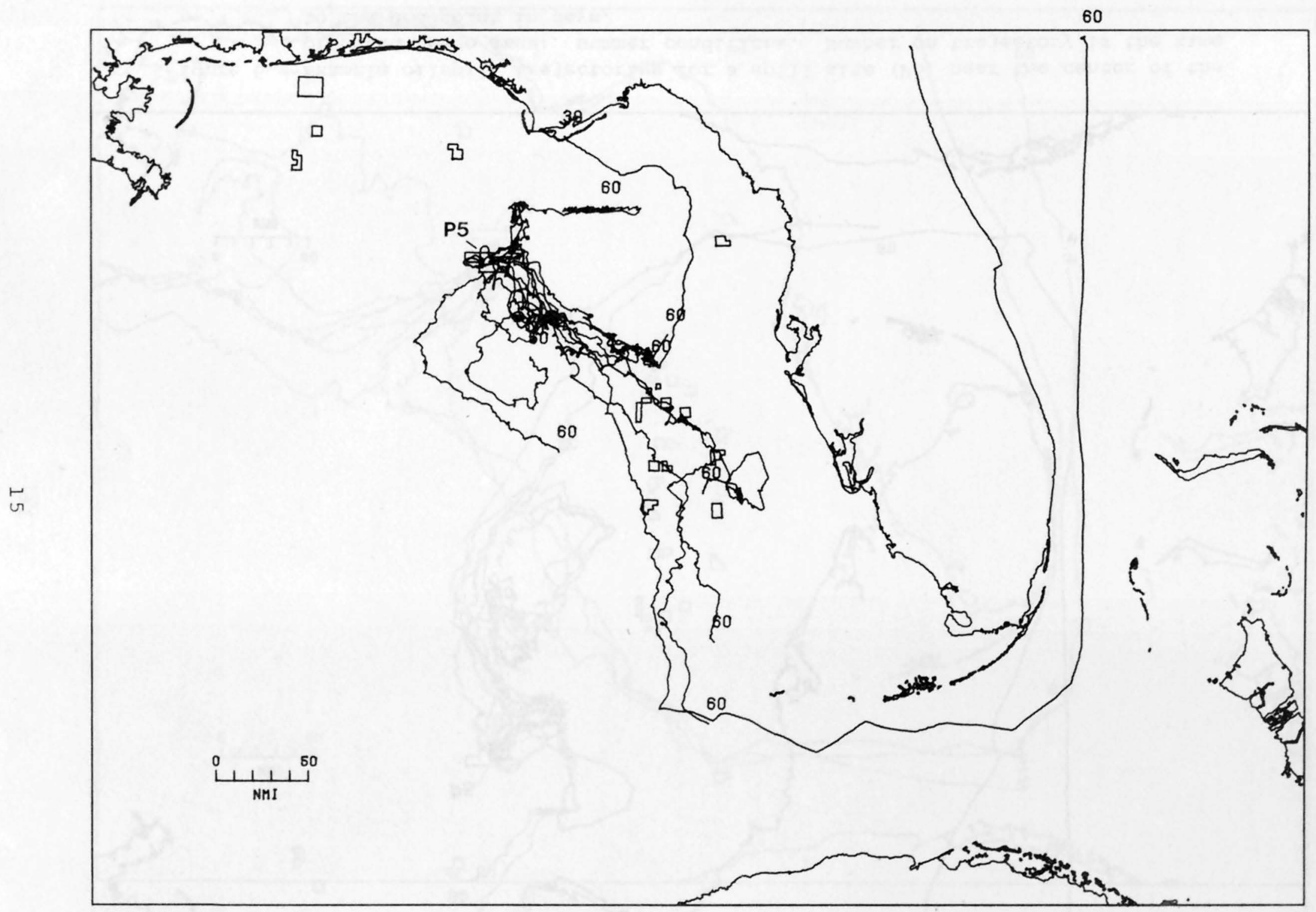

Figure 5.--Example oilspill trajectories for a spill site (P5) near the center of the proposed lease area: spring corditions. Number on trajectory is the time to the enc point in days. 


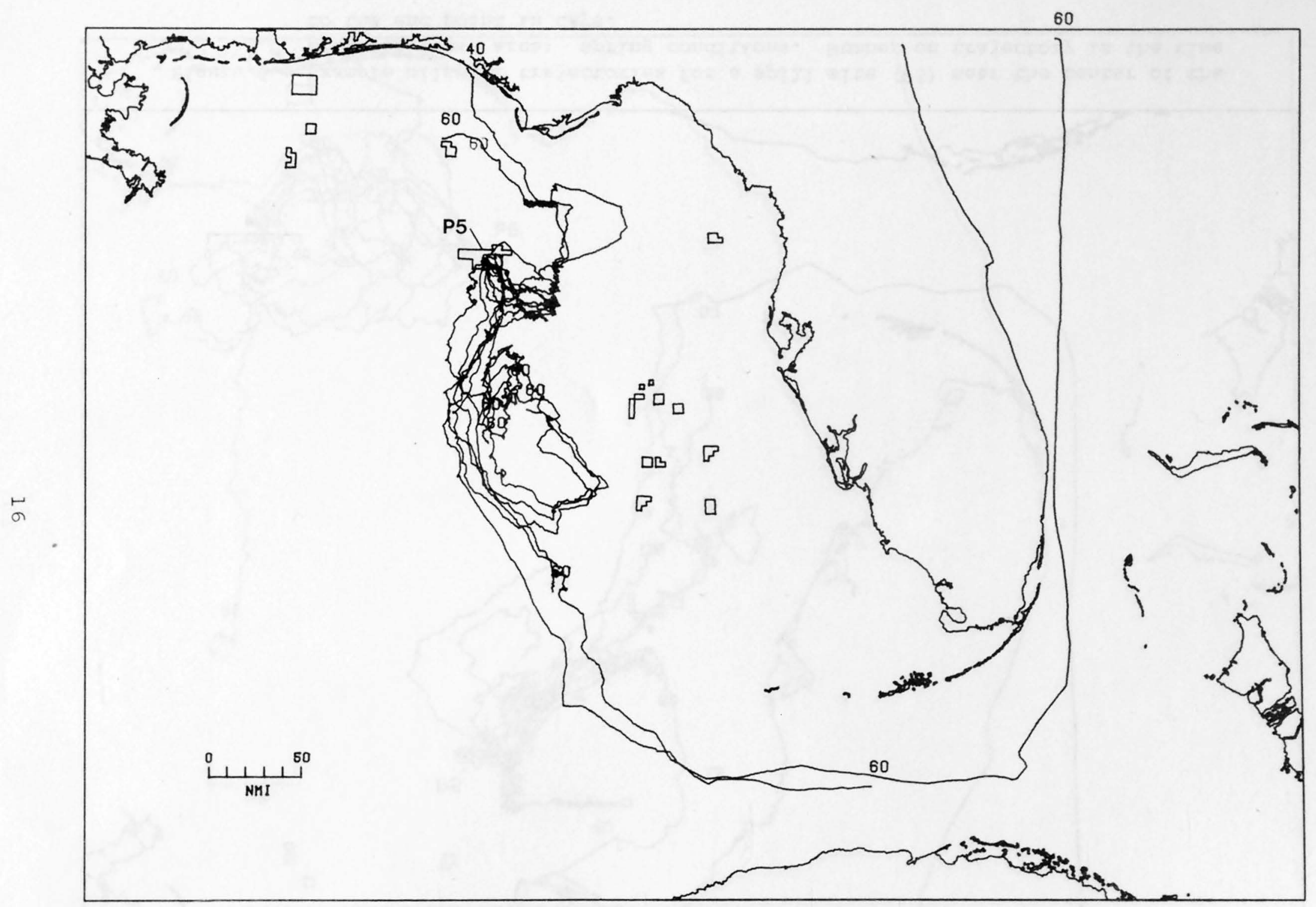

Figure 6.--Example oilspill trajectories for a spill site (P5) near the center of the proposed lease area: summer conditions. Number on trajectory is the time to the end point in days. 


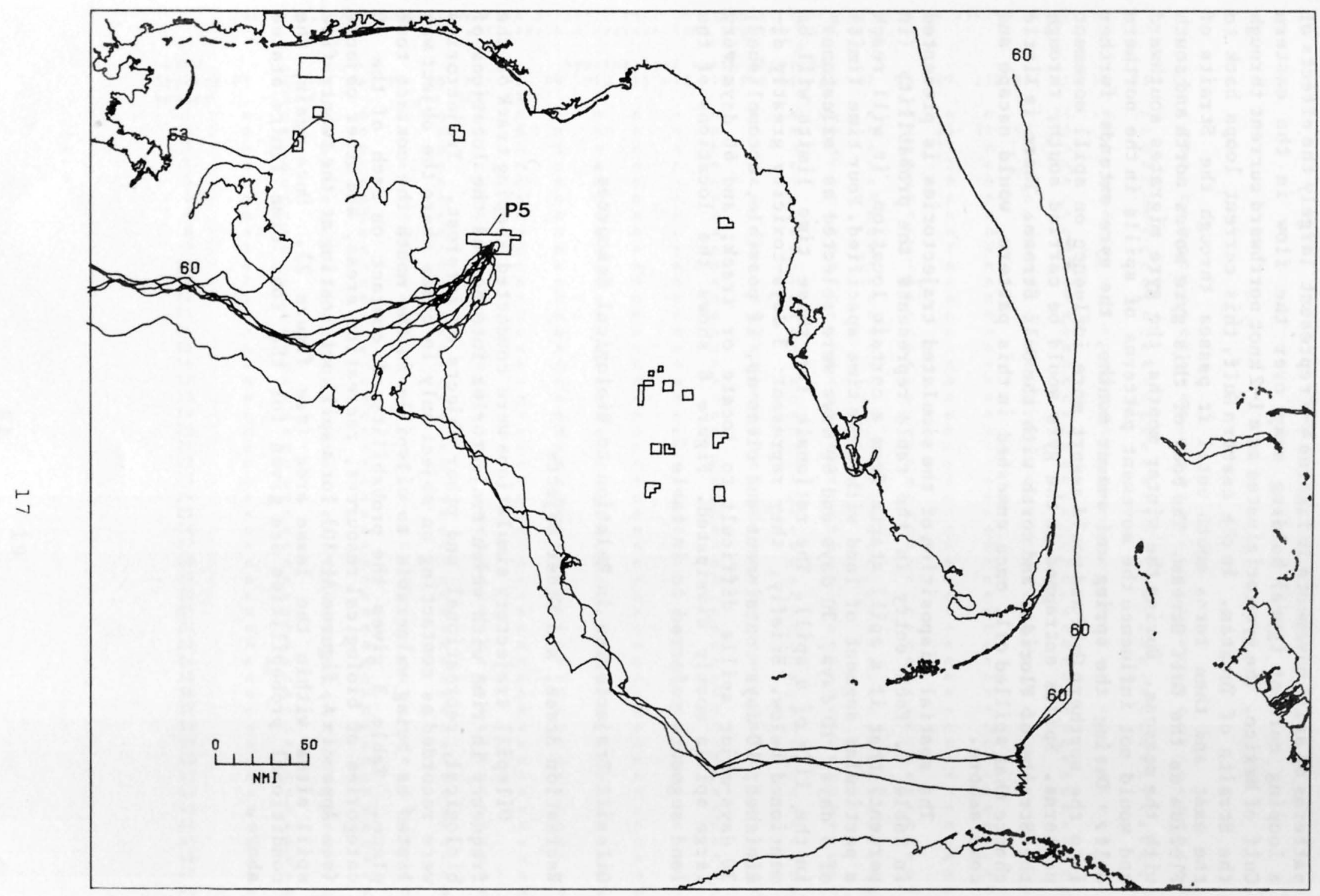

Figure 7.--Example oilspill trajectories for a spill site (P-5) near the center of the proposed lease area: autumn conditions. Number on trajectory is the time to the end point in days. 
patterns of spill movements in figures 4-7 represent 1 argely the effects of a looping current (gyre) holding sway over the flow in the eastern Gulf of Mexico. The gyre originates as a 1-2 knot northward current through the Straits of Yucatan. In the eastern Gulf, this current loops back to the east and then turns south until it passes through the Straits of Florida as the Gulf Stream. The body of this gyre moves north and south with the seasons. During the winter months, the gyre migrates southward and would not influence the movement patterns of spills in the northern Gulf. During the spring and summer months, the gyre extends further into the northern Gulf and would assert more influence on spill movement patterns. Spills entrapped in the gyre would be carried south, through the Straits of Florida, and north with the Gulf Stream. There is little chance that spilled oil, once enmeshed in this pattern, would escape and come ashore.

The spatial disposition of the simulated trajectories is presented in table 2. Each entry in the table represents the probability (in percent) that if a spill starts from a certain location, it will reach a particular segment of 1 and within the time specified. Four time limits of 3 days, 10 days, 30 days and 60 days were selected as "milestones" in the life of a spill. The rationale for these time limits will be mentioned below. Briefly, they represent: 3 days-toxicity greatly diminished; 10 days-containment and clean-up, if possible, accomplished; 30 days-major spills difficult to locate or track; and 60 days-very large spills mostly dissipated. Figure 8 shows the locations of the land segments referred to in table 2 .

Oilspil1 Trajectories in Relation to Biological Resources,

Recreation Areas, and Other Objects

Oilspill trajectory simulations were conducted keeping track of the frequency in time with which trajectories intersected the locations of biological, recreational and other objects of interest. Trajectories were recorded as contacting an object only in cases where the object was listed as being vulnerable to oilspills in the month the contact took place. Table 3 gives the probability of contact on each of the 30 categories of biological resources, recreation areas, and other objects (see Appendix A, figures A1-30) for a spill originating at the twenty-five spill sites within the lease area (see figure 2). Once again, the conditional probabilities are given for the four time limits stated above. 


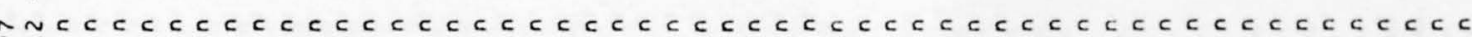
a

\section{a} a $\vec{a}$

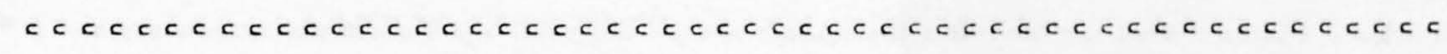
mis

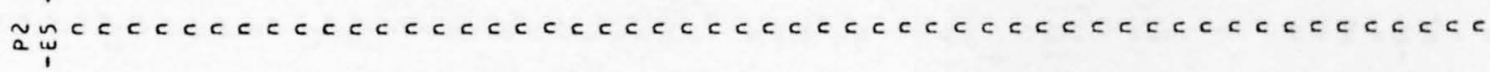
$\bar{a}$

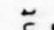

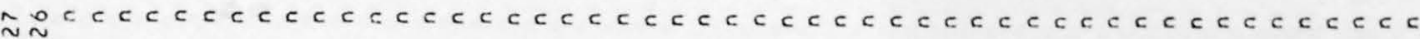

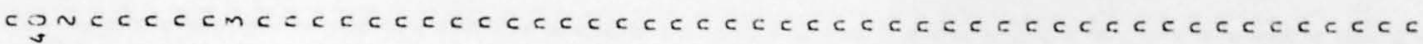
fy

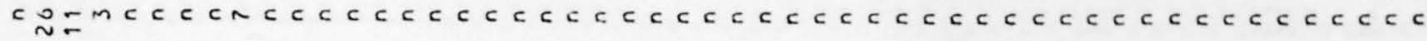

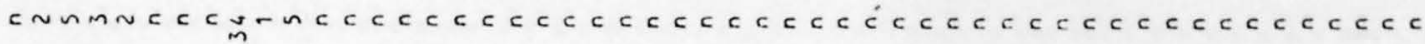

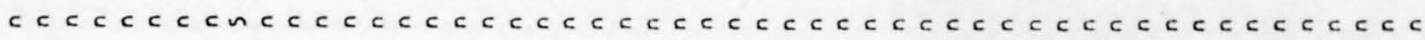

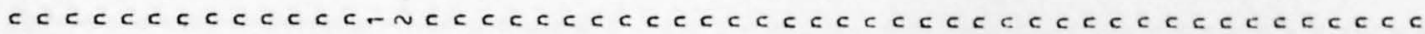

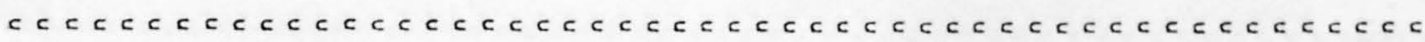

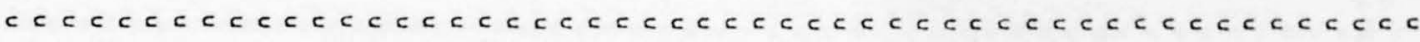

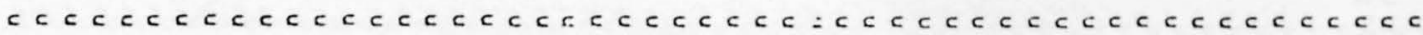

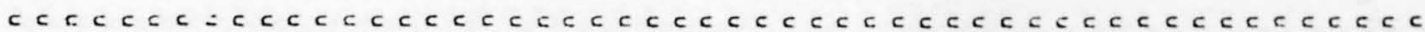

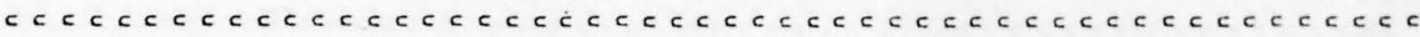

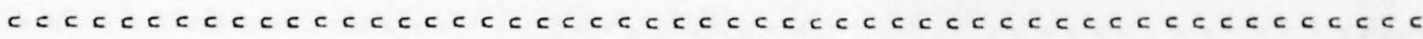

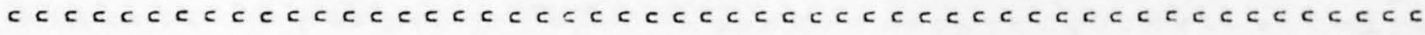

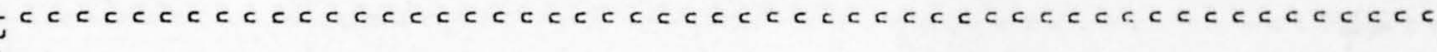
i

С̆ is 
a che

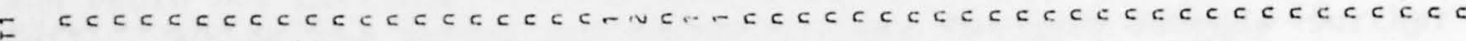
아 c i f c $\sim c c c c c a c m \sim c c c c c c c c c c c c c c c c c c c c c c c c c c c c c c c c c c c c c c c$

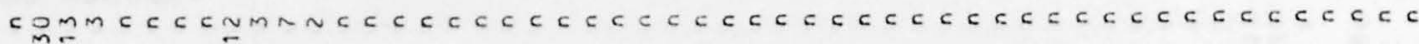
$c \sim 00 \sim c c \backsim m m \leq m c c c c c c c c c c c c c c c c c c c c c c c c c c c c c c c c c c c c c c c c$

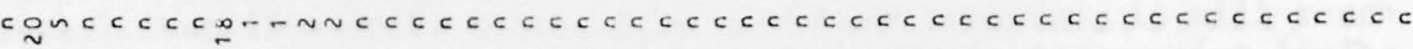

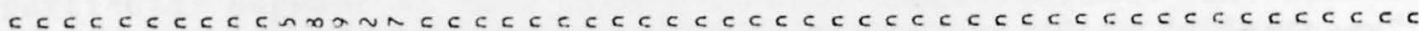

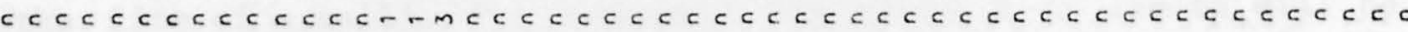

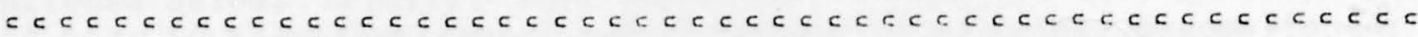

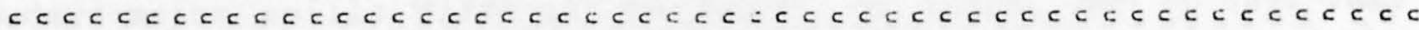
10 (1)

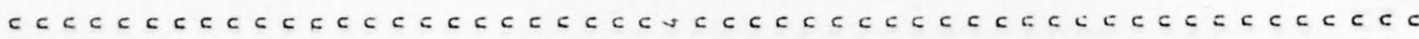

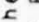

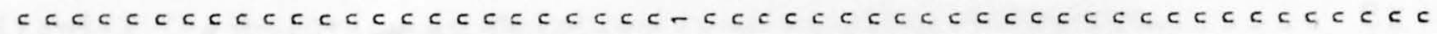

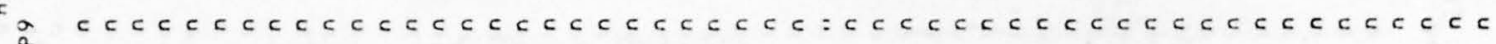

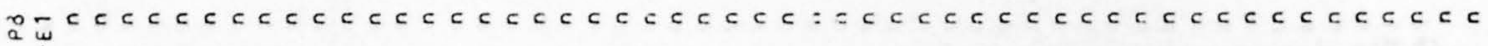

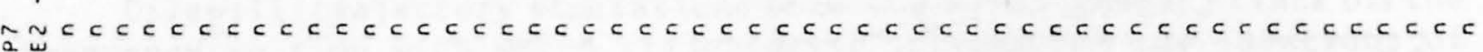

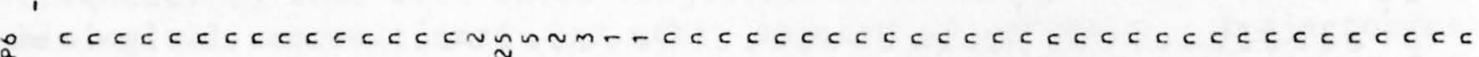

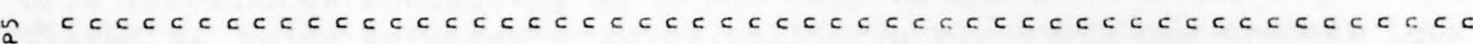
$\therefore$

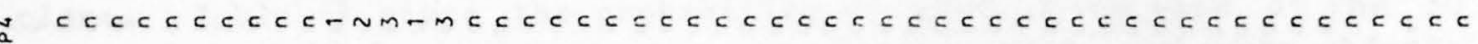

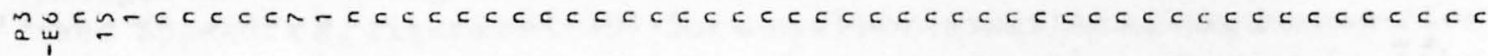

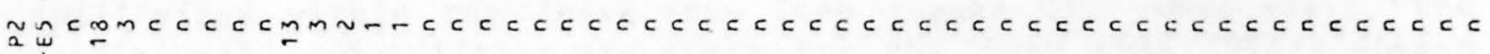

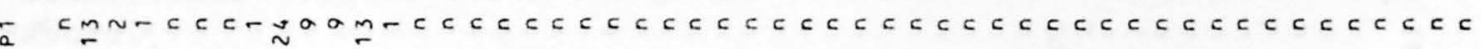
c c

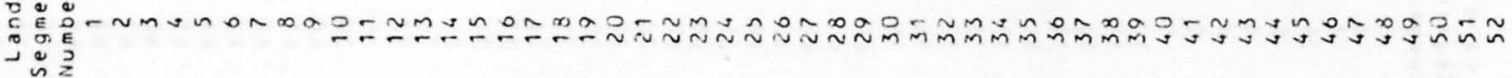




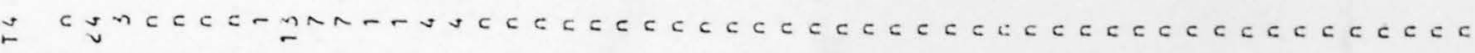

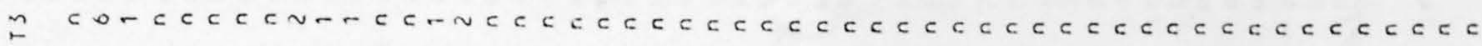

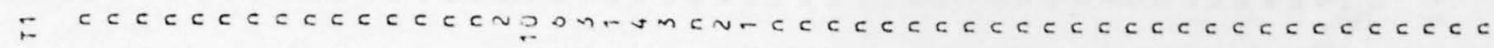

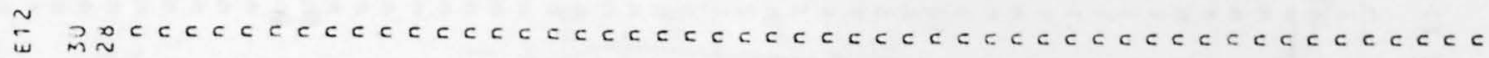

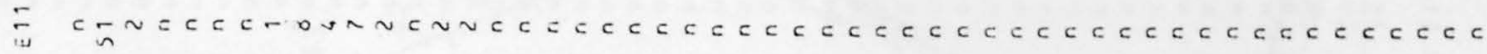
a a

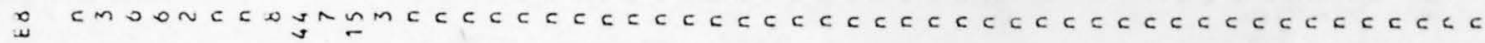

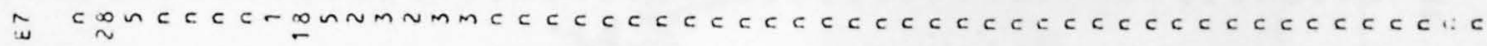
c

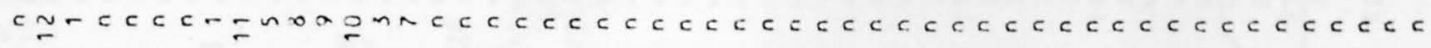

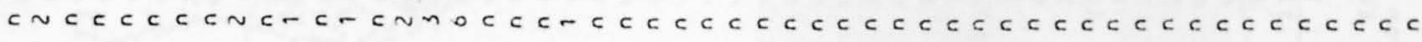

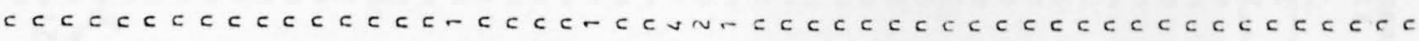

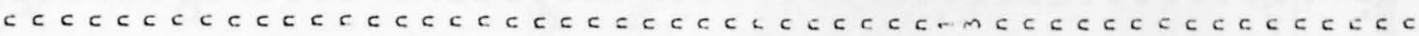

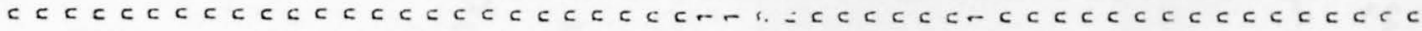
$i^{2}$

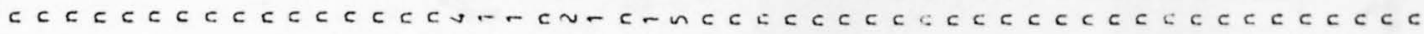

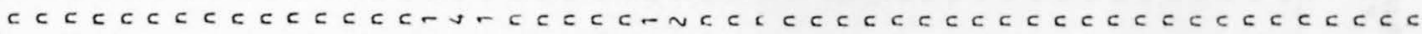

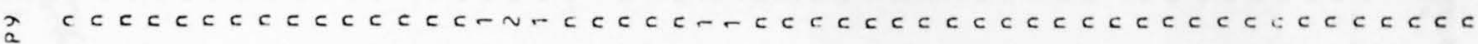

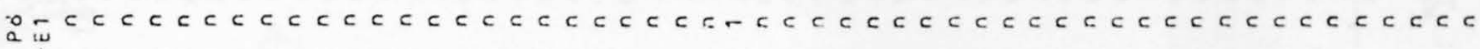

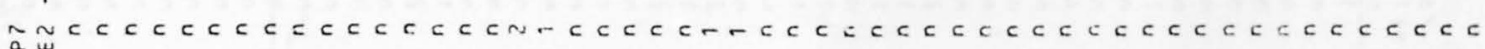
i

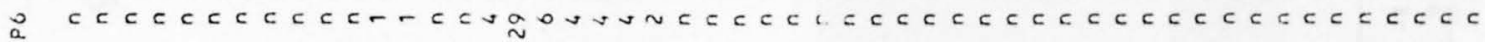

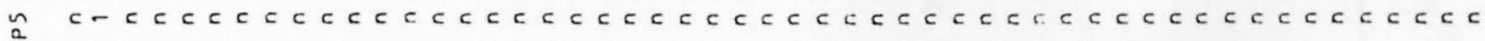

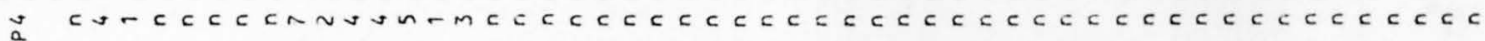
a b-

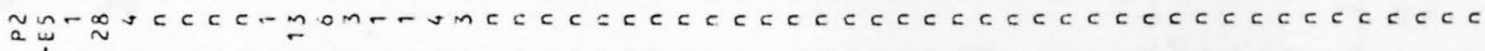
a c c c

总 $\rightarrow$ is 2 
Table 20. -- probabilities (in percent) that an oilspill starting at a particular location will reach a certain land segment in 60 days.

\begin{tabular}{|c|c|c|c|c|c|c|c|c|c|c|c|c|c|c|c|c|c|c|c|c|c|c|c|c|c|}
\hline \multirow{2}{*}{$\begin{array}{l}\text { Land } \\
\text { Segment }\end{array}$} & \multirow{2}{*}{$P_{1}$} & \multirow{2}{*}{\multicolumn{2}{|c|}{ P2 P3 }} & \multirow{3}{*}{$P_{4}$} & \multirow{3}{*}{ PS } & \multirow{3}{*}{ P6 } & \multirow{2}{*}{\multicolumn{2}{|c|}{ P) Py }} & \multicolumn{8}{|c|}{ Hypothetical spill location } & \multirow{3}{*}{ E7 } & & & & & & & & \\
\hline & & & & & & & & & PQ & P10 & P11 & P12 & P13 & P14 & E3 & E4 & & EB & Eq & $=10$ & E 11 & E 12 & T1 & T3 & is \\
\hline Number & & -ES & $-E_{0}$ & & & & $-E_{2}$ & $-E_{1}$ & & & & & & & & & & & & & & & & & \\
\hline 1 & $n$ & 1 & 1 & $n$ & $n$ & $n$ & $n$ & $n$ & $n$ & $n$ & $n$ & $n$ & $n$ & $n$ & $n$ & 1 & 1 & $n$ & $n$ & 1 & $n$ & 30 & n & $n$ & 1 \\
\hline 2 & 22 & 32 & 31 & 8 & 3 & 2 & 1 & 1 & 1 & $n$ & $n$ & $\mathrm{n}$ & $n$ & $n$ & 7 & 17 & 32 & 3 & 35 & 34 & 53 & 28 & 2 & 10 & 30 \\
\hline 3 & 2 & 5 & 3 & 1 & $n$ & $n$ & $n$ & $n$ & $n$ & $n$ & $n$ & $n$ & $n$ & $n$ & 1 & 2 & 5 & 0 & 13 & 4 & 2 & $n$ & $n$ & 2 & 3 \\
\hline 4 & 1 & $n$ & $n$ & $n$ & $n$ & $n$ & $n$ & $n$ & $n$ & $n$ & $n$ & $n$ & $n$ & $n$ & $n$ & $n$ & $n$ & 6 & 3 & $n$ & $n$ & $n$ & $n$ & n & 1 \\
\hline 5 & 1 & $n$ & $n$ & $n$ & $n$ & $n$ & $n$ & $n$ & $n$ & $n$ & $n$ & $n$ & $n$ & $n$ & $n$ & $n$ & $n$ & 3 & 1 & 2 & 1 & $n$ & $n$ & $n$ & \\
\hline 6 & $n$ & $n$ & $n$ & $n$ & $n$ & $n$ & $n$ & $n$ & $n$ & $n$ & $n$ & $n$ & $n$ & $n$ & $n$ & $n$ & $n$ & $n$ & $n$ & $n$ & $n$ & $n$ & $n$ & $n$ & $n$ \\
\hline 7 & $n$ & $n$ & $n$ & $n$ & $n$ & $n$ & $n$ & $n$ & $n$ & $n$ & $n$ & $n$ & $n$ & $n$ & $n$ & $n$ & $n$ & $n$ & $n$ & $n$ & $n$ & $n$ & $n$ & n & n \\
\hline 8 & 4 & 1 & 1 & 1 & n & $n$ & $n$ & $n$ & $n$ & $n$ & $n$ & $n$ & $n$ & $n$ & $n$ & 1 & 1 & 9 & 4 & 3 & $i$ & $n$ & $n$ & 1 & 2 \\
\hline 9 & 25 & 16 & 8 & 9 & 1 & 2 & $n$ & 1 & 1 & $n$ & $n$ & $n$ & $n$ & $n$ & 4 & 12 & 18 & 44 & 13 & 10 & 8 & $n$ & 1 & 2 & 14 \\
\hline 10 & 14 & 9 & 8 & 4 & $n$ & 2 & $n$ & $n$ & $n$ & 1 & $n$ & $n$ & $n$ & $n$ & 2 & 5 & 7 & 0 & 10 & 5 & 3 & $n$ & 1 & 2 & 10 \\
\hline 11 & 10 & 4 & 3 & 5 & 1 & 1 & $n$ & $n$ & $n$ & $n$ & $n$ & $n$ & $n$ & $n$ & 1 & 9 & 3 & 15 & 8 & j & 7 & $n$ & 1 & 3 & 8 \\
\hline 12 & 13 & 1 & 1 & 4 & $n$ & 1 & $n$ & $n$ & $n$ & n & $n$ & $n$ & $n$ & $n$ & 1 & 9 & 3 & 3 & 3 & 2 & 2 & $n$ & 1 & 1 & 1 \\
\hline 13 & 1 & 1 & 1 & 0 & $n$ & 2 & $n$ & $n$ & 1 & n & $n$ & $n$ & $n$ & $n$ & 1 & 10 & 2 & $n$ & 1 & 1 & 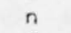 & & 1 & n & 1 \\
\hline 14 & 1 & 4 & 4 & 2 & $n$ & $n$ & $n$ & $n$ & $n$ & $n$ & $n$ & $n$ & $n$ & $n$ & $i$ & 3 & 4 & $n$ & , & 3 & 3 & $n$ & $n$ & 2 & 4 \\
\hline 15 & 1 & 3 & 3 & 3 & $n$ & $n$ & $n$ & $n$ & $n$ & $n$ & $n$ & $n$ & $n$ & $n$ & 2 & 8 & 3 & $n$ & 2 & 4 & 3 & $n$ & $n$ & 2 & 5 \\
\hline 10 & $n$ & $n$ & $n$ & $n$ & $n$ & 5 & 1 & $n$ & 1 & 1 & 1 & $n$ & $n$ & 1 & 3 & $n$ & $\mathrm{n}$ & $n$ & $n$ & $n$ & $n$ & $n$ & 3 & n & n \\
\hline 17 & $n$ & $n$ & $n$ & $n$ & $n$ & 30 & 6 & 2 & 4 & 5 & 5 & $n$ & $n$ & 3 & 0 & $n$ & $n$ & $n$ & $n$ & $n$ & $n$ & $n$ & 12 & n & \\
\hline 18 & $n$ & $n$ & $n$ & $n$ & $n$ & 6 & 2 & 1 & 2 & 3 & 2 & $n$ & $n$ & 1 & $n$ & $n$ & ก & $n$ & $n$ & $n$ & $n$ & $n$ & 6 & n & n \\
\hline 19 & $n$ & $n$ & $n$ & $n$ & $n$ & 4 & 1 & 1 & 1 & 1 & 1 & $n$ & $n$ & 1 & $n$ & $n$ & $n$ & $n$ & $n$ & $n$ & $n$ & $n$ & 3 & n & \\
\hline 20 & $n$ & $n$ & $n$ & $n$ & $n$ & 4 & $n$ & $n$ & $n$ & $n$ & $n$ & $n$ & n & $n$ & n & n & $n$ & $n$ & $n$ & a & $n$ & $n$ & 1 & $n$ & $n$ \\
\hline 21 & $n$ & $n$ & $n$ & $n$ & $n$ & 4 & 1 & 1 & 2 & 2 & 3 & $n$ & $n$ & 1 & 1 & $n$ & 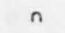 & $n$ & $n$ & $n$ & $\mathrm{n}$ & $n$ & 4 & $n$ & \\
\hline 22 & $n$ & $n$ & $n$ & $n$ & $n$ & 2 & 1 & 1 & 2 & 1 & 2 & $n$ & $n$ & 2 & $n$ & $n$ & $n$ & n & $n$ & n & n & $n$ & 3 & $n$ & $n$ \\
\hline 23 & $n$ & $\mathrm{n}$ & $n$ & $n$ & $n$ & $n$ & $n$ & $n$ & $n$ & $n$ & $n$ & $n$ & $n$ & $n$ & $n$ & $n$ & $n$ & $n$ & $n$ & $n$ & $n$ & $n$ & $n$ & n & $n$ \\
\hline 24 & $n$ & $n$ & n & $n$ & $n$ & $n$ & 1 & $n$ & 1 & 1 & 1 & $n$ & $n$ & $n$ & $n$ & $n$ & $n$ & $n$ & $n$ & $n$ & $n$ & $n$ & 2 & $n$ & $n$ \\
\hline 25 & $n$ & $n$ & $n$ & $n$ & $n$ & $n$ & 1 & 2 & 1 & 3 & 0 & 1 & $n$ & 5 & $n$ & $n$ & $n$ & $n$ & $n$ & $n$ & $n$ & $n$ & 1 & n & $n$ \\
\hline 26 & $n$ & $n$ & $n$ & $n$ & $n$ & $n$ & 1 & 1 & 1 & $n$ & 1 & 1 & 1 & 3 & $n$ & $n$ & $n$ & $n$ & $n$ & $n$ & $n$ & $n$ & $n$ & n & $r$ \\
\hline 27 & $n$ & $n$ & $n$ & $n$ & $n$ & $n$ & 1 & 2 & 1 & 1 & 1 & 1 & 1 & 2 & $n$ & $n$ & 11 & $n$ & $n$ & $n$ & n & $n$ & 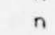 & n & 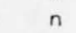 \\
\hline 28 & $n$ & $n$ & $n$ & $n$ & $n$ & $n$ & $n$ & $n$ & $n$ & $n$ & $n$ & 1 & $n$ & $n$ & $n$ & $n$ & $n$ & $n$ & $n$ & $n$ & $\mathrm{n}$ & $n$ & $n$ & $n$ & \\
\hline 29 & $n$ & $n$ & $n$ & $n$ & $n$ & $\therefore$ & $n$ & $n$ & a & - & $n$ & .. & $n$ & $n$ & $n$ & $n$ & $n$ & $n$ & $n$ & $n$ & $n$ & $n$ & n & & \\
\hline 30 & $n$ & $n$ & $n$ & $n$ & $n$ & $n$ & $n$ & $n$ & $n$ & $n$ & $n$ & $n$ & $n$ & $n$ & $n$ & $n$ & $n$ & $n$ & $n$ & $n$ & $n$ & $n$ & $n$ & n & \\
\hline 31 & $n$ & $n$ & $n$ & $n$ & $n$ & $n$ & $n$ & $n$ & $n$ & $n$ & $n$ & $n$ & 1 & $n$ & $n$ & $n$ & 0 & $n$ & $n$ & $n$ & $n$ & $n$ & n & & \\
\hline 32 & $n$ & $n$ & $n$ & $n$ & $n$ & $n$ & $n$ & $n$ & $n$ & $n$ & $n$ & 1 & 1 & $n$ & $n$ & $n$ & $n$ & $n$ & $n$ & $n$ & $\mathrm{n}$ & $n$ & n & & \\
\hline 33 & $n$ & $n$ & $n$ & $n$ & $n$ & $n$ & $n$ & $n$ & $n$ & $n$ & $n$ & 1 & 2 & 1 & $n$ & $n$ & 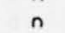 & $n$ & $n$ & $n$ & 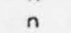 & $n$ & n & & \\
\hline 36 & $n$ & $n$ & $n$ & $n$ & $n$ & $n$ & $n$ & $n$ & $n$ & $n$ & $n$ & $n$ & $n$ & $n$ & $n$ & $n$ & $n$ & $n$ & $n$ & $n$ & H & $\pi$ & $n$ & & \\
\hline 35 & $n$ & $n$ & $n$ & $n$ & $n$ & $n$ & $n$ & 1 & 1 & $n$ & $n$ & 3 & 3 & 1 & $n$ & $n$ & $n$ & $n$ & $n$ & $n$ & n & $n$ & $n$ & & \\
\hline 36 & $n$ & $n$ & $n$ & $n$ & $n$ & $n$ & 1 & 2 & 1 & 1 & 1 & 5 & 7 & 2 & $n$ & $\mathrm{n}$ & $n$ & $n$ & $n$ & $n$ & $n$ & $n$ & $n$ & & \\
\hline 37 & $n$ & $n$ & $n$ & $n$ & $n$ & $n$ & $n$ & $n$ & $n$ & $n$ & $n$ & 1 & 1 & $n$ & $n$ & $n$ & $n$ & $n$ & $n$ & $n$ & $n$ & $n$ & n & & \\
\hline 38 & $n$ & $n$ & $n$ & $n$ & $n$ & $n$ & $n$ & $n$ & $n$ & $n$ & $n$ & $n$ & $\mathrm{n}$ & $n$ & $n$ & $n$ & $n$ & $n$ & $n$ & $n$ & $n$ & n & n & & \\
\hline 39 & $n$ & $n$ & $n$ & $n$ & $n$ & $n$ & $n$ & $n$ & $n$ & $n$ & $n$ & $n$ & $n$ & $n$ & $n$ & $n$ & $n$ & $n$ & $n$ & $n$ & $n$ & 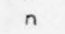 & $n$ & & \\
\hline 40 & $n$ & $n$ & $n$ & $n$ & 1 & $n$ & $n$ & $n$ & $n$ & $n$ & $n$ & 1 & 1 & 1 & $n$ & $n$ & $n$ & $n$ & $n$ & $n$ & $n$ & n & n & & \\
\hline 41 & $n$ & $n$ & $n$ & $n$ & $n$ & $n$ & $n$ & $n$ & $n$ & $n$ & $n$ & $n$ & $n$ & $n$ & $n$ & $n$ & $n$ & $n$ & $n$ & $n$ & $n$ & $m$ & $n$ & & \\
\hline 42 & $n$ & $n$ & $n$ & $n$ & $n$ & $n$ & $n$ & $n$ & $n$ & $n$ & $n$ & $n$ & $n$ & $n$ & $n$ & $n$ & 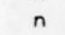 & $n$ & $n$ & $n$ & $n$ & $n$ & $n$ & & \\
\hline 43 & $n$ & $n$ & $n$ & $n$ & $n$ & $n$ & $n$ & $n$ & $n$ & $n$ & $n$ & $n$ & $n$ & $n$ & $n$ & $n$ & $n$ & $n$ & $n$ & $n$ & $n$ & $n$ & $n$ & & \\
\hline 44 & $n$ & $n$ & $n$ & $n$ & $n$ & $n$ & $n$ & $n$ & $n$ & $n$ & $n$ & $n$ & $n$ & $n$ & $n$ & $n$ & $n$ & $n$ & $n$ & $n$ & $n$ & $n$ & n & & \\
\hline 45 & $n$ & $n$ & $n$ & $n$ & $n$ & $n$ & $n$ & $n$ & $n$ & $n$ & $n$ & $n$ & $n$ & $n$ & $n$ & $n$ & $n$ & $n$ & $n$ & $n$ & $n$ & $n$ & & & \\
\hline 40 & $n$ & $n$ & $n$ & $n$ & $n$ & $n$ & $n$ & $n$ & $n$ & $n$ & $n$ & $n$ & $n$ & $n$ & $n$ & $n$ & $n$ & $n$ & $n$ & $n$ & $n$ & n & n & & \\
\hline 47 & $n$ & $n$ & $n$ & $n$ & $i$ & $n$ & $n$ & $n$ & $n$ & $n$ & $n$ & $n$ & $n$ & $n$ & $n$ & $n$ & $n$ & $n$ & $n$ & $n$ & $n$ & 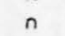 & ח & & \\
\hline 48 & $n$ & $n$ & $n$ & $n$ & $n$ & $n$ & $n$ & $n$ & $n$ & $n$ & $n$ & $n$ & $n$ & $n$ & $n$ & $n$ & $n$ & $n$ & $n$ & $n$ & $n$ & $n$ & & & \\
\hline 49 & $n$ & $n$ & $n$ & $n$ & $n$ & $n$ & $n$ & $n$ & $n$ & $n$ & $n$ & $n$ & $n$ & $n$ & $n$ & $n$ & $n$ & $n$ & $n$ & $n$ & $n$ & $n$ & $n$ & & \\
\hline 50 & $n$ & $n$ & $n$ & $n$ & $n$ & $n$ & $n$ & n & $n$ & $n$ & $n$ & $n$ & $n$ & $n$ & $n$ & $n$ & $n$ & $n$ & $n$ & $n$ & $n$ & $n$ & $n$ & & \\
\hline 51 & $n$ & $n$ & $n$ & $n$ & $n$ & $n$ & $n$ & $n$ & $n$ & $n$ & $n$ & $n$ & $n$ & $n$ & $n$ & $n$ & $n$ & $n$ & $n$ & $n$ & $n$ & $n$ & n & & \\
\hline 52 & $n$ & $n$ & $n$ & $n$ & $n$ & $n$ & $n$ & $n$ & $n$ & $n$ & $n$ & . & $n$ & $\therefore$ & $n$ & r. & " & $r$ & $n$ & $n$ & $n$ & $n$ & $n$ & & \\
\hline
\end{tabular}




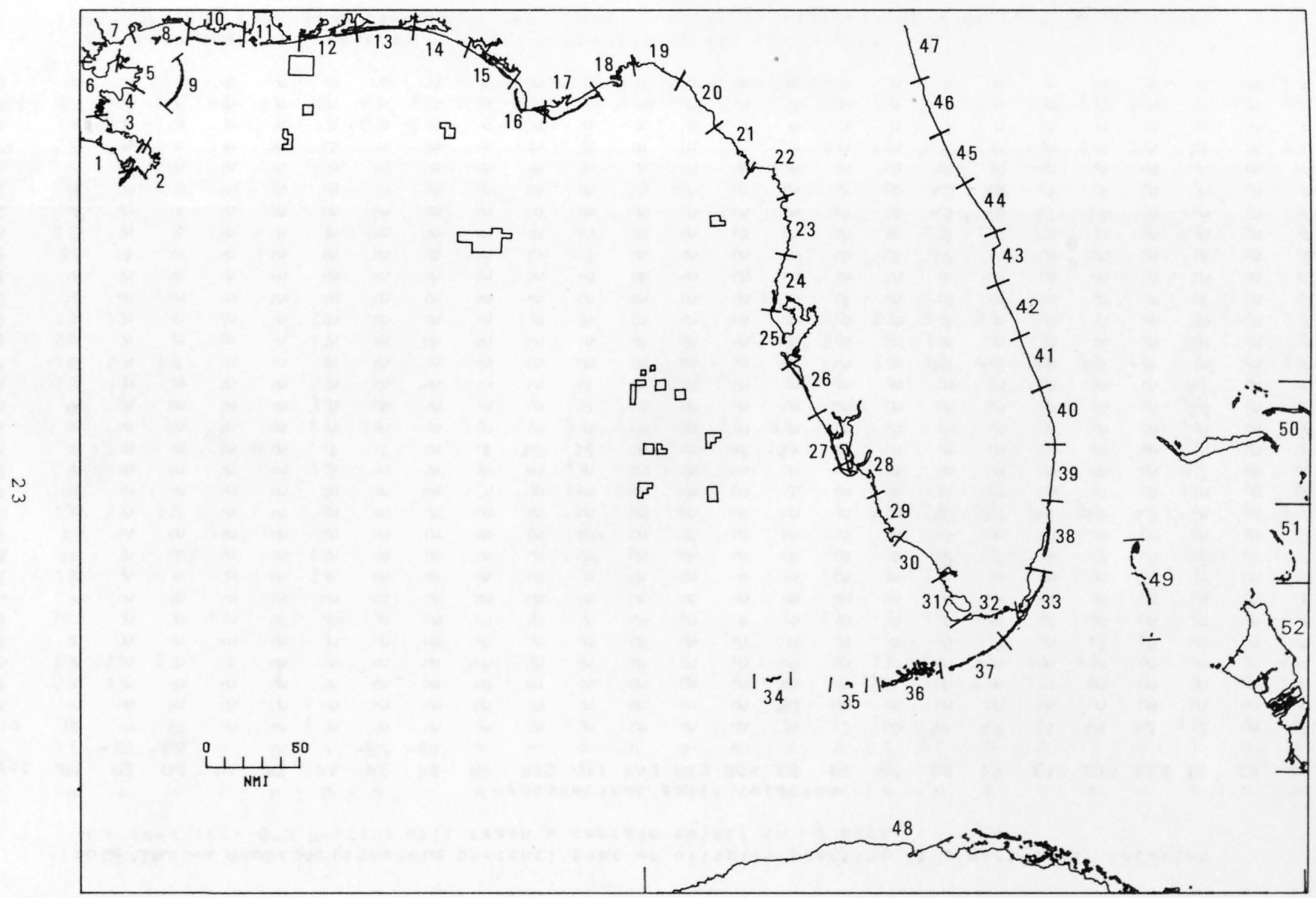

Figure 8.--Map of land segment numbers. 
Table 3A. -- Probabilities (in percent) that an oilspill starting at a particular location will reach a certain object in 3 days.

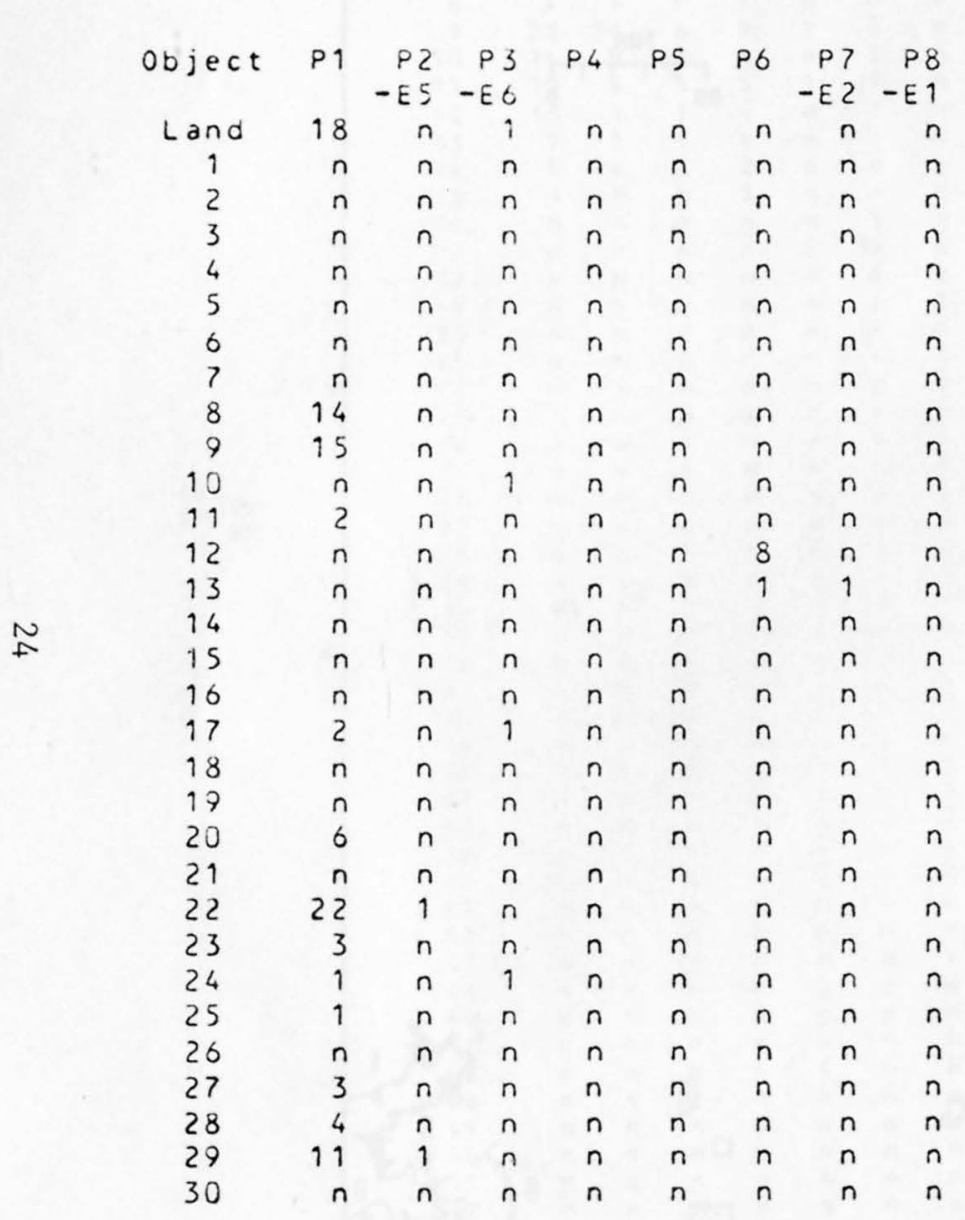

Hypothetical spill Location
P9 P10 P11 P12 P13 P14 E3 E4 E7 E8 E9 E10 E11 E12 T1 T3 T4

n - Less than 0.5 percent

* - greater than 99.5 percent 
Table 3b. -- probabilities (in percent) tnat an oilspill starting at a particular location will reach a certain object in 10 days.

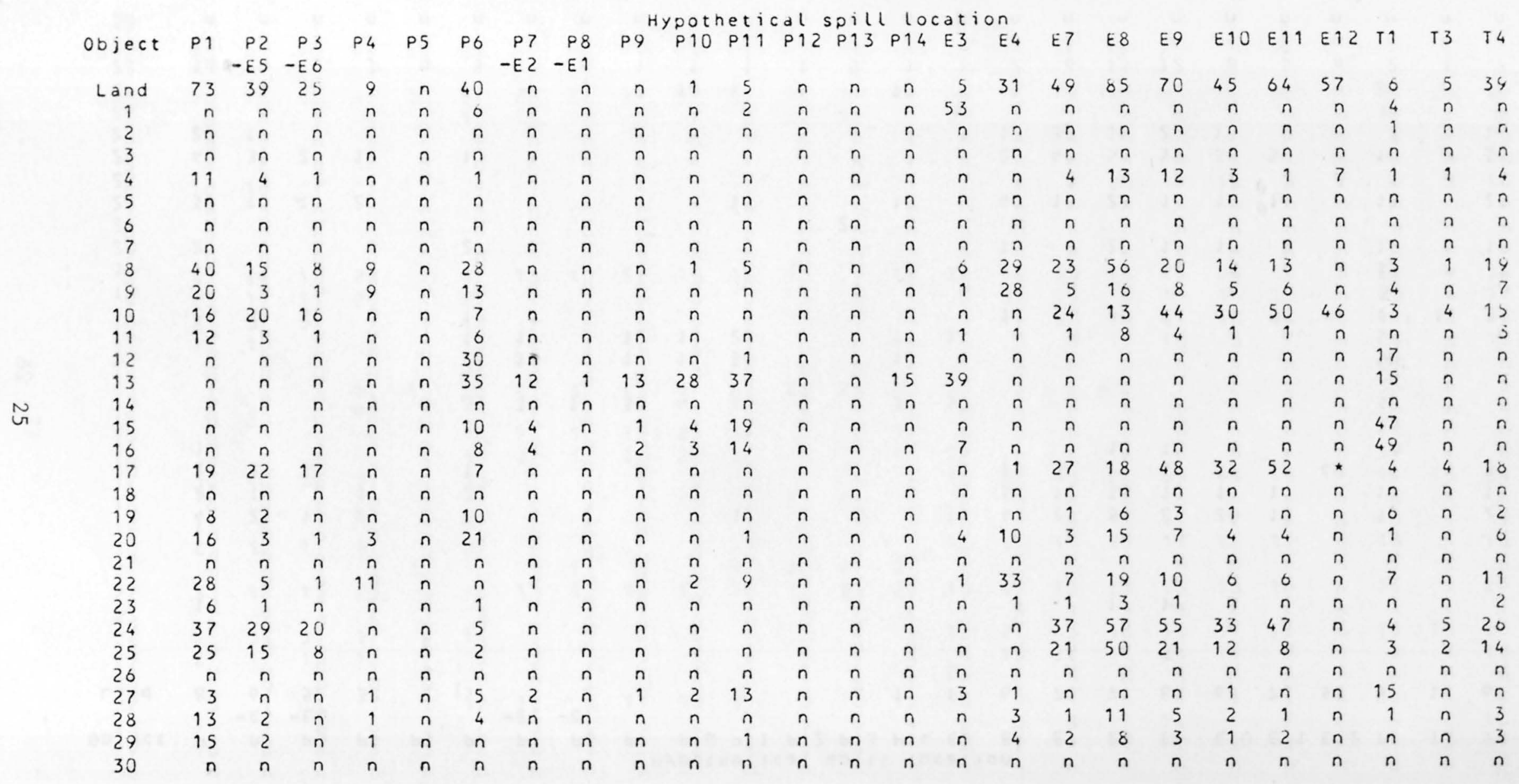

$n$ - less than 0.5 percent

* - greater than 99.5 percent 
Table 3C. - Probabilities (in percent) that an oilspill starting at a particular location will reach a certain object in 30 days.

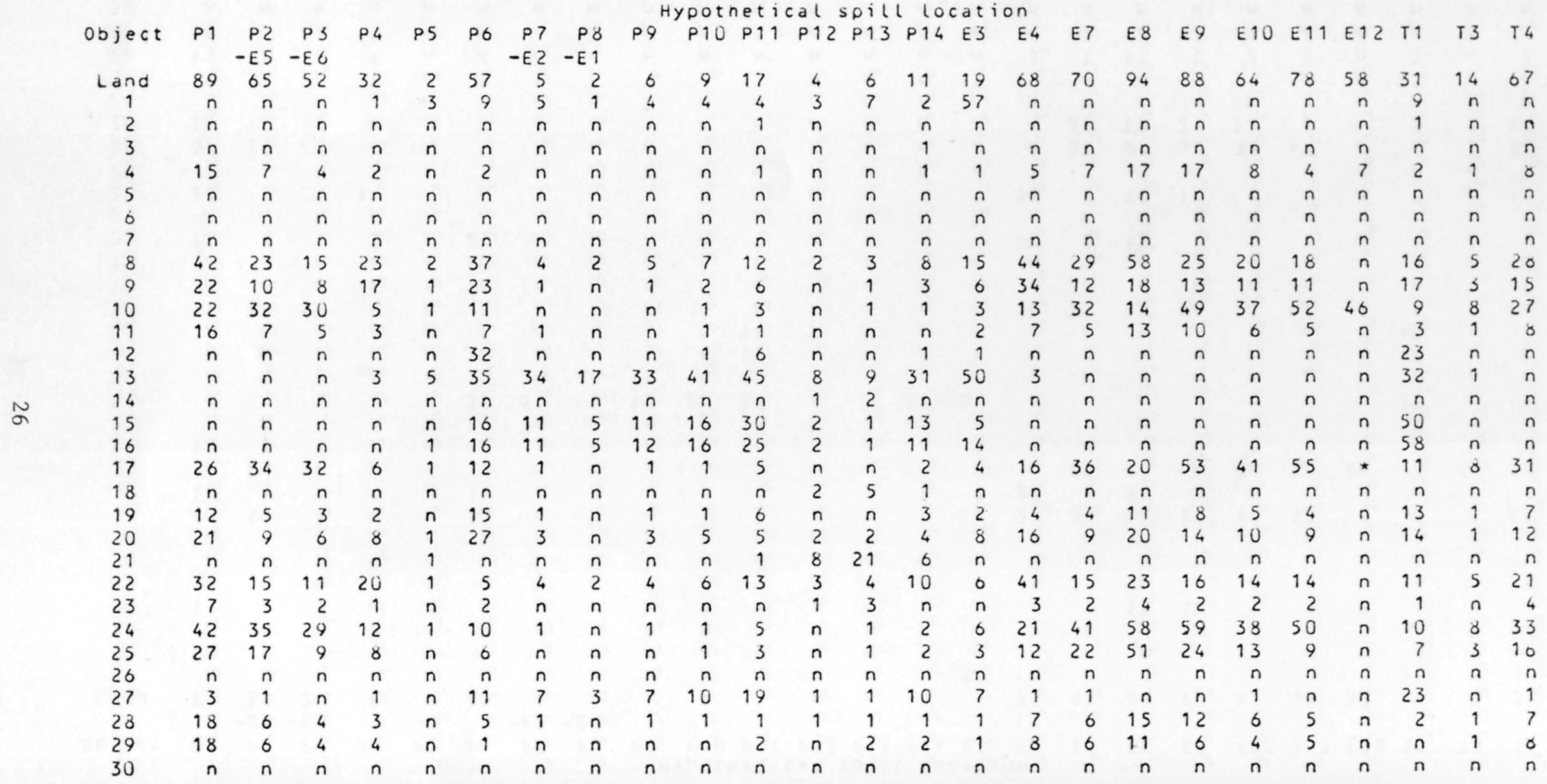


Table 30. - probabilities (in percent) that an oilspill starting at a particular location will reach a certain object in 60 days.

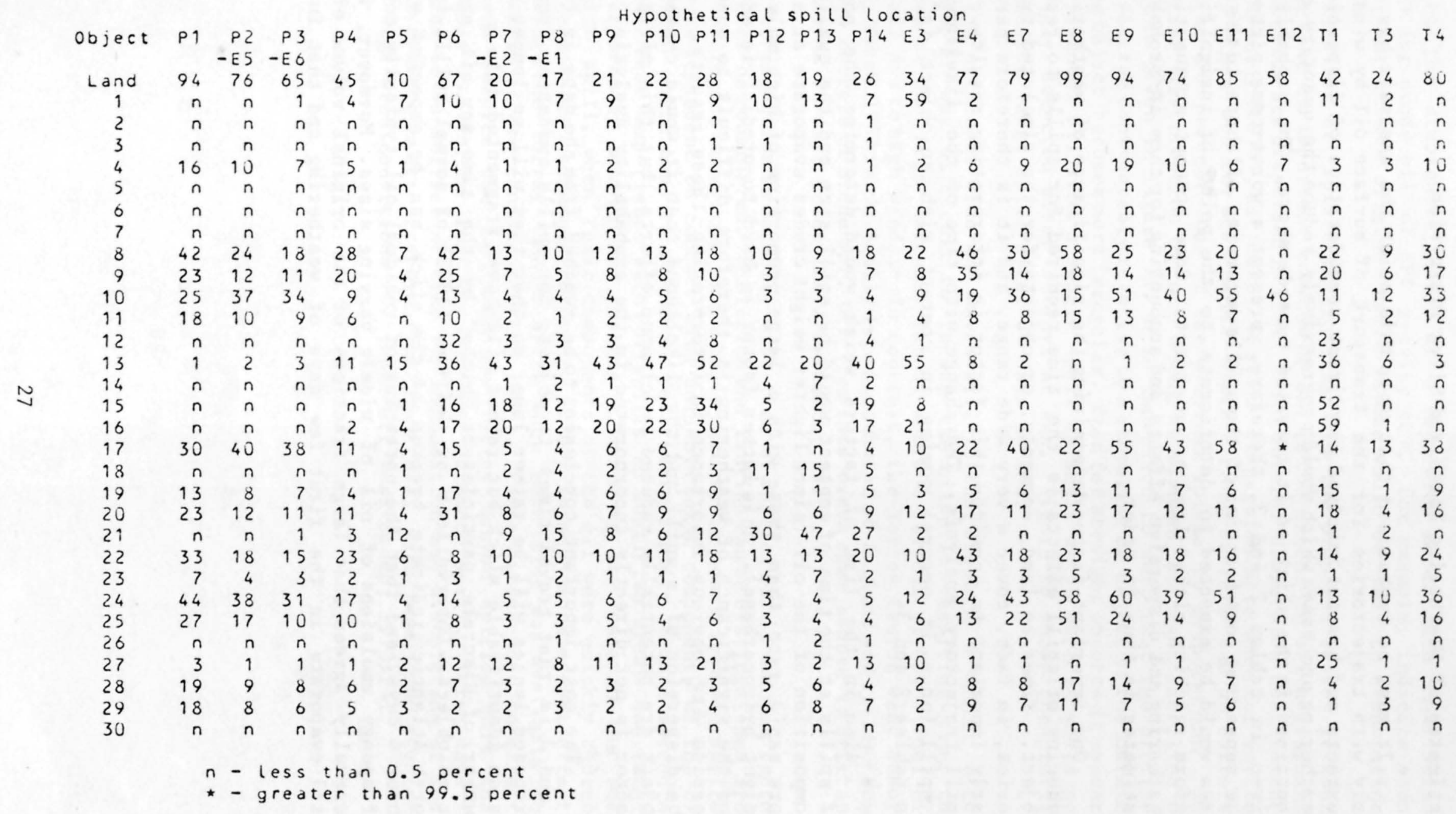


It must be emphasized that up to this point the analysis has dealt only with trajectories for the transport of surface oil by winds and currents and has not involved any direct consideration of dispersion or weathering processes which would progressively reduce the quantity of oil contained in the slick as it traveled towards shore. The probabilities given in tables 2 and 3 , therefore, present a worst-case picture in the sense that some fraction of the spills occurring offshore in the lease area would be expected to deteriorate to the point of insignificance before reaching either land or an object. Some attempt at quantifying weathering and dispersive effects and accounting for them in probability estimates is thus in order.

One important factor determining the significance of weathering in reducing oilspill effects is the time required for spills to reach an object. Times to land, segments, or objects for the simulated trajectories, in fact, cover a very wide range, and it is therefore particularly important to consider this factor in interpreting results of the spill trajectory analysis. The change with time of the likelihood of a spill (once it occurs) coming in contact with an object is shown in tables 2 and 3 .

Also in the list of factors which would determine the potency of spills at the time of contact would be spill size and the quality or composition of the oil (since lighter weight crudes evaporate at a much more rapid rate than those with a large proportion of high molecular weight hydrocarbons). This latter factor is hard to predict in advance and the significance of weathering is therefore difficult to quantify despite its obvious importance in interpreting these results. Also, the dispersion of a spill and the likelihood that it would contact an object are potentially reduced by cleanup efforts, but this mitigating factor is not directly incorporated in the probability analysis.

The most important conclusion to be reached from the data in tables 2 and 3 is that travel times to objects for spills emanating from the proposed leases will be rather long, so that they will no longer exist as an identifiable slick but rather will have fragmented into a large number of discrete particles or "blobs" by the time any oil arrives at an object. Observations by Jeffery (1973) of actual spills in the North Atlantic indicate breakup of the slick can be expected within about 4 days, and that the particles of residual oil typically consist of spongy emulsions of oil of widely varying sizes. Moreover, it is generally agreed that large fractions of the original volume of oil will evaporate in the first few days of weathering and that further 
loss to the atmosphere occurs at a very slow rate. Data from Nelson (1958) for crude oil of API gravity $40 \circ$, for example, indicate about 50 percent of the original spill volume would be lost to evaporation.

Thus for oil spills originating from the proposed leases it would appear that an important consideration is the extent to which fragments of the slick are dispersed in time. Using lateral dispersion coefficients from Csanady (1974), estimates of slick dispersion were made for various travel times and for two spill sizes, 1,000 barrels and 50 barrels, assuming 50 percent loss of the original volume by evaporation. The resulting distribution of oil along an assumed straight shoreline or object is given in figure 9A. It is important to note that the profiles will flatten considerably relative to a shoreline or object as the outline of the object becomes more irregular. Even for straight objects it appears that residual oil from a single spill as small as 50 barrels would not be easily detected after 30 days at sea. Figure $9 \mathrm{~B}$ shows the profile of a medium large spill after 30 days at sea.

The action of wind and waves will furtherdisperse a spill. After 30 days it was difficult to locate the oilspill resulting from the breakup of the Argo Merchant (about 180,000 barrels of No. 6 fuel oil spilled) due tohigh winds. In contrast, the Torrey Canyon went ashore on 18 March 1967 in the Scilly Isles southwest of England and spilled some 700,000 barrels of crude oil. Oil from this wreck came ashore in Brittany as late as 60 days later (Wardley-Smith, 1976).

The reduction in toxicity with time of spilled oil is another factor that must be considered. Shellfish and finfish can be distinguished from other biological resources on the basis that their sensitivity to spilled crude is dependent on contact with soluable toxic components of the oil fractions which tend to evaporate relatively rapidly from a spreading slick. Past experience with oilspills in shellfish areas has ranged from reportedly severe and lasting effects in the case of the West Falmouth spill, when toxic components of the oil were quickly churned into near-shore sediments (Blummer, 1970), to much more modest effects following the Torrey Canyon spill when more time was available for weathering before contact (Smith, 1968). These differences in effects occurred despite the fact that the Torrey Canyon spilled more than 150 times the volume lost in the West Falmouth spill. Three days is reported to be sufficient time for evaporation and dissolution of most of the toxic aromatic fractions of crude oil, with less time required under high wind conditions (Offshore Oil Task Group, 1973). 

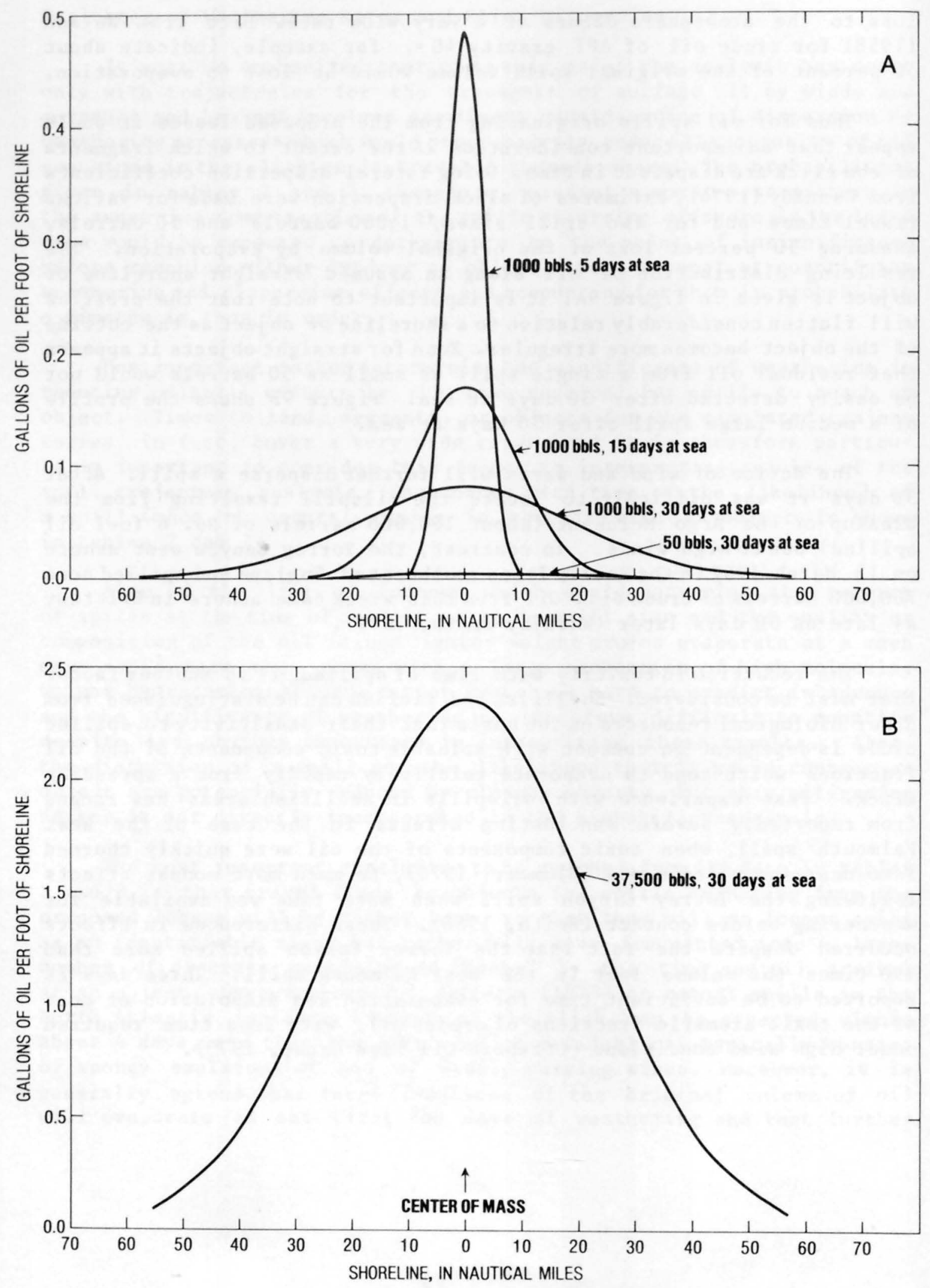

Figure 9.--Density of oil reaching an idealized shoreline (or object) as a function of travel time and initial size. $\quad 30$ 
It is worth briefly summarizing some of the important points to be drawn from the results presented thus far. Data in table 1 indicate that the proposed leasing will add about $260 \mathrm{spills}$ to the already existing expected number of spills of about 6470 (a ratio of about 25 to 1) and none are likely to exceed 1,000 barrels. Furthermore, consideration of travel time to contact (tables 2 and 3 ), evaporation rates, and rates of slick dispersion (figure 9) leads to the conclusion that an individual spill would need to be as large as 1,000 barrels in size in order to have significant ecological contact. The probabilities in tables 2 and 3 give the chances that if a spill occurs in the lease area it would contact an object within the allotted time.

With respect to the hazard of major spills (that is, greater than 1,000 barrels), the data presented in tables 2 and 3 represent only a partial solution to the problem of assessing oilspill risks to important resources. The overall oilspill risk posed by oil and gas development in the proposed sale must be assessed as a joint function of the probability that spills will occur in the course of development as well as the likelihood that spills will follow certain trajectories. Thus, the data in tables 2 and 3 must be combined with the spill frequency estimates presented in figures 2 and 3 to obtain a total probability distribution for contacts with individual objects.

Despite the intuitive logic of simply multiplying the probabilities in figure 3 by those in tables 2 and 3 , the correct computation of the overall or "total" probability is in fact somewhat more complicated. This results from the fact that the probabilities presented in tables 2 and 3 are actually conditional probabilities and refer to the probabilities of contact on objects "conditioned" on the chance of spills occurring in the first place. The overall probability that oilspills will contact a particular object exactly $\mathrm{k}$ times during the production life of the area, $P(k)$, is given by

$$
P(k)=\sum_{n=k}^{\infty} P(k \mid n) P(n)
$$


where $\mathrm{P}(\mathrm{k} n)$ is the probability of k contacts with the resource given the occurrence of $n$ spills, and $P(n)$ is the probability of $n$ spills occurring. The conditional probability $P\left(\begin{array}{ll}k & n\end{array}\right)$ can be assumed to be distributed binomially and is given by

$$
P(k \mid n)=\left(\begin{array}{l}
n \\
k
\end{array}\right) p^{k}(1-p)^{n-k}
$$

where $\mathrm{p}$ is the probability of contact with the object given the occurrence of a spill (tables 2 and 3 ).

The combined probability distributions calculated in the above manner for spills coming ashore is presented in figure 10 for the four "milestones" time periods. The distributions are based on spill frequency estimates from figure 3 and therefore refer to contacts from all spills originating as 1,000 barrels or greater during the production life of the total lease area. Figure 10 indicates that there is a 98.5 percent probability that no oilspill greater than 1,000 barrels will occur and come ashore within 3 days in the course of oil production in the proposed leases and that there is an $84 \%$ chance that no oilspill greater than 1,000 barrels will occur and come ashore within 60 days from the proposed leases. In contrast, the comparable numbers for the existing leases are $5 \%$ and $0.5 \%$ respectively, and almost the same, respectively, for the combination of both the proposed and existing leases.

Probability distributions similar to those in figure $10 \mathrm{can}$ be developed and likewise interpreted for each of the 30 categories of biological resources, recreation areas, and other objects. Statistics for spills greater than 1,000 barrels occurring during the production life of the area and contacting the various resource groups are given in table 4. Similar statistics for land segments are given in table 5 .

It is emphasized that probability estimates refer only to the chances that oil in some form or another, from a spil1 originating larger than 1,000barrels will come in contact with some portion of an object. The mitigating effects of weathering processes and clean-up efforts are only indirectly reflected in the probabilities in tables 4 and 5 by virtue of the fact that estimates apply only to large spills. Figure 9 provides a rough description of the likely effects of evaporation and dispersion on spills of various sizes as a function of time. To this must be added the likelihood of at least some, and perhaps considerable, success in containing oil in the course of the days or weeks separating the occurrence of a spill on the OCS and its arrival on shore. 


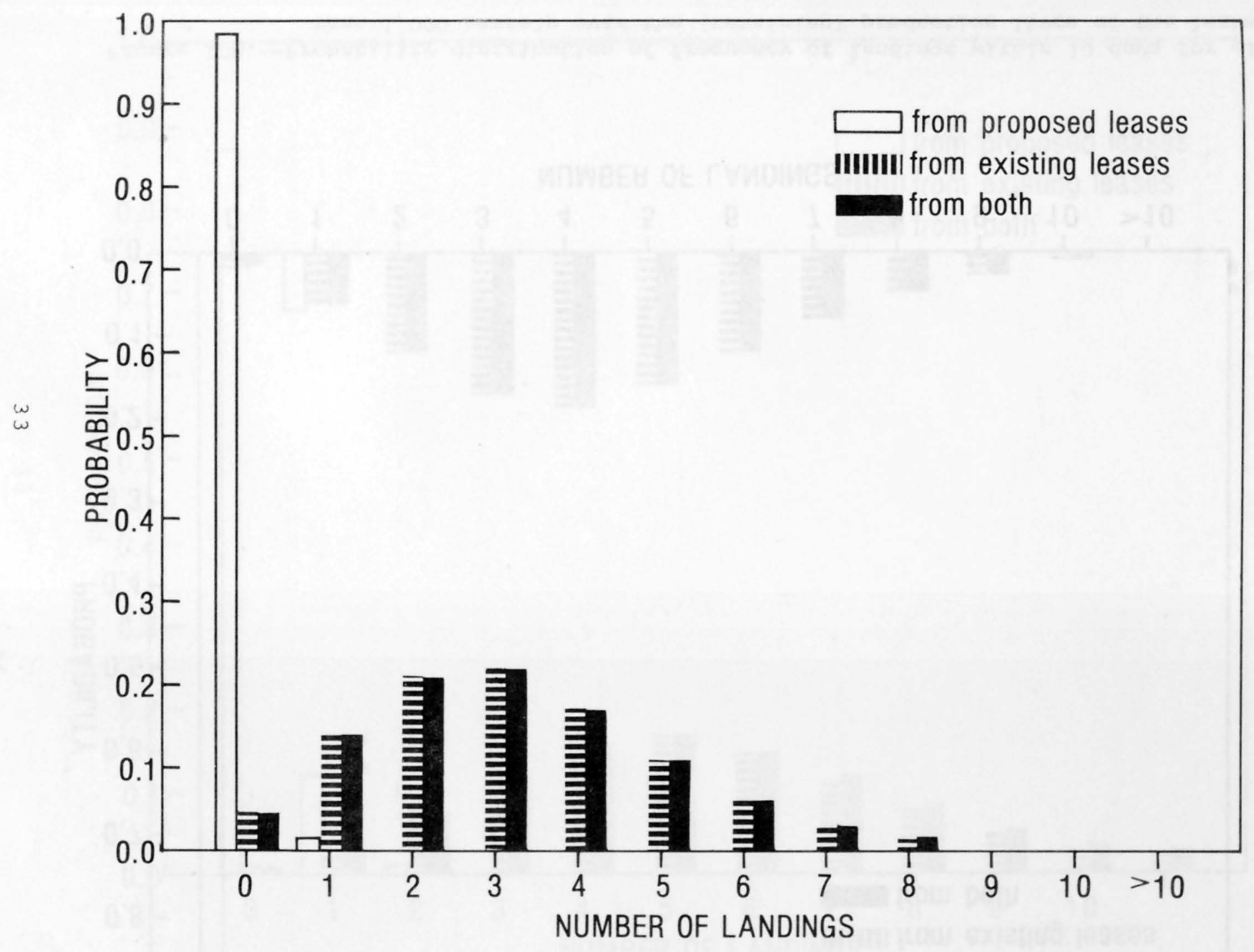

Figure 10A.--Probability distribution of frequency of landings within 3 days for oilspills greater than 1,000 barrels over the (remaining) production lives of the leases. 


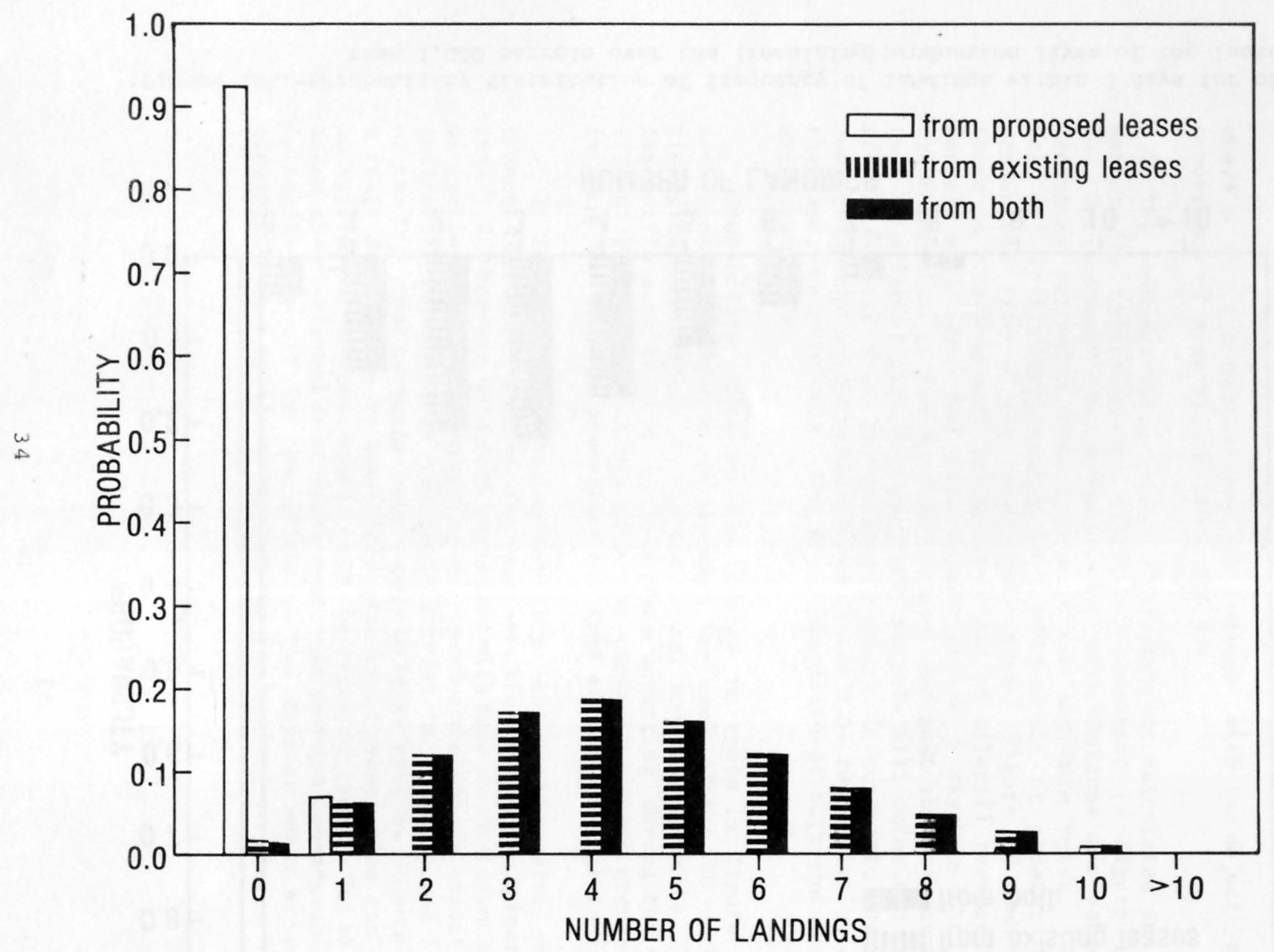

Figure 10B.--Probability distribution of frequency of landings within 10 days for oilspills greater than 1,000 barrels over the (remaining) production lives of the leases. 


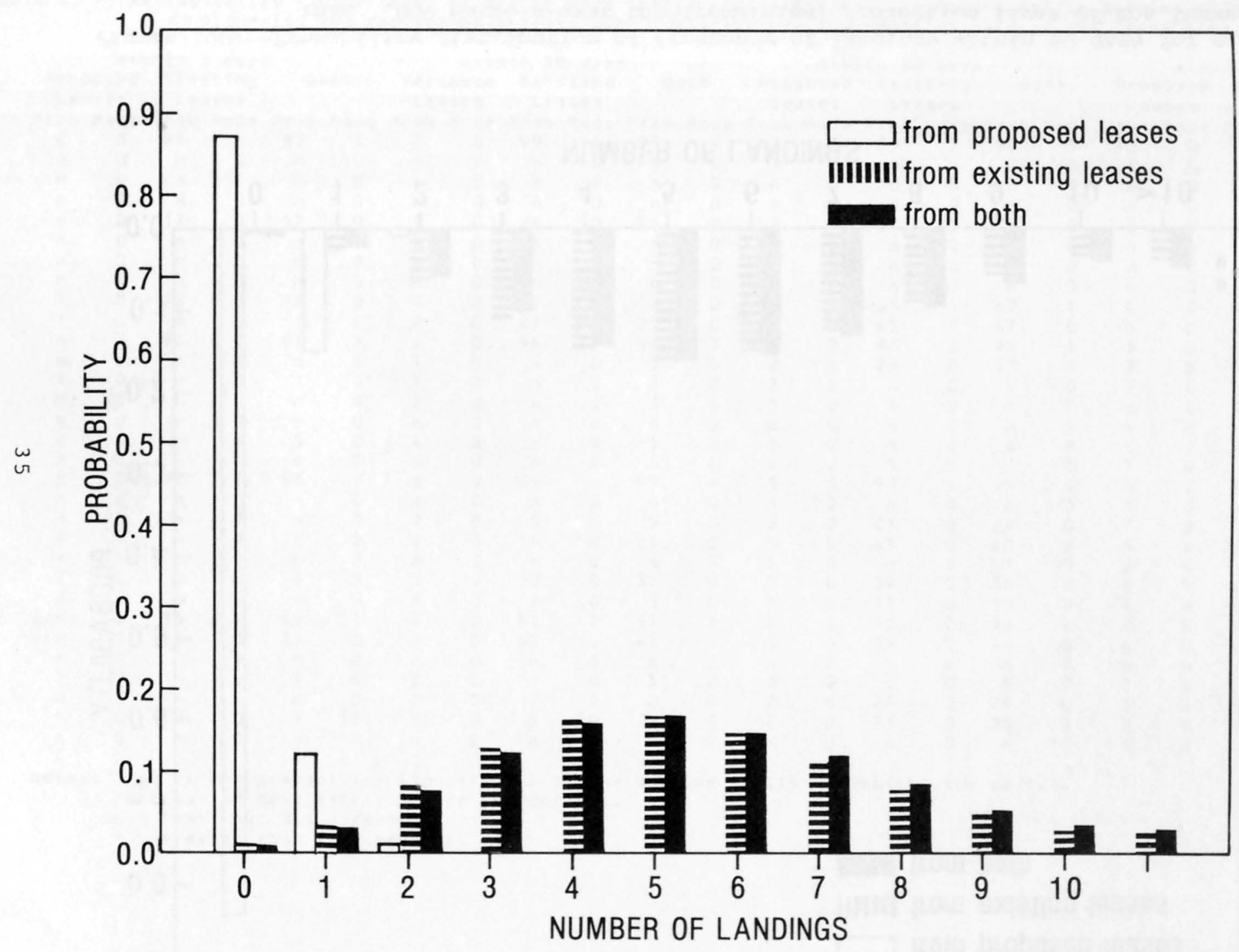

Figure 10C.--Probability distribution of frequency of landings within 30 days for oilspills greater than 1,000 barrels over the (remaining) production lives of the leases. 


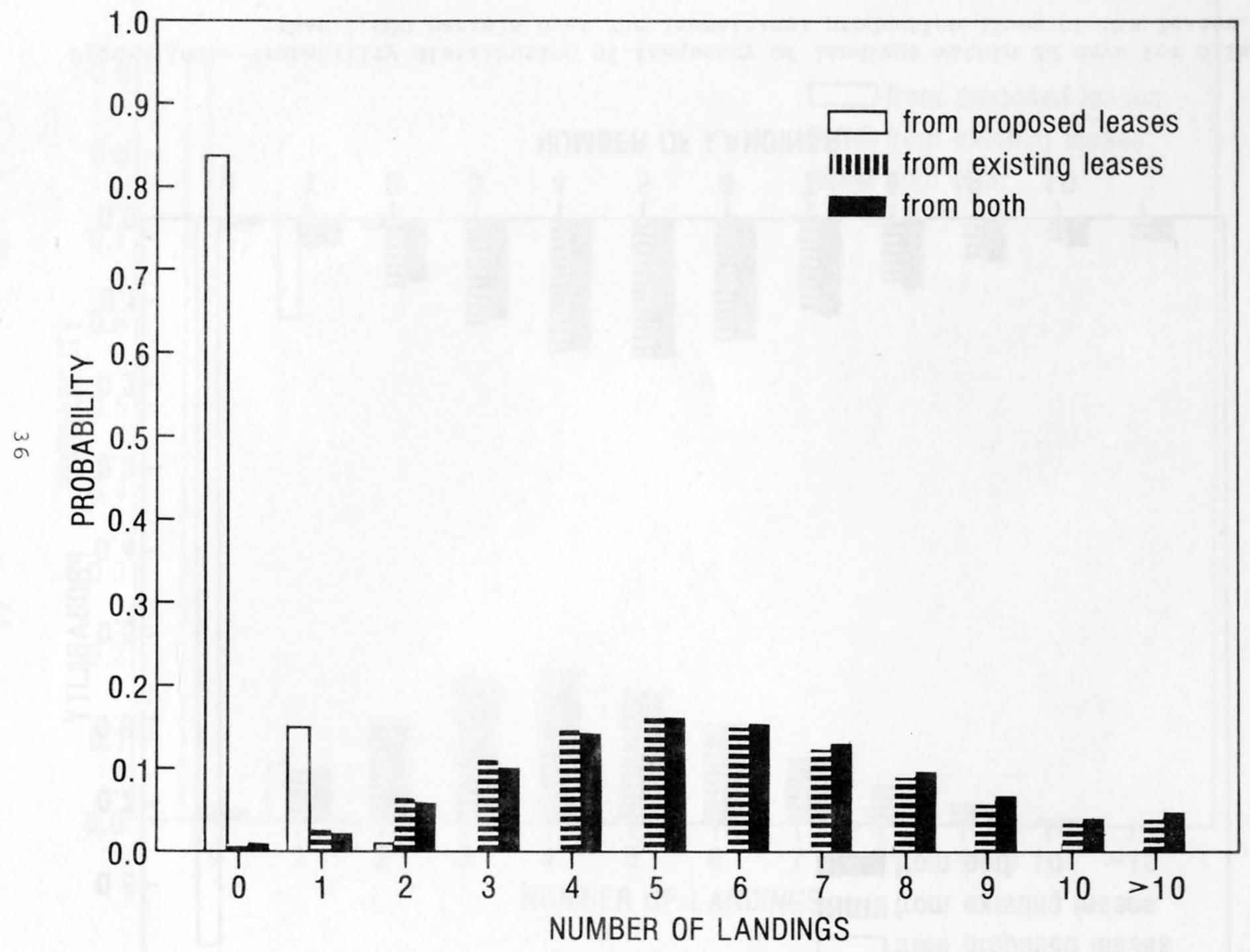

Figure 10D.--Probability distribution of frequency of landings within 60 days for oilspills greater than 1,000 barrels over the (remaining) production lives of the leases. 


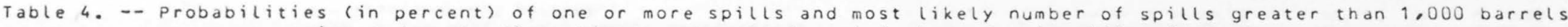
occurring and contacting objects over the (remaining) production life of the lease area.

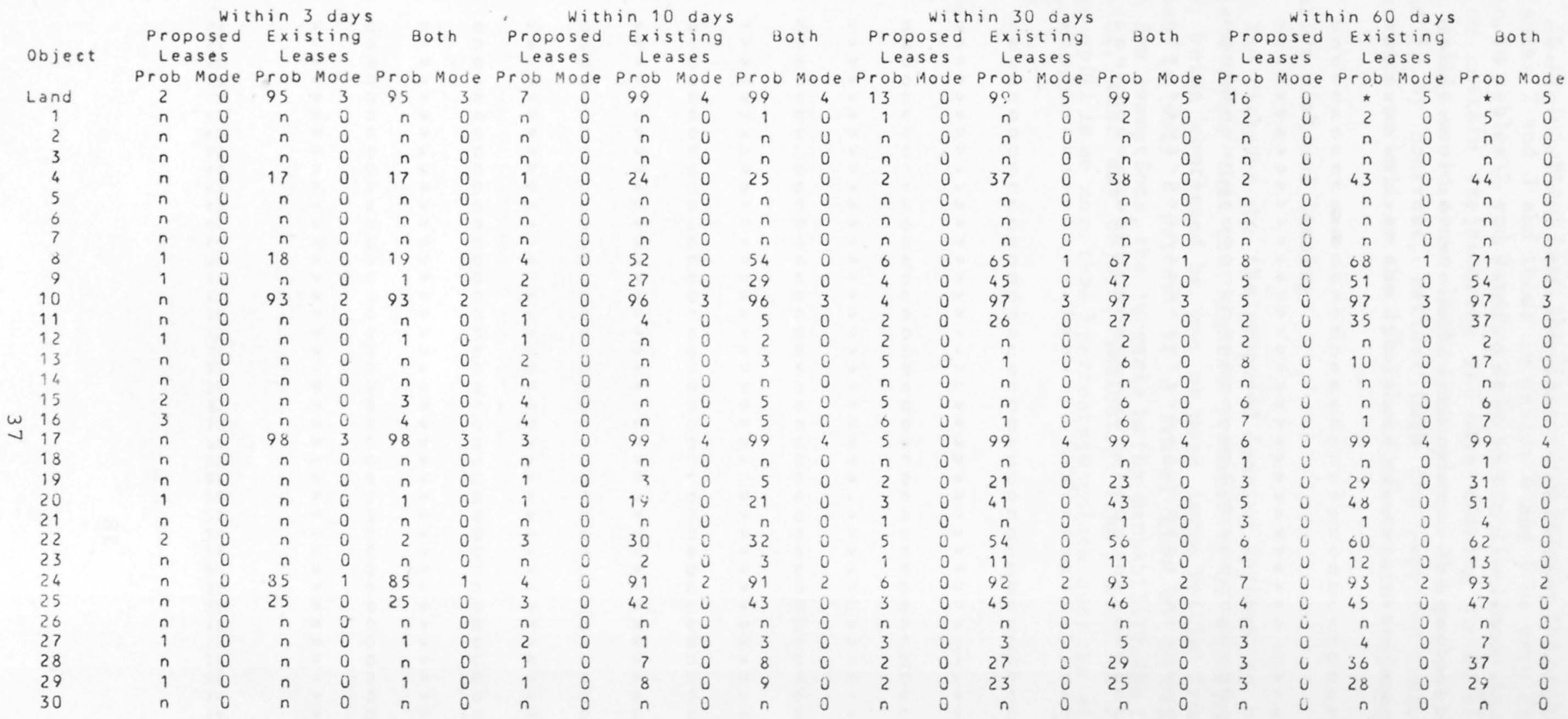

Notes: Prob is the probability (in percent) of one or more spills contacting the object. Mode is the most likely number of contacts.

n - less than 0.5 percent.

* - greater than 99.5 percent. 
Table 5. -- Probabilities (in percent) of one or more spills and most likely number of spills greater than 1 , ooo barrels occurring and contacting land segments over the (remaining) production life of the lease area.

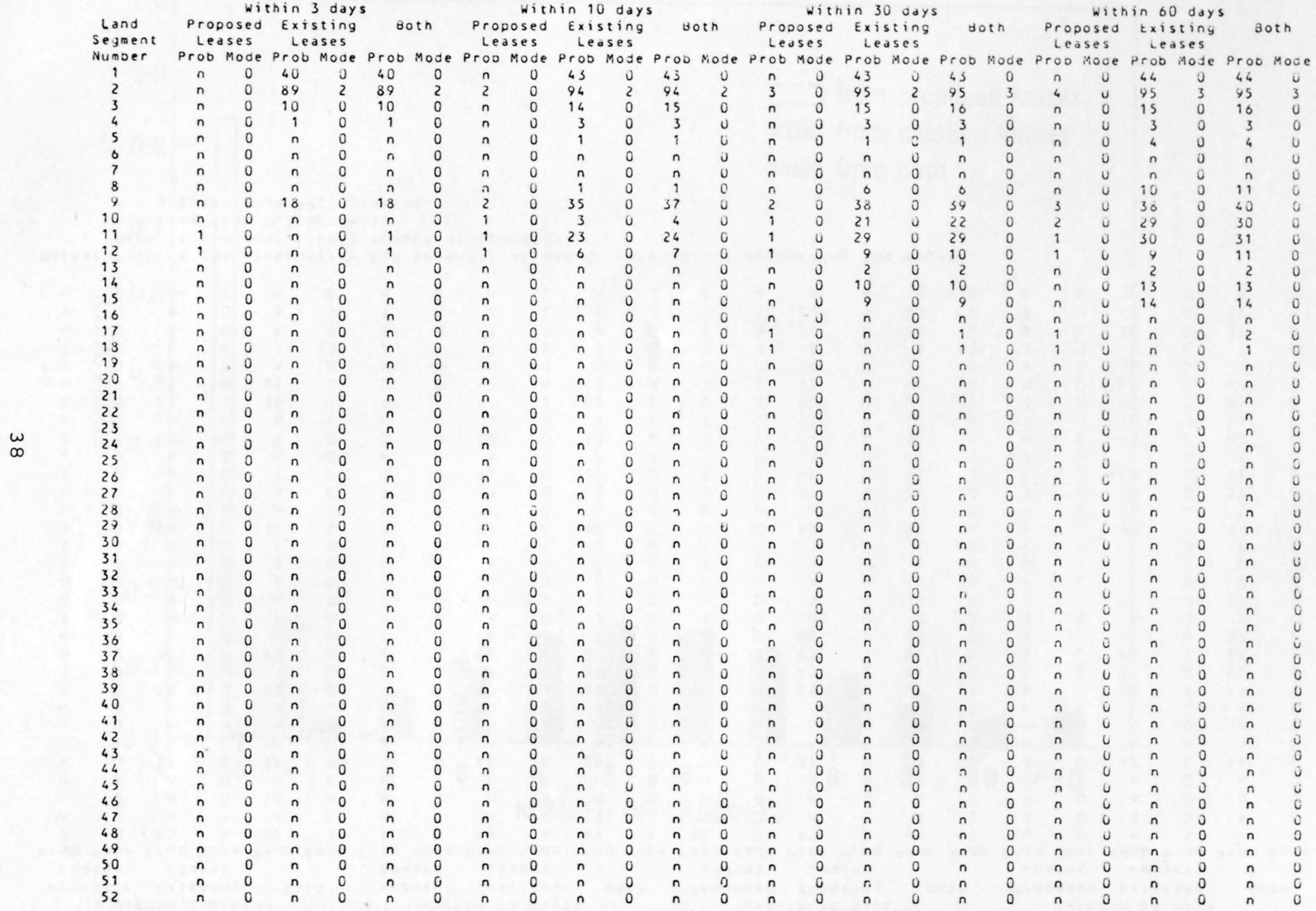

Notes: Prob is the probability (in percent) of one or more spills contacting the opject. Mode is the most likely number of contacts. - less than 0.5 percent. 
It is important that the distinction between the probabilities given in tables 2 and 3 and those in tables 4 and 5 be very clear. The data given in tables 2 and 3 refer only to the likelihood that spills would follow certain trajectories and have nothing to do with the chances that spills would occur in the first place. The probabilities in tables 4 and 5, by contrast, reflect both the expected frequency of spill occurrence as we 11 as the likelihood of certain trajectories.

Relative Risks of Leasing

The risk due to the proposed leasing appears to be quite small. Table 4 shows that the highest probability of an object, other than land, being contacted by one or more large spills from the proposed leases is only 8 percent if a travel time of 60 days is allowed. With few exceptions, the increase in the probability, due to the proposed leasing, that any object, including land, will be contacted by a large spill is no more than 3 percentage points over the already existing risk. 
Blummer, M., Sonza, S., and Sass, J., 1970, Hydrocarbon polluting of edible shellfish by an oil spill: Marine Biology, v.5, p. 195-202.

Csanady, G.T., 1973, Turbulent diffusion in the environment: D. Reidel Publishing Co., Geophysics and Astrophysics Monographs, v. 3, Boston.

Danenberger, E. P., 1976, Oil spil1s, 1971-75, Gulf of Mexico Outer Continental Shelf: Geological Survey Circular 741, 47 p.

Devanney, J. W., III, and Stewart, R. J., 1974, Analysis of oilspil1 statistics: Report to Council on Environment Quality, Wash., D. C., $126 \mathrm{p}$.

Jeffery, P. G., 1973, Large-scale experiment on the spreading of oil at sea and its disappearance by natural forces, In Proceedings of Conference on Preventon and Control of Oil Spil1s (1973): p.469-474.

Nelson, W. L., 1958, Petroleum refinery engineering, New York, McGraw-HI11.

Offshore Oil Task Group, 1973, The Georges Bank petroleum study, v. II: MIT Sea Grant Report, 311 p •

Ralph M. Parsons Laboratory, 1976, A review and evaluation of basic techniques for predicting the behavior of surface oil slicks, In Report to Deepwater Ports office: Nat1. Oceanog. Ae ronaut. Admin, $171 \mathrm{p}$.

Smith, J. E., ed., 1968, Torrey Canyon pollution and marine life, Cambridge University Press, Cambridge.

Stewart, R. J., 1975, Oil spillage associated with the development of offshore petroleum resources, In Report to Organization for Economic Co-operation and Development: $49 \mathrm{p}$.

Stewart, R. J., 1976, A survey and critical review of U.S. oil spill data resources with application to the tanker/pipeline controversy, Report to U.S. Department of the Interior, Wash., D. C., 69 p. 
U. S. Department of the Interior, Bureau of Land Management, 1977, Proposed 1977 outer continental shelf oil and gas lease sale in the Western Gulf of Alaska (OCS Draft Environmental Statement), 4 volumes.

Wardley - Smith, J., ed., 1976, The control of oil pollution on the sea and inland waters, Graham and Trotman, Ltd., United Kingdom, 251 p. 
APPENDIX A

Figures $\mathrm{A}-1$ to $\mathrm{A}-30$

The locations of biological resources in the vicinity of the Eastern Gulf of Mexico Outer Continental Shelf Lease Area 


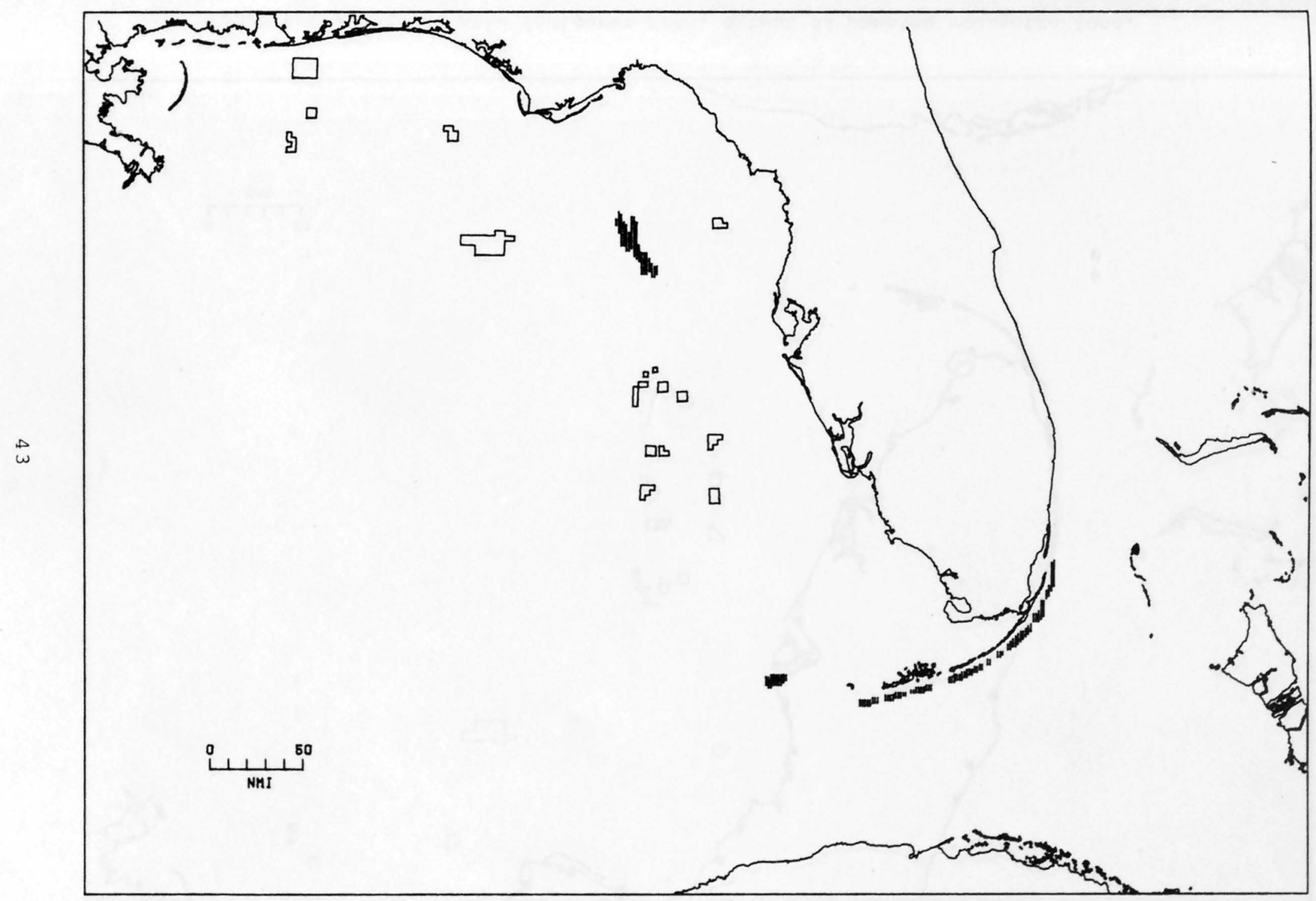

Figure A-1.--Hatched area indicates areal extent of coral areas. 


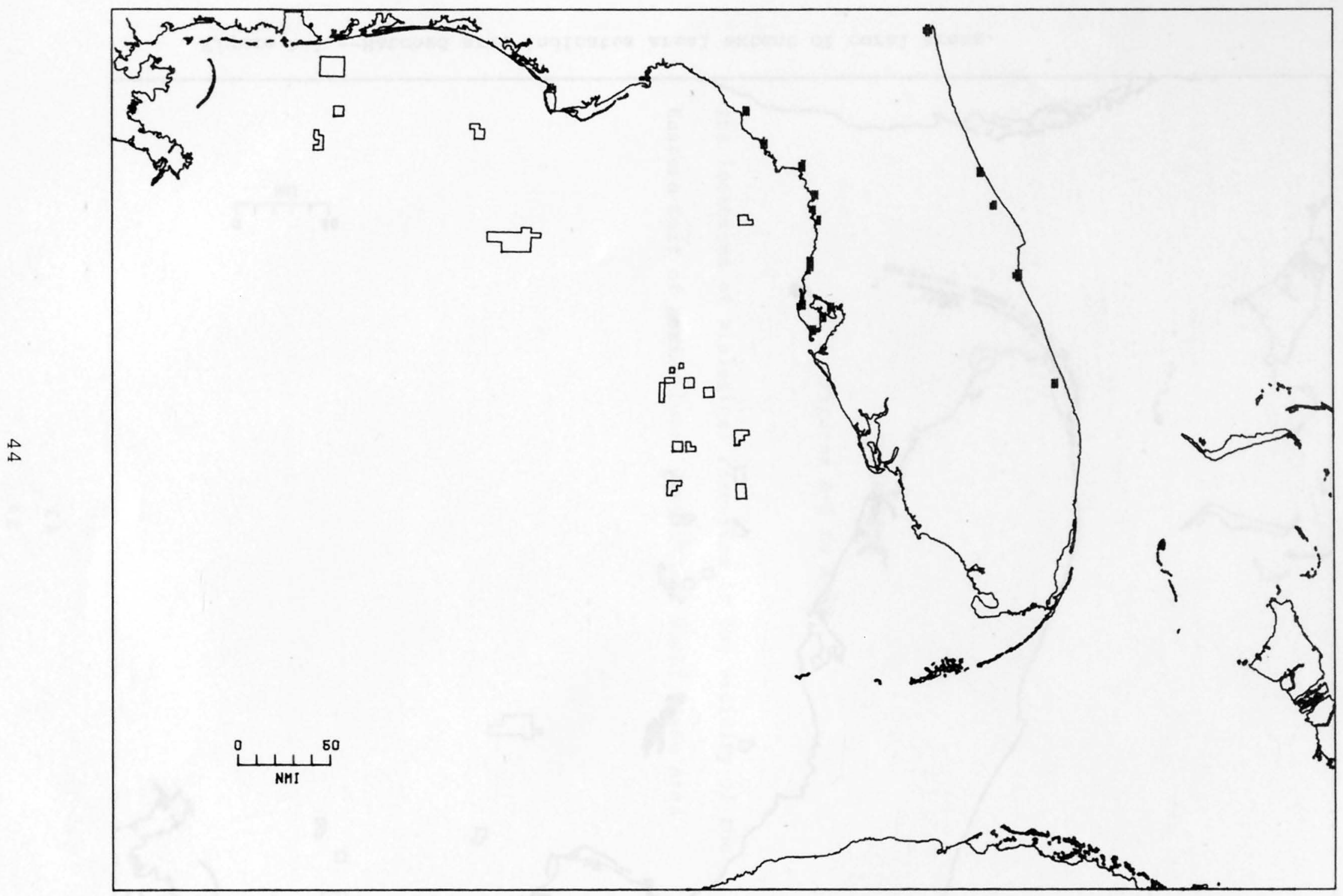

Figure A-2.--Hatched area indicates areal extent of manatee concentrations. 


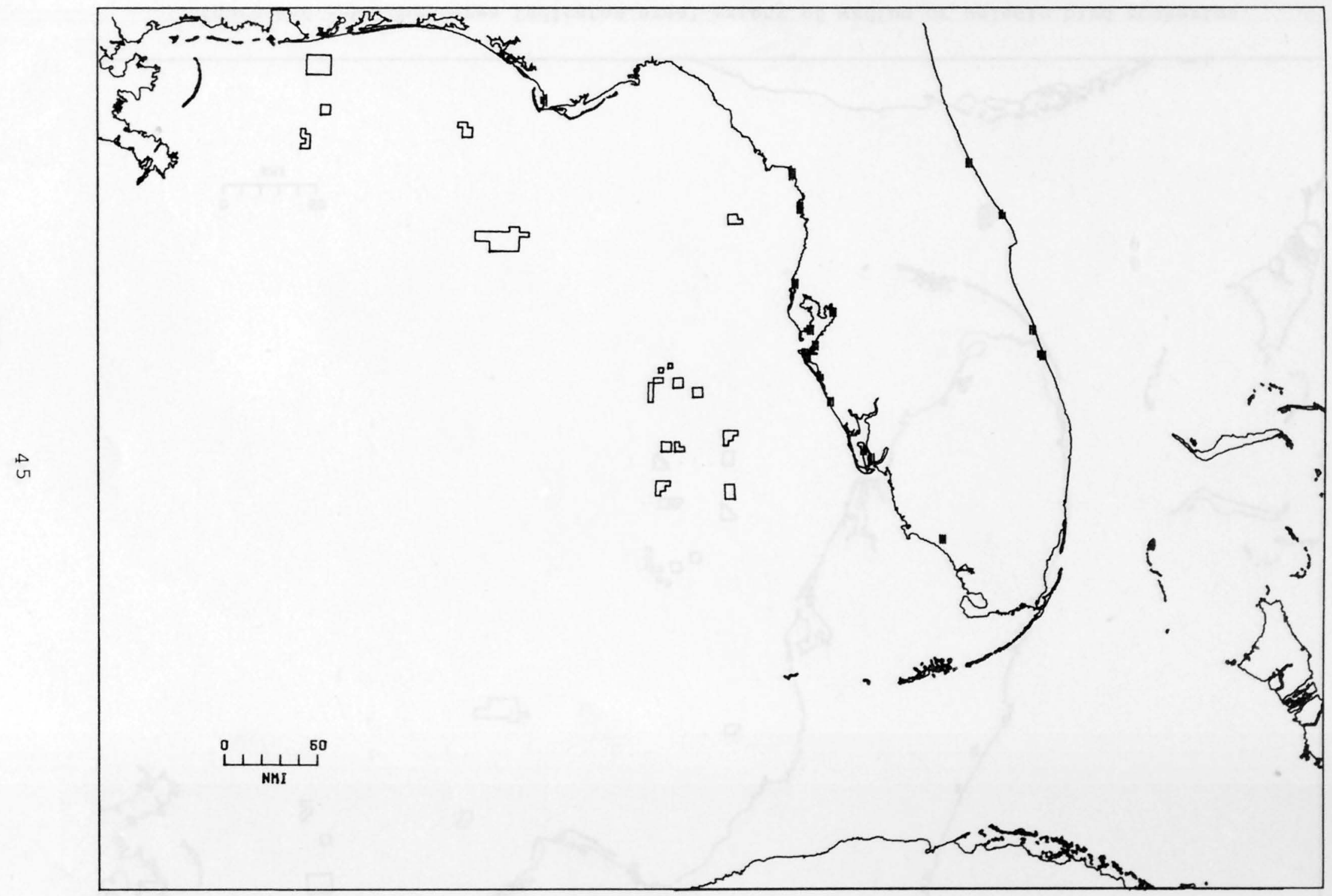

Figure A-3.--Hatched area indicates areal extent of brown pelican rookeries. 


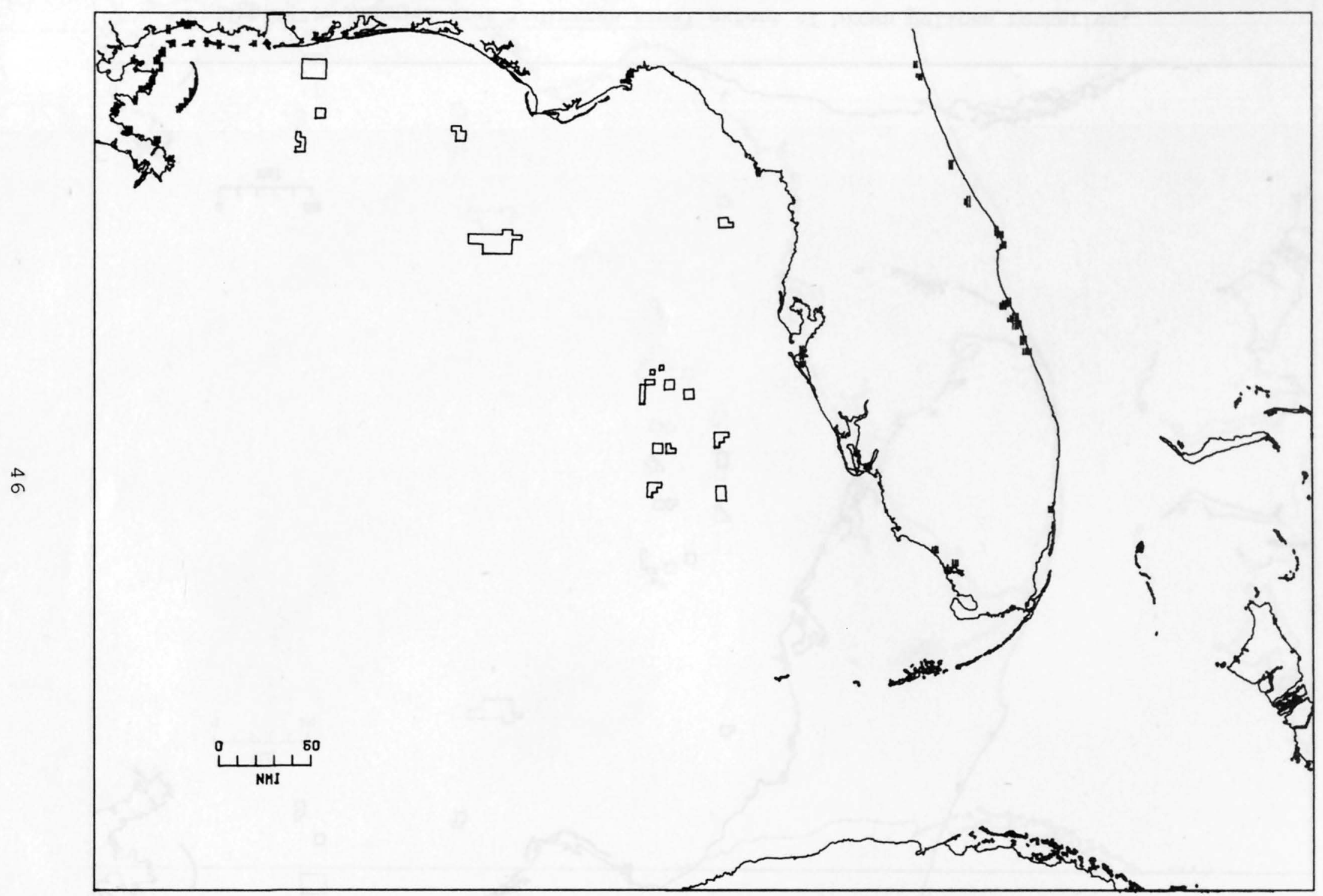

Figure A-4.--Hatched area indicates areal extent of wading or pelagic bird rookeries. 


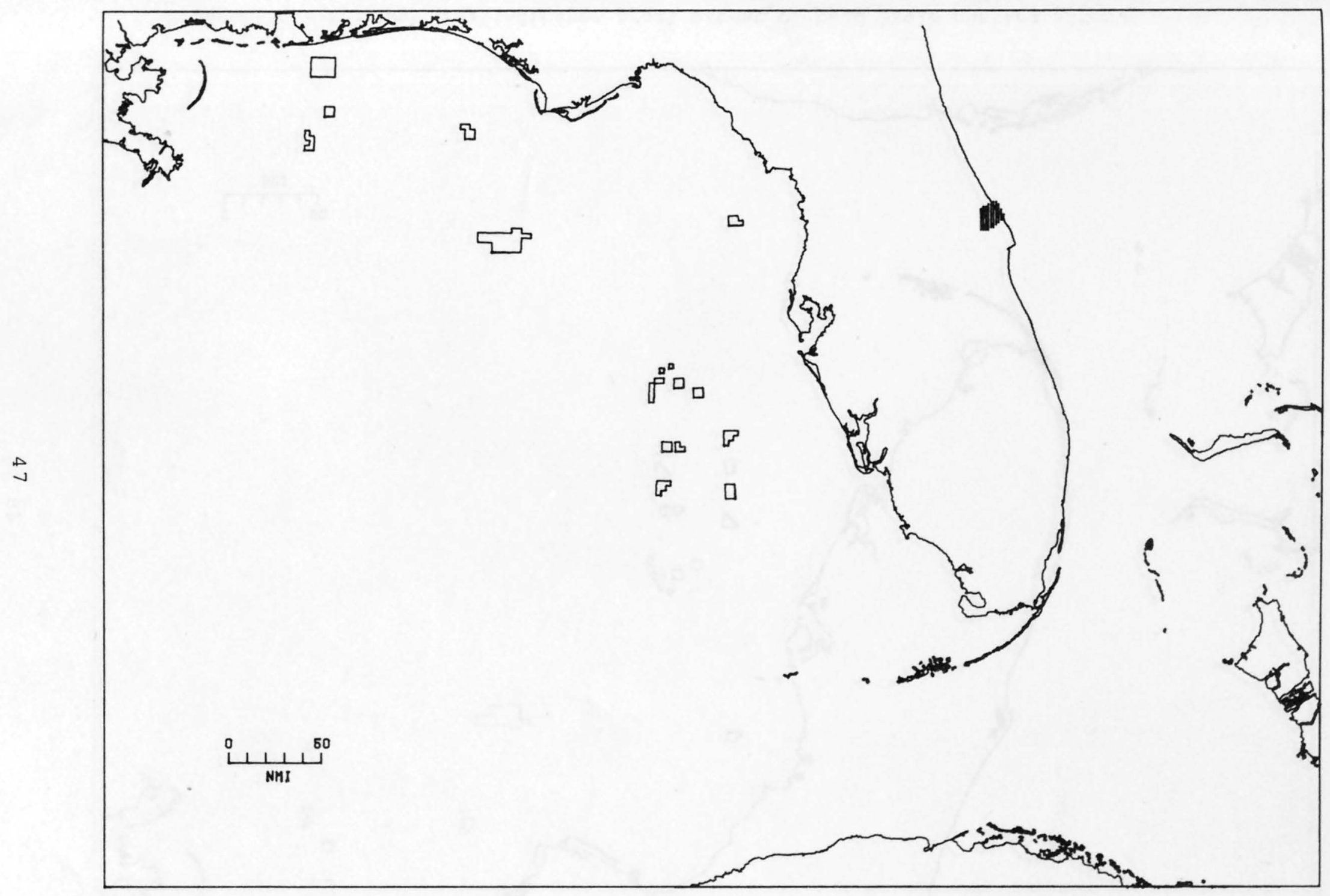

Figure A-5.--Hatched area indicates areal extent of dusky seaside sparrow habitat. 


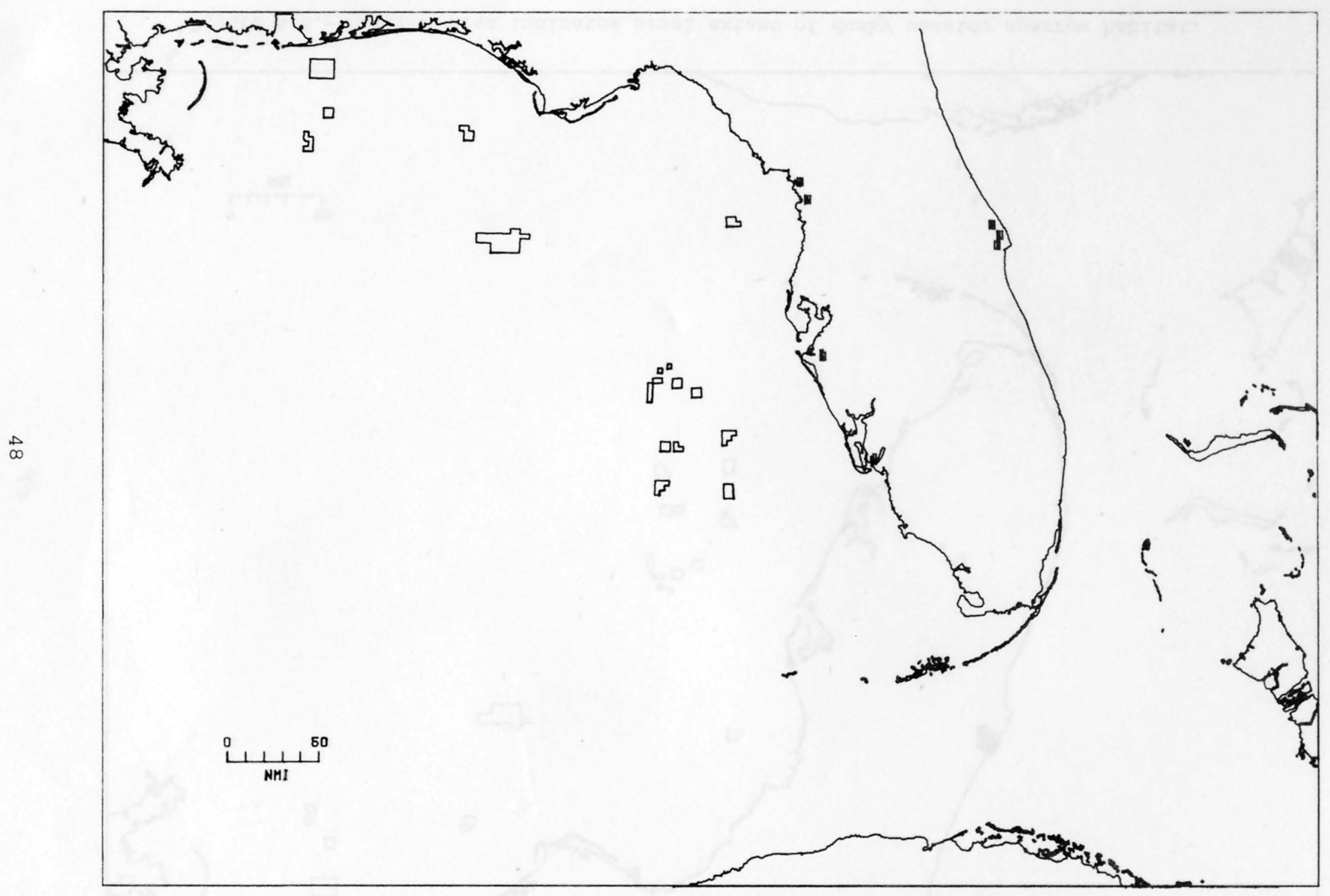

Figure A-6.--Hatcheä area indicates areal extent of bald eagle nesting sites. 


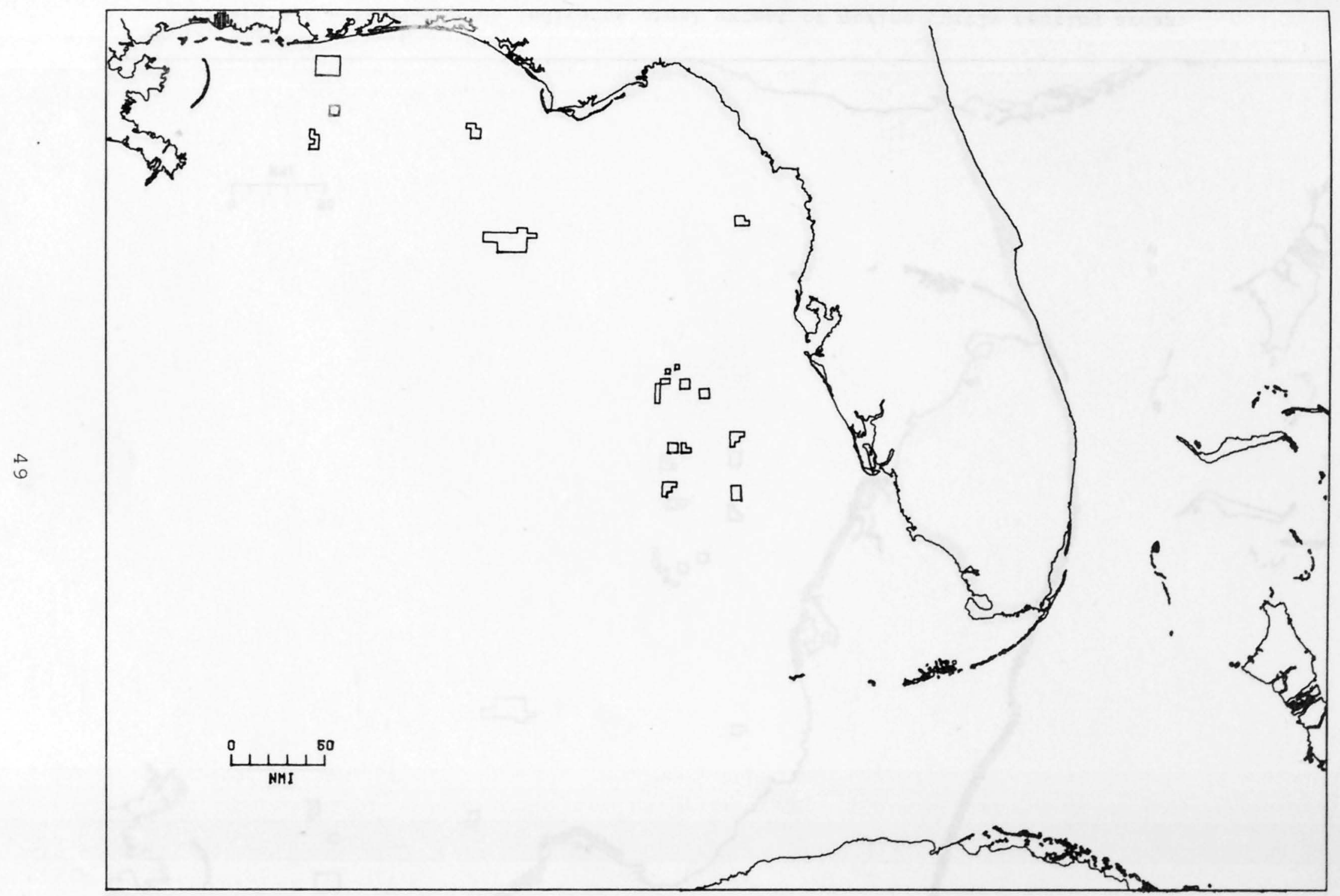

Figure A-7.--Hatched area indicates areal extent of Mississippi sandhill crane habitat. 


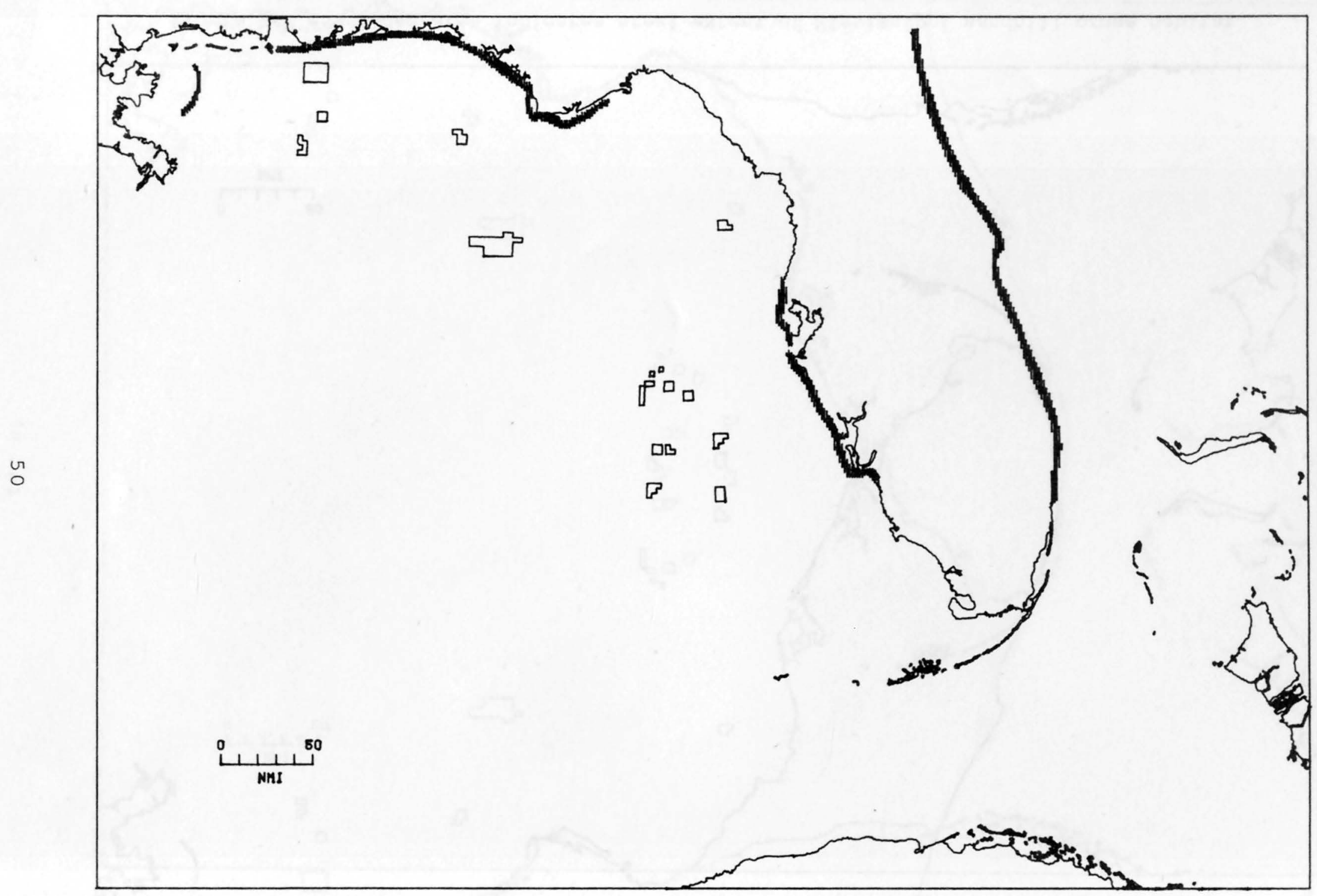

Figure A-8.--Hatched area indicates areal extent of marine turtle nesting areas. 


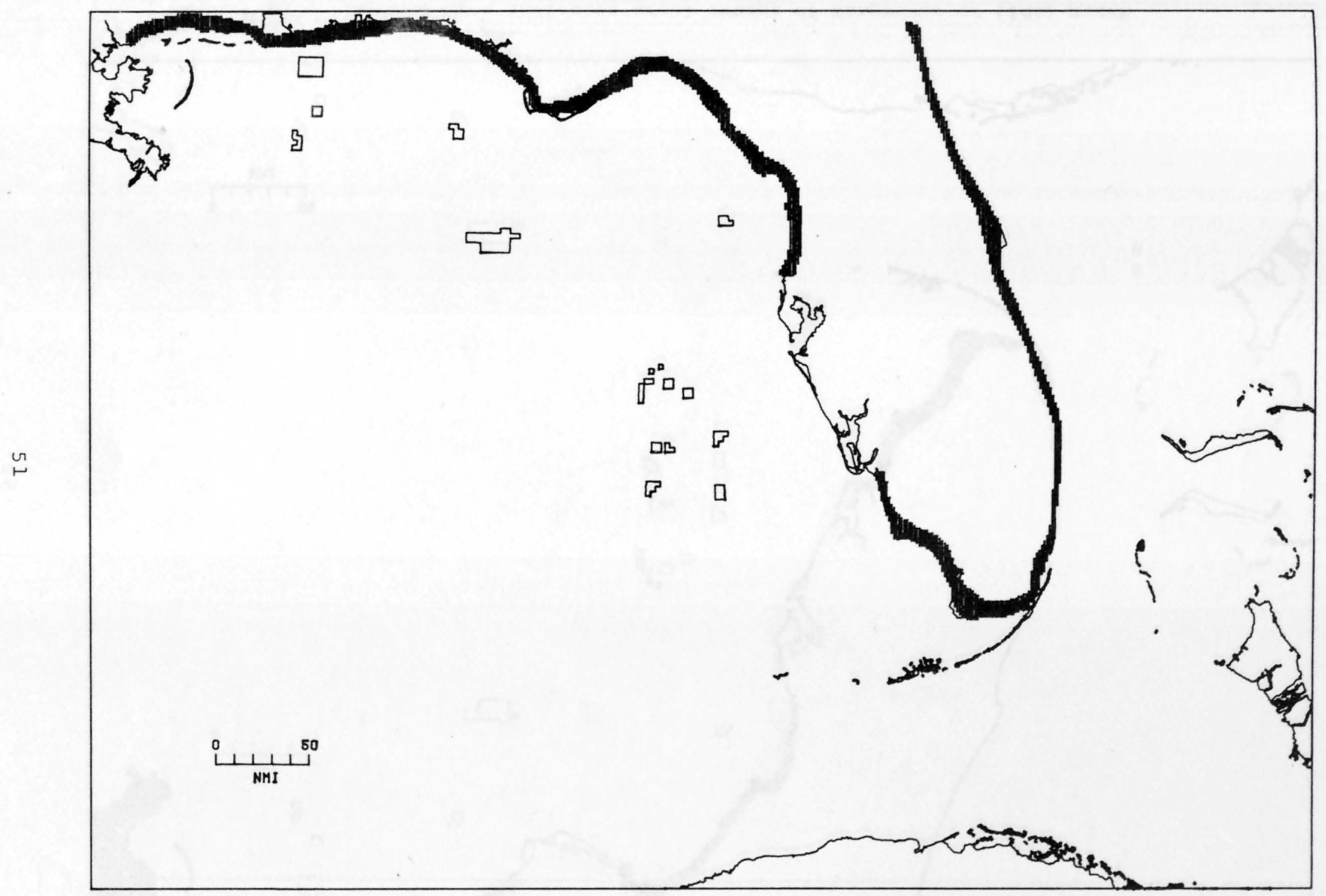

Figure A-9.--Hatched area indicates areal extent of American alligator habitat. 


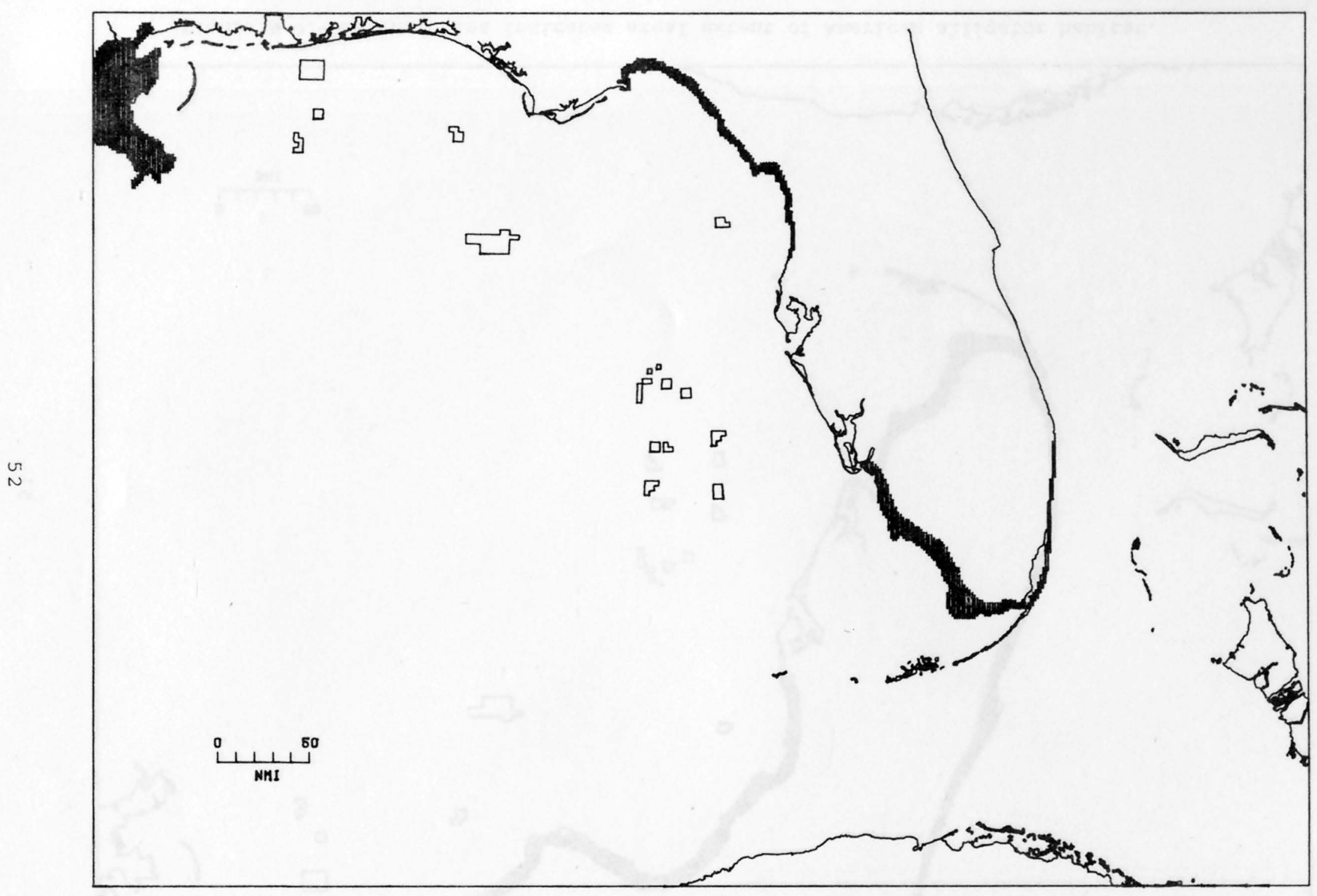

Figure A-10.--Hatched area indicates areal extent of mangroves or tidal marsh. 


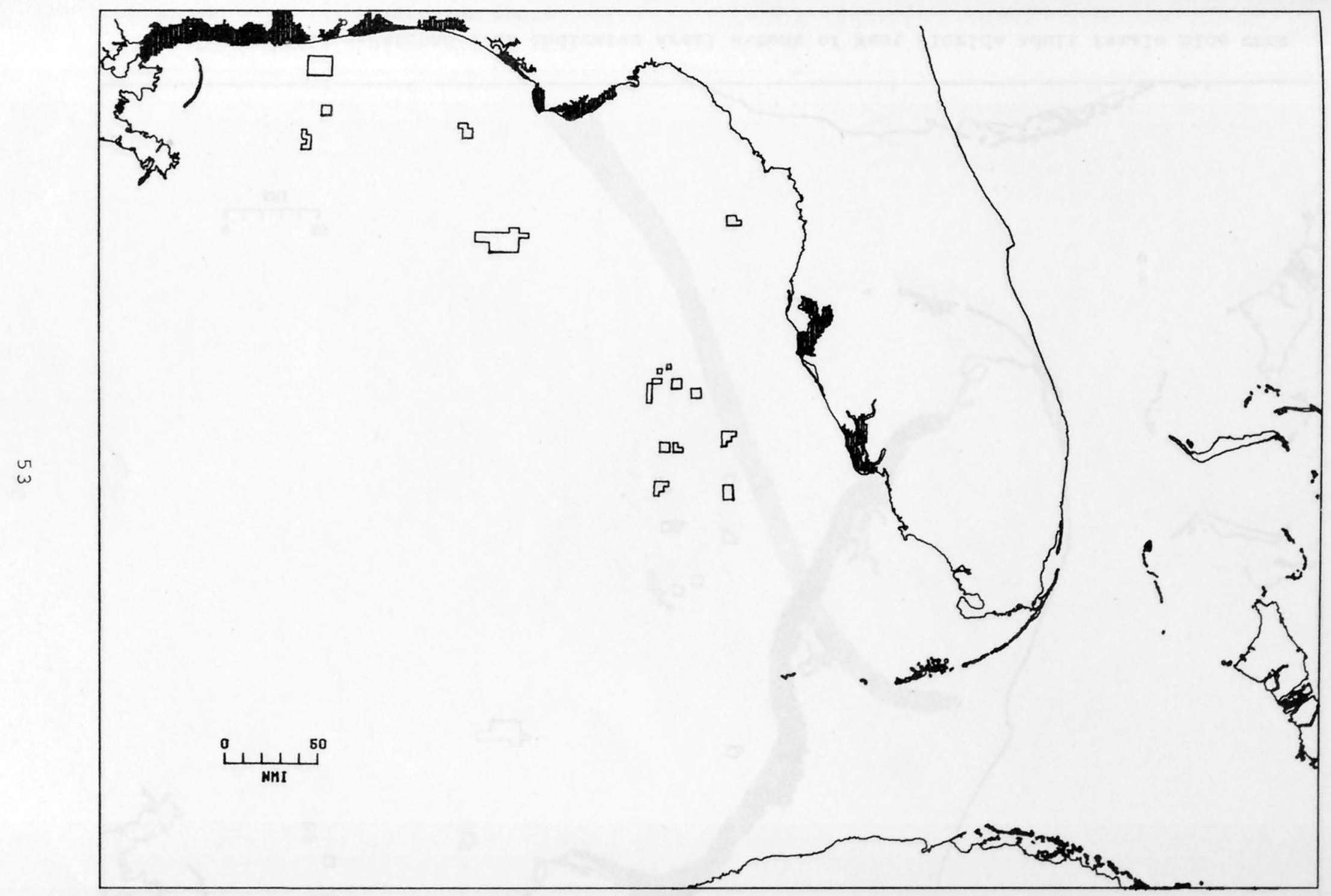

Figure A-11.--Hatched area indicates areal extent of estuarine nursery areas. 


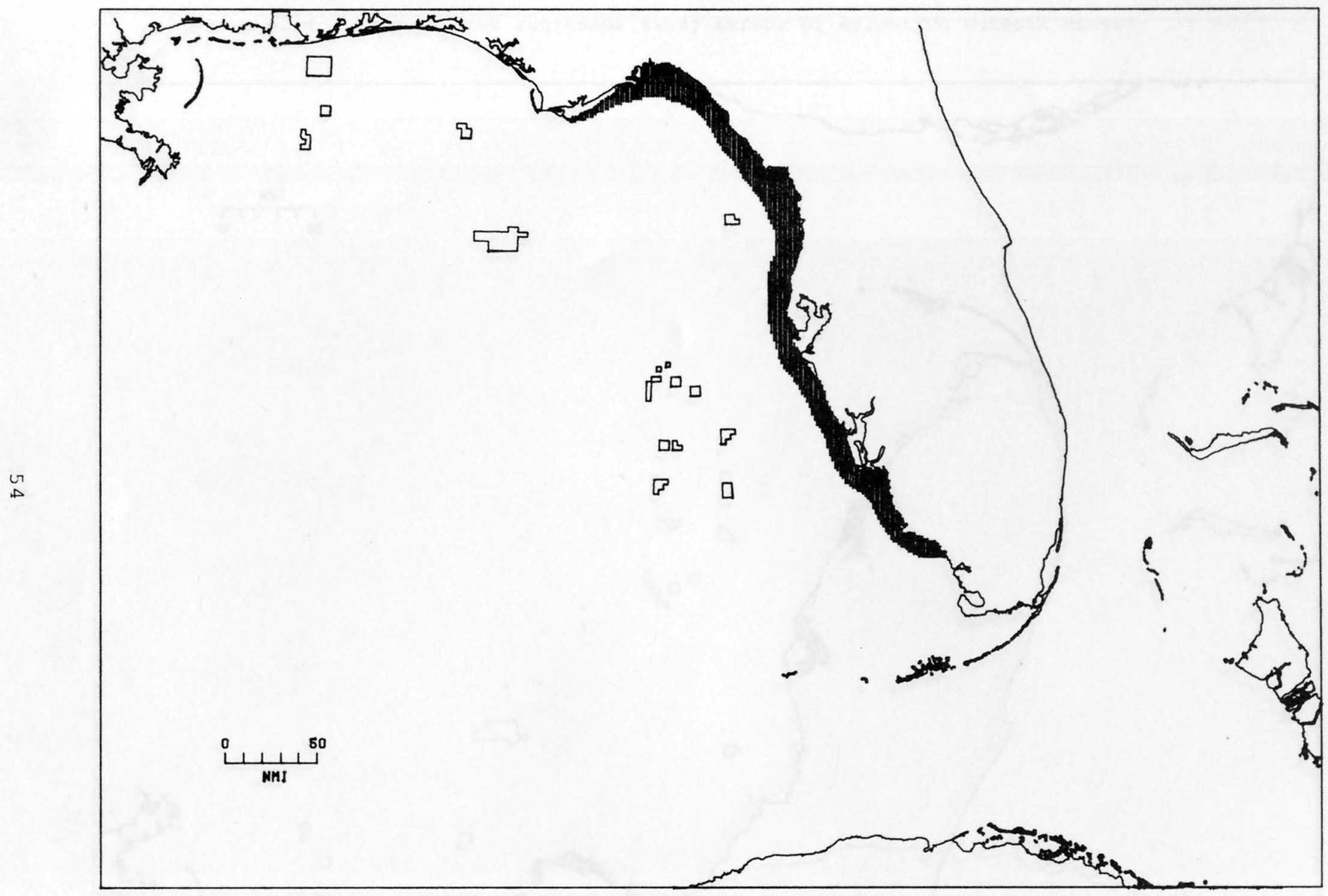

Figure A-12.--Hatched area indicates areal extent of West Florida adult female blue crab migration route. 


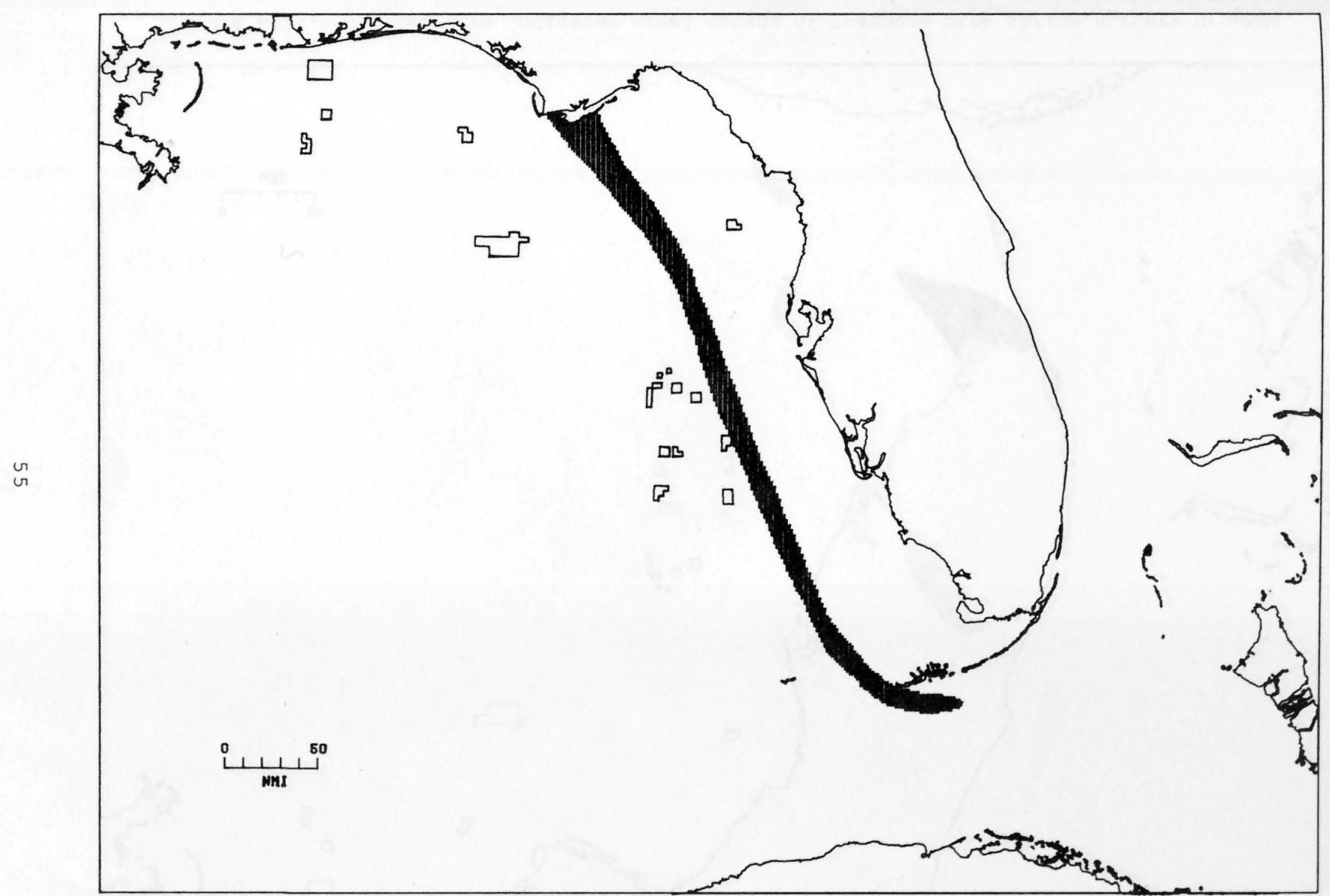

Figure A-13.--Hatched area indicates areal extent of West Florida blue crab larval transport route. 


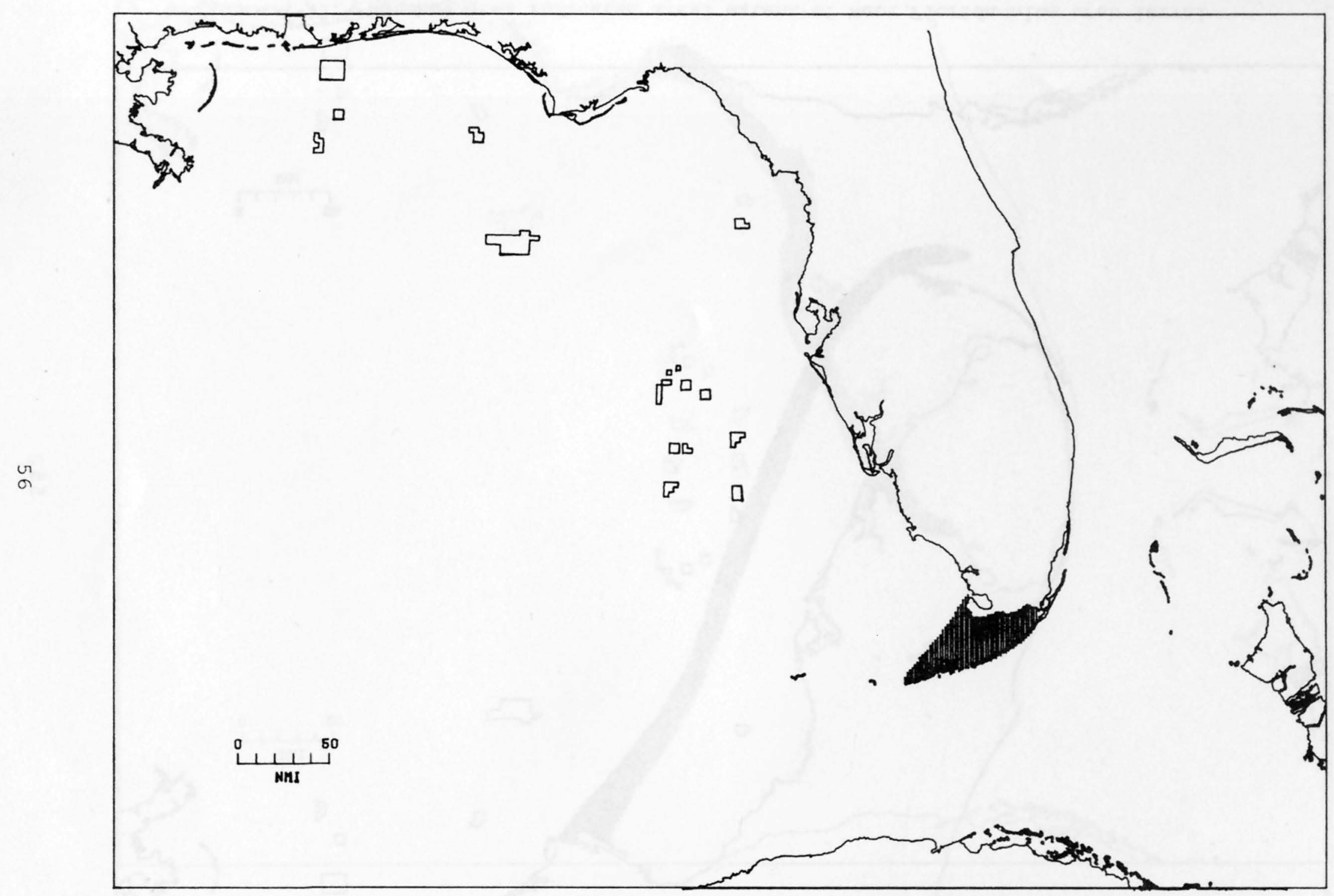

Figure A-14.--Hatched area indicates areal extent of Tortugas pink shrimp nursery grounds. 


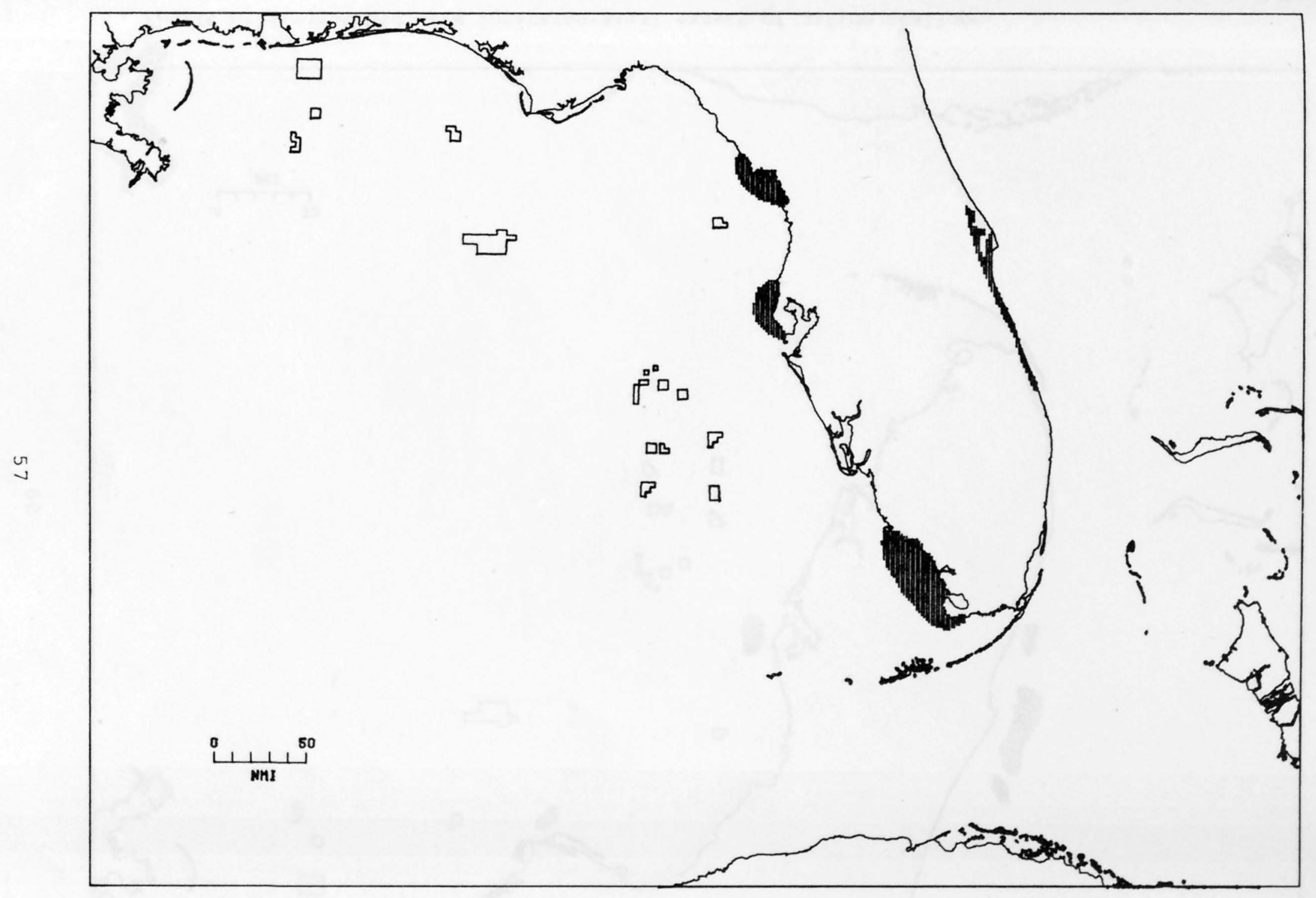

Figure A-15.--Hatched area indicates areal extent of stone crab habitat. 


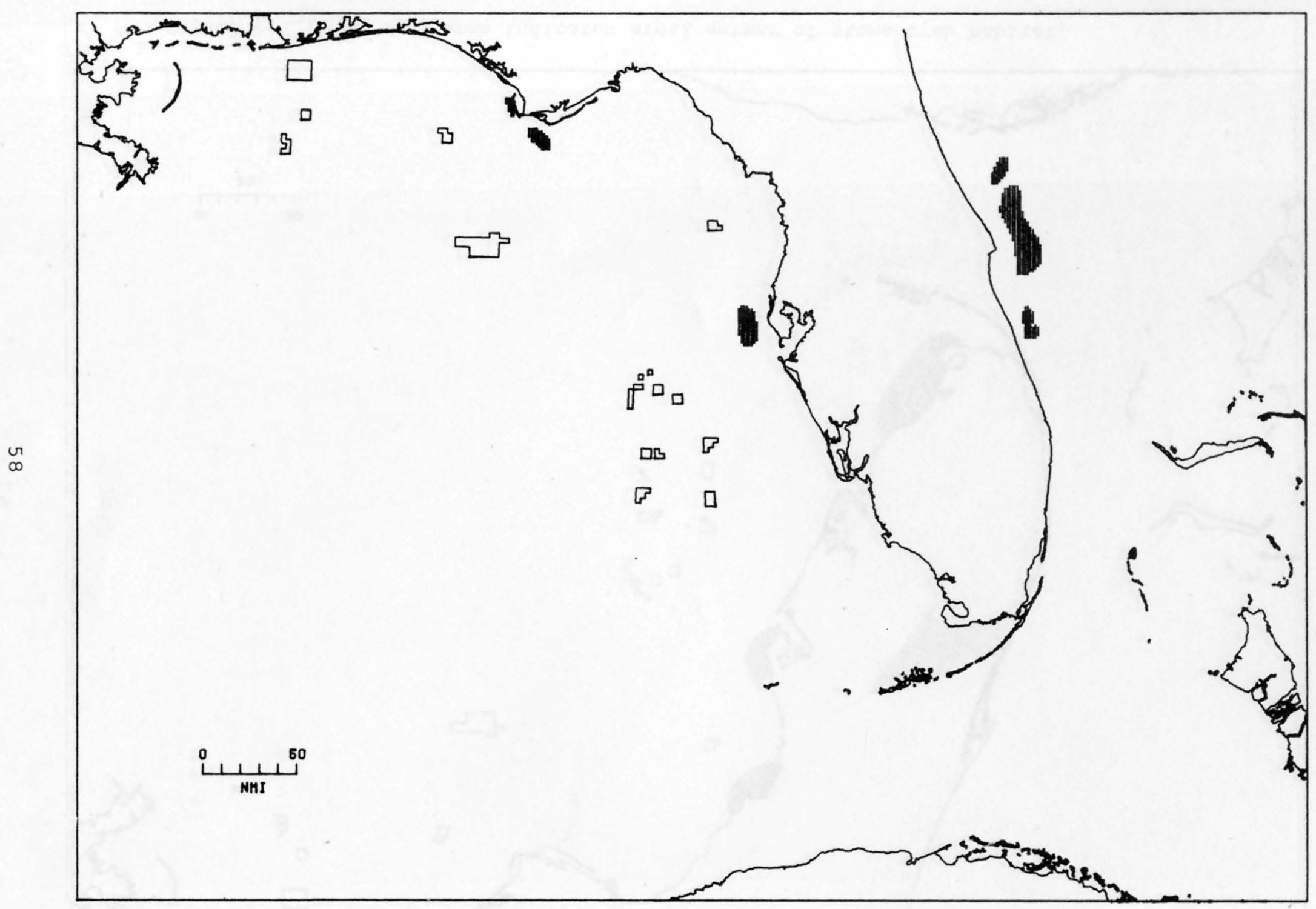

Figure A-16.--Hatched area indicates areal extent of calico scallops. 


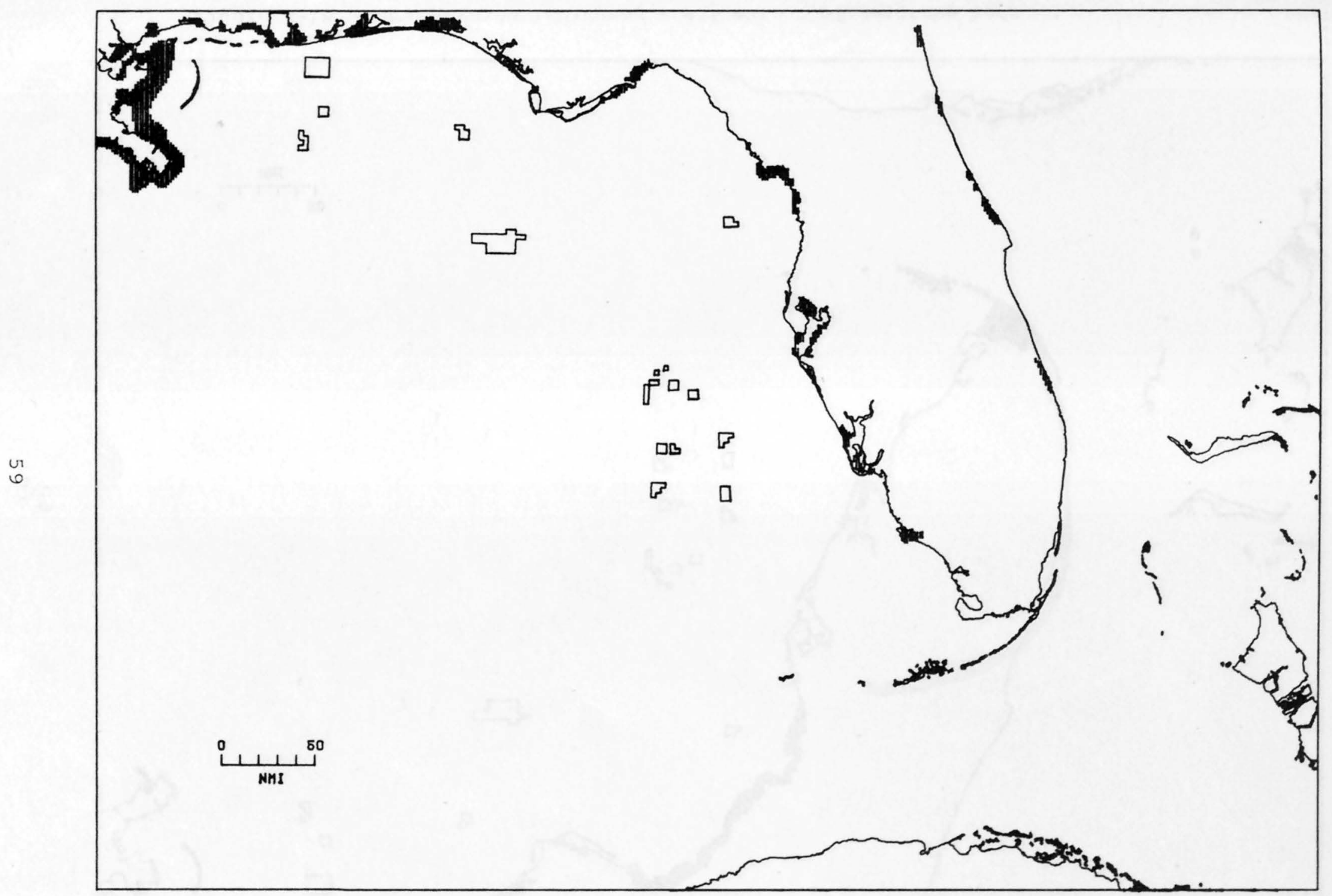

Figure A-17.--Hatched area indicates areal extent of oysters and bay scallops. 


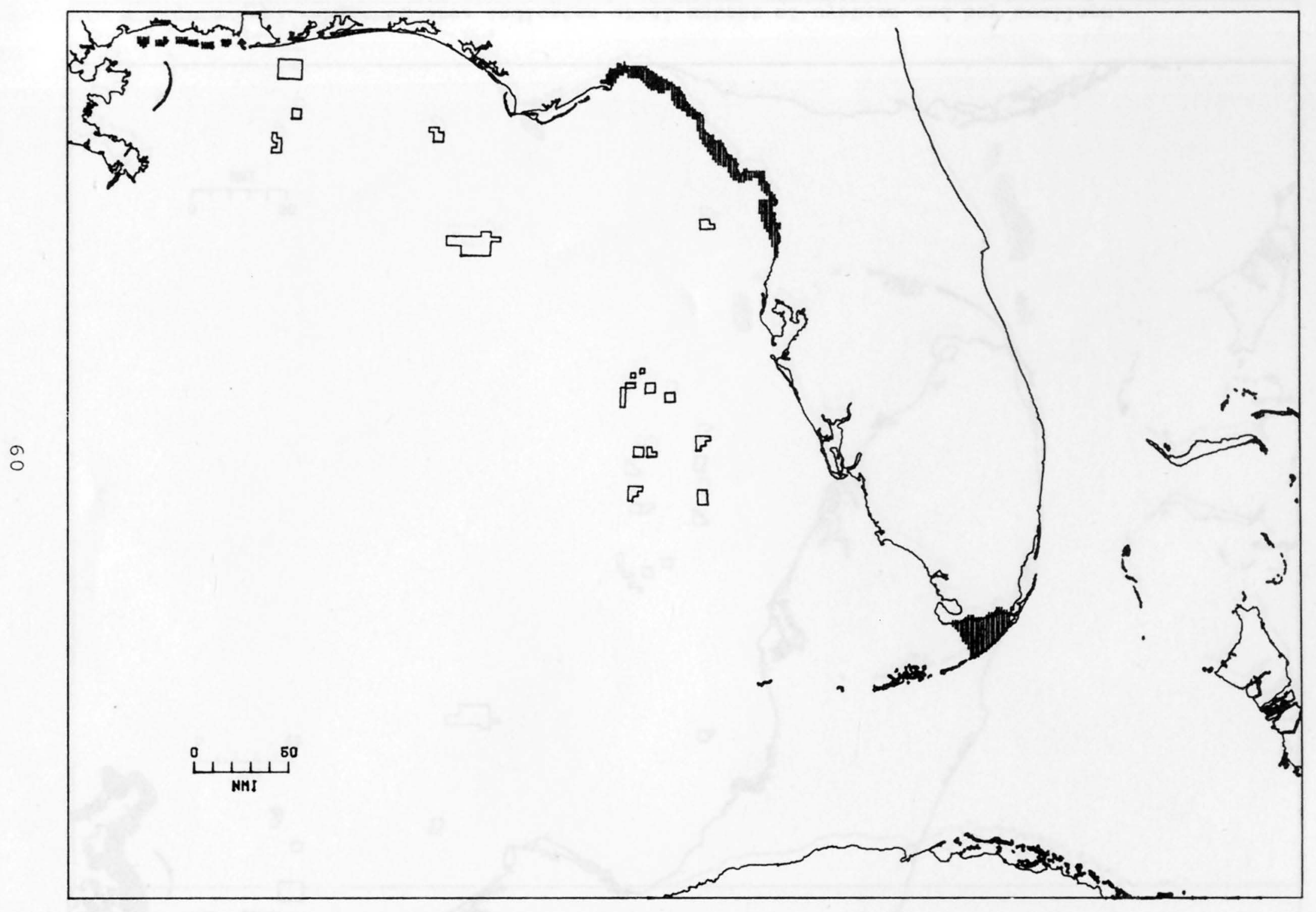

Figure A-18.--Hatched area indicates areal extent of seagrass beds. 


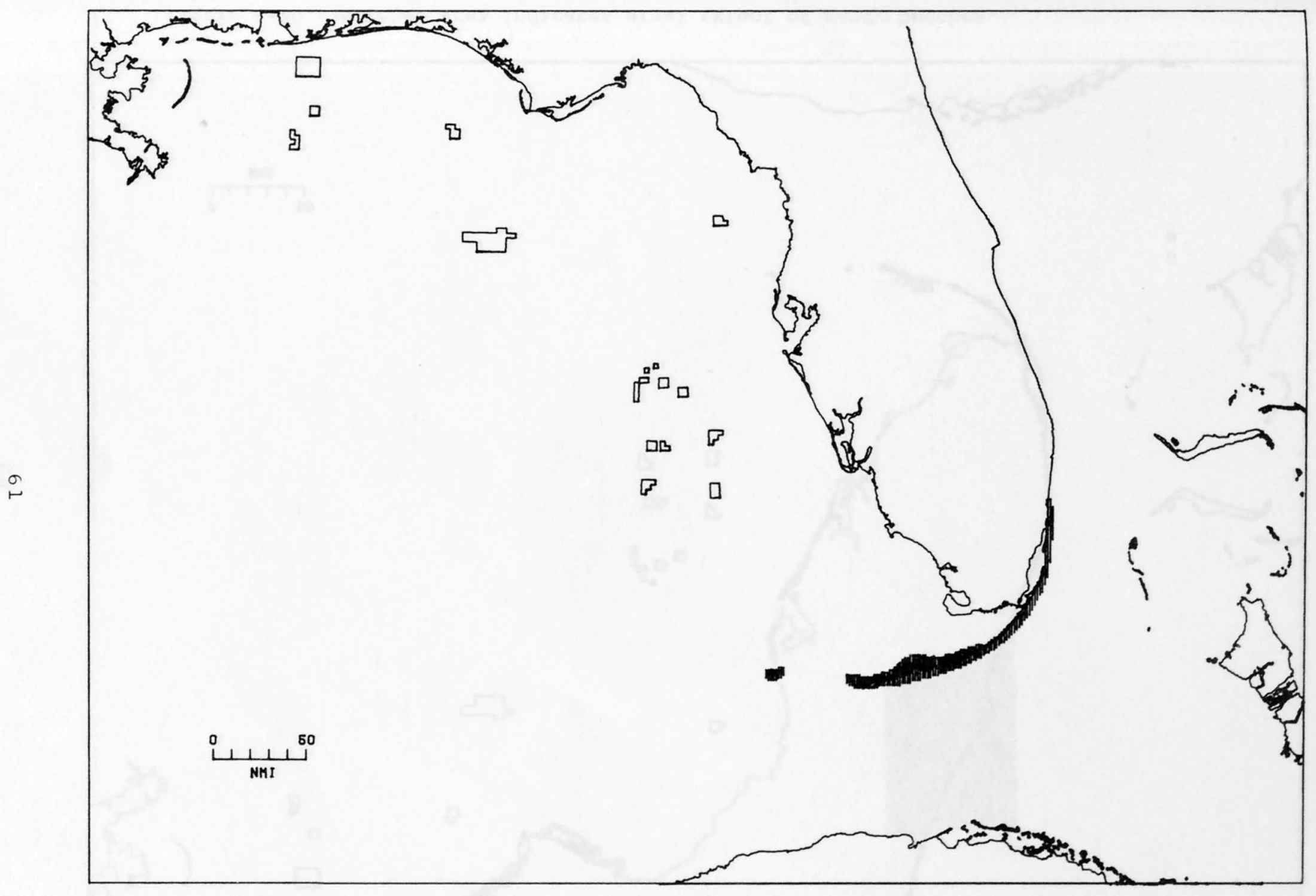

Figure A-19.--Hatched area indicates areal extent of spiny lobster. 


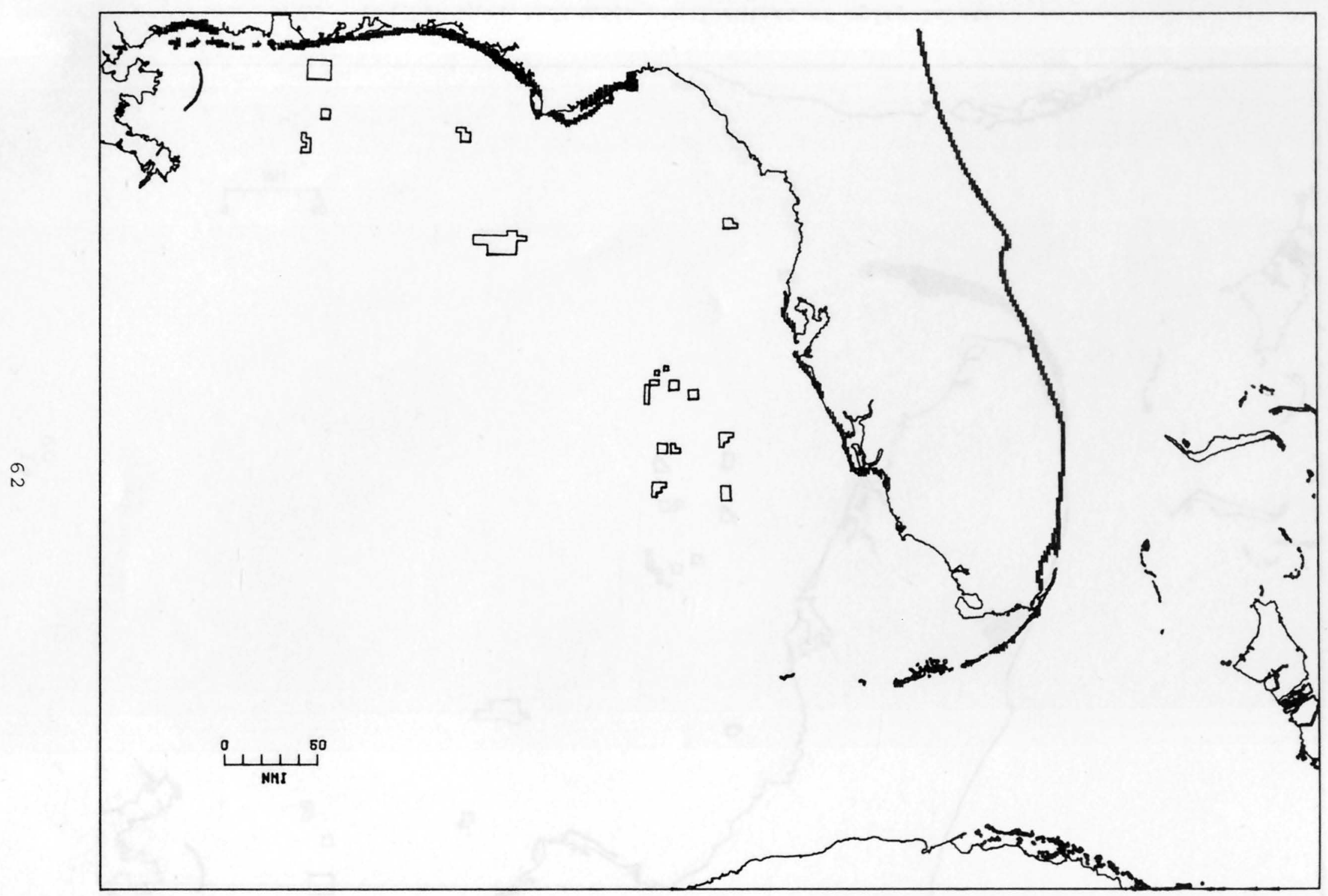

Figure A-20.--Hatched area indicates areal extent of sandy beaches. 


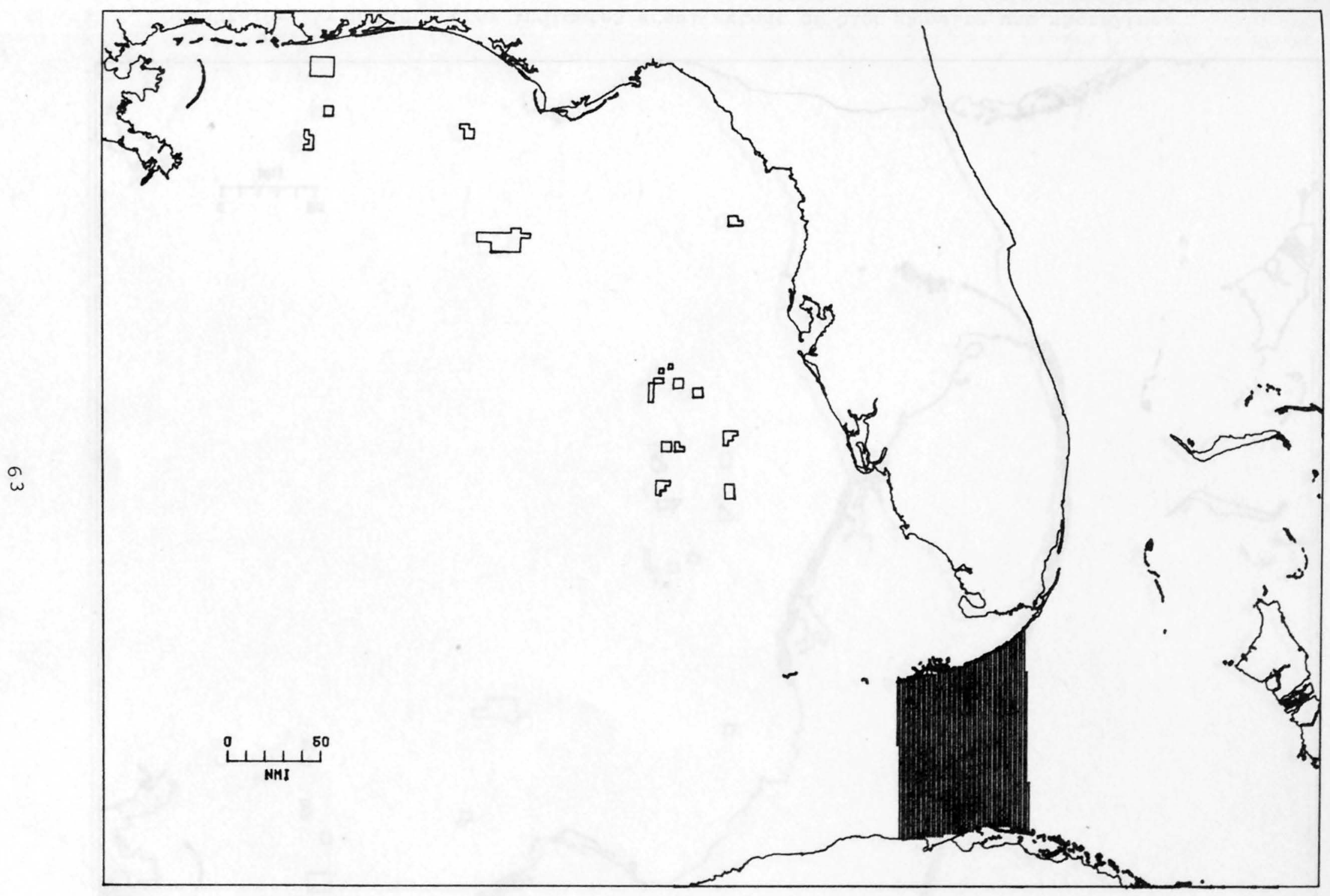

Figure A-21.--Hatched area indicates areal extent of Florida Straits. 


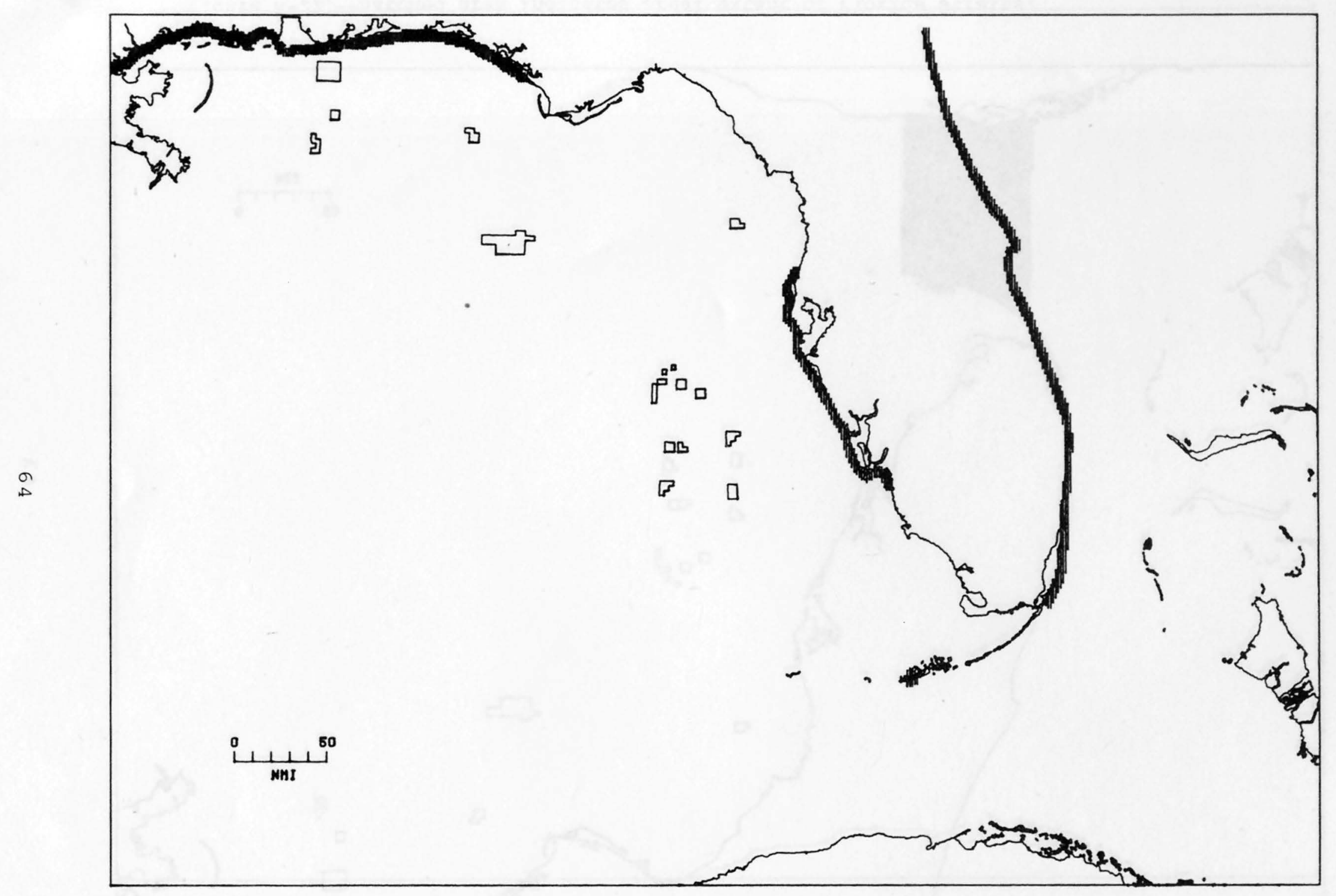

Figure A-22.--Hatched area indicates areal extent of high density use shoreline. 


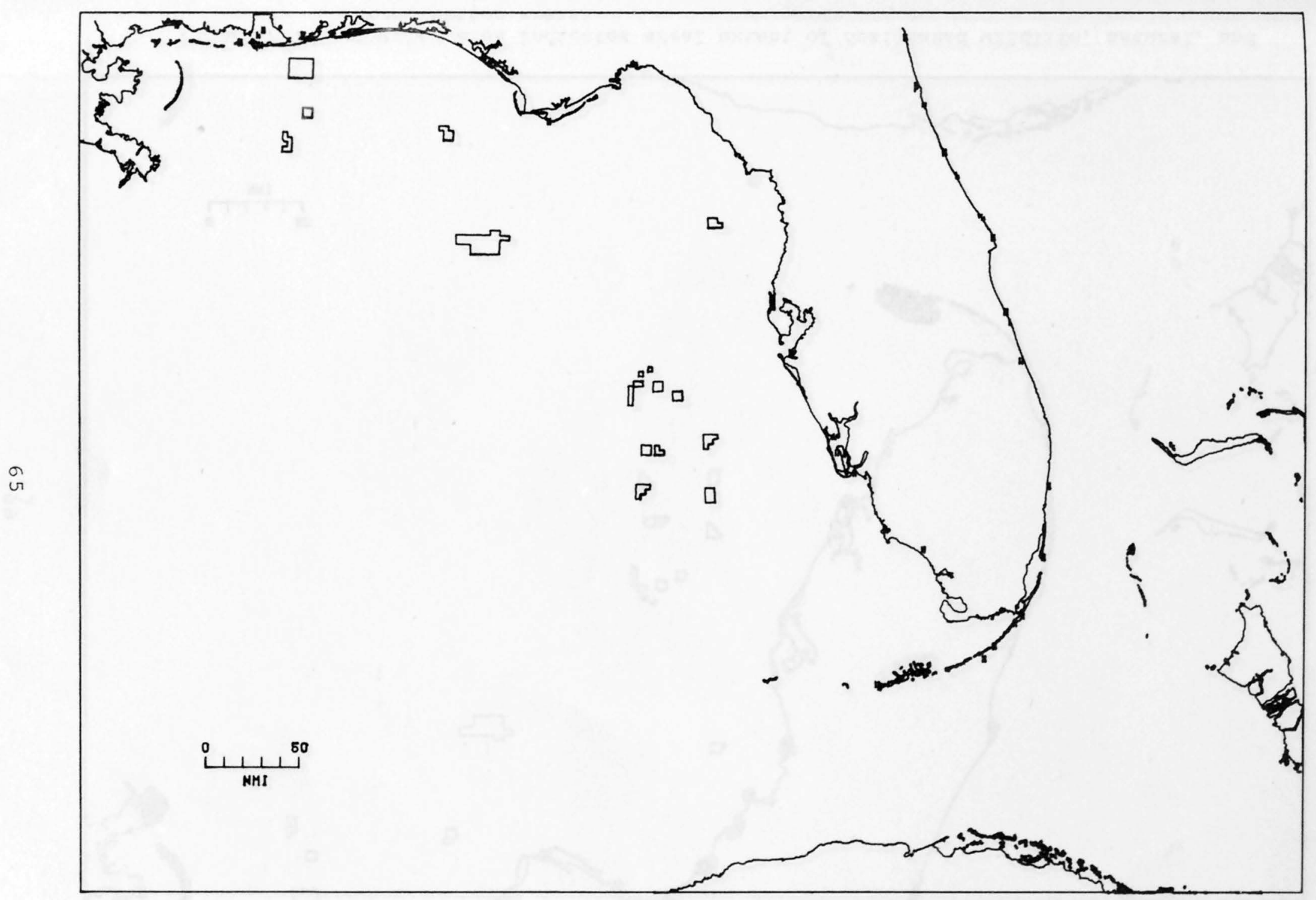

Figure A-23.--Hatched area indicates areal extent of national register sites. 


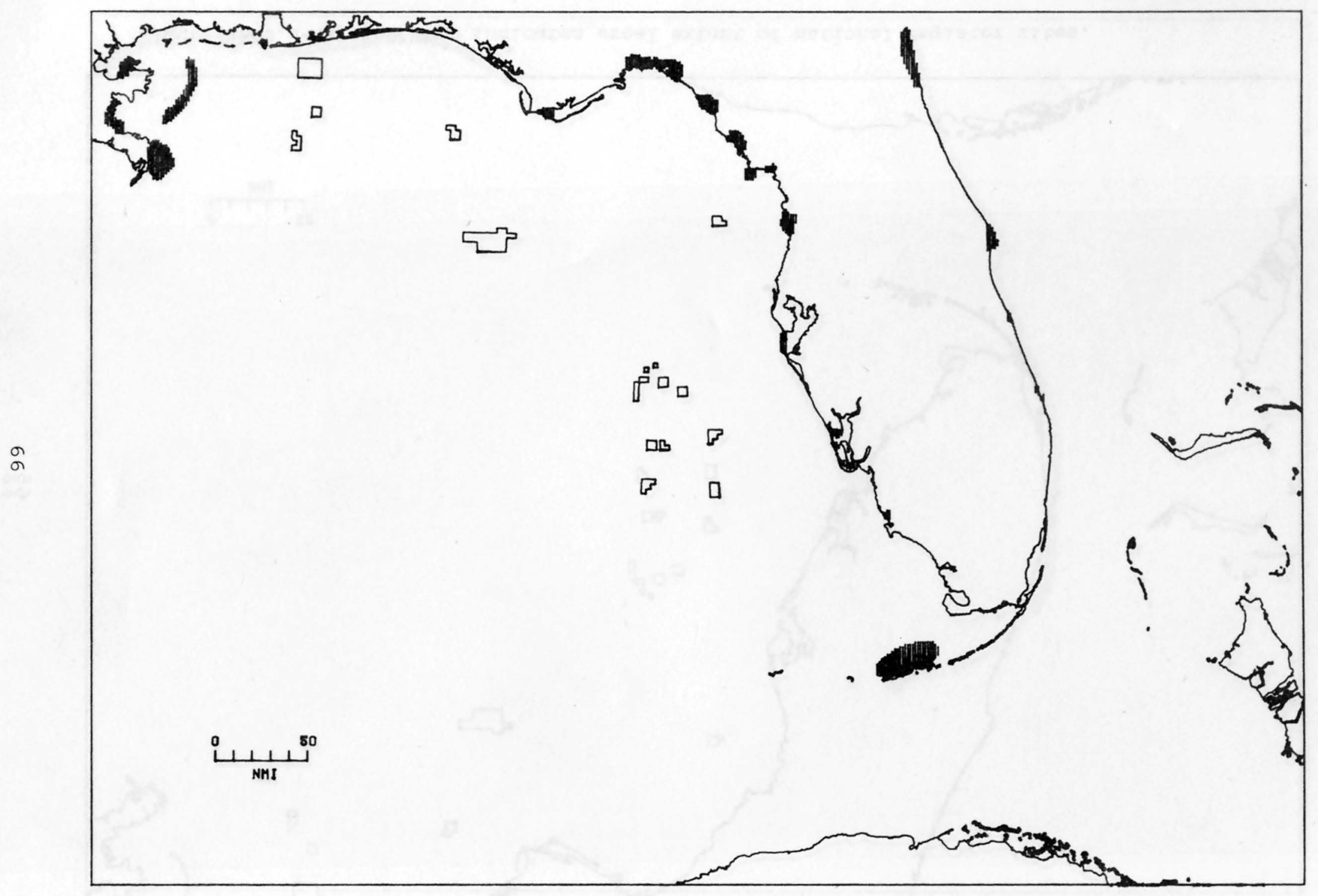

Figure A-24.--Hatched area indicates areal extent of designated wildlife, natural, and conservation areas. 


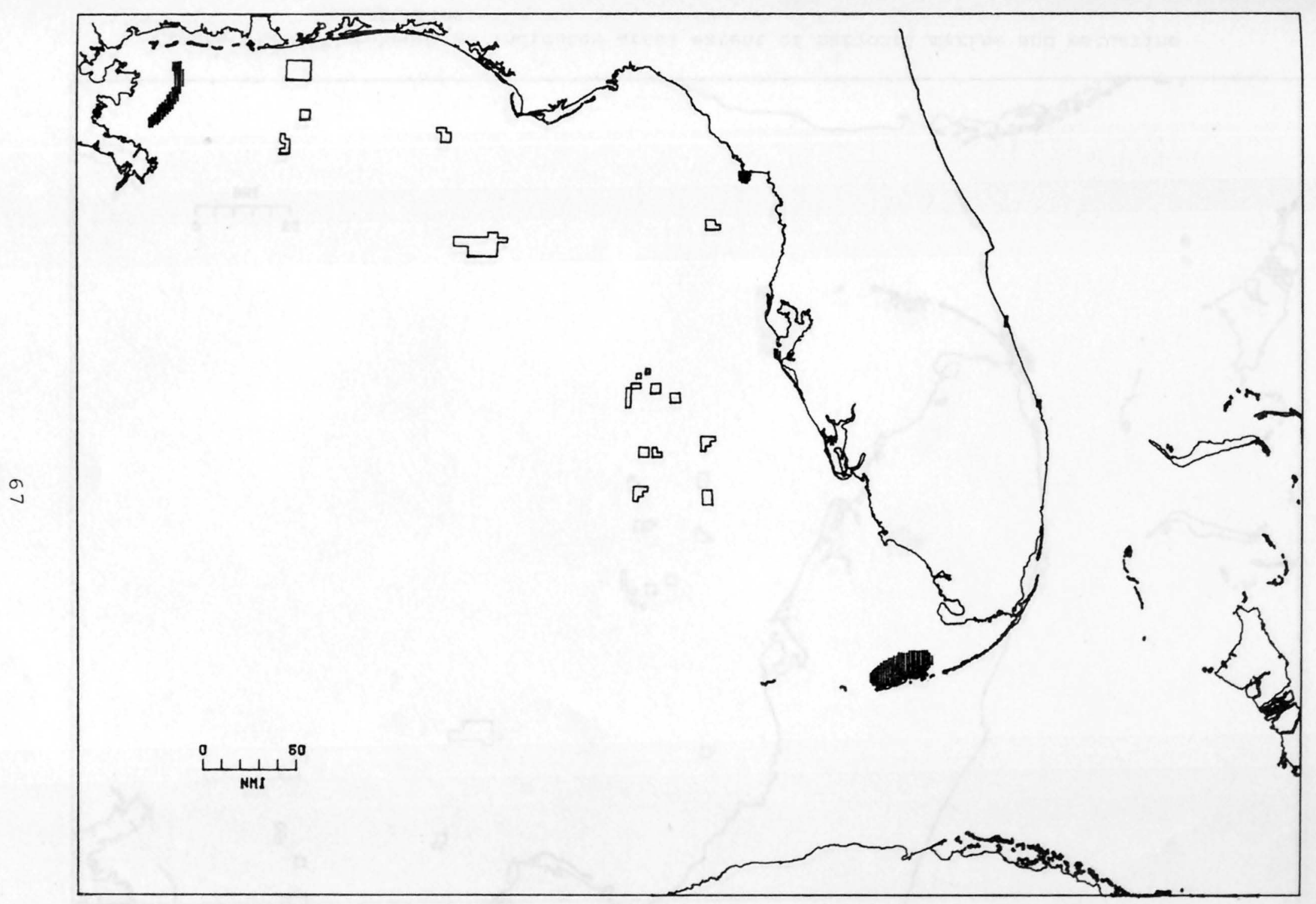

Figure A-25.--Hatched area indicates areal extent of designated national wilderness areas. 


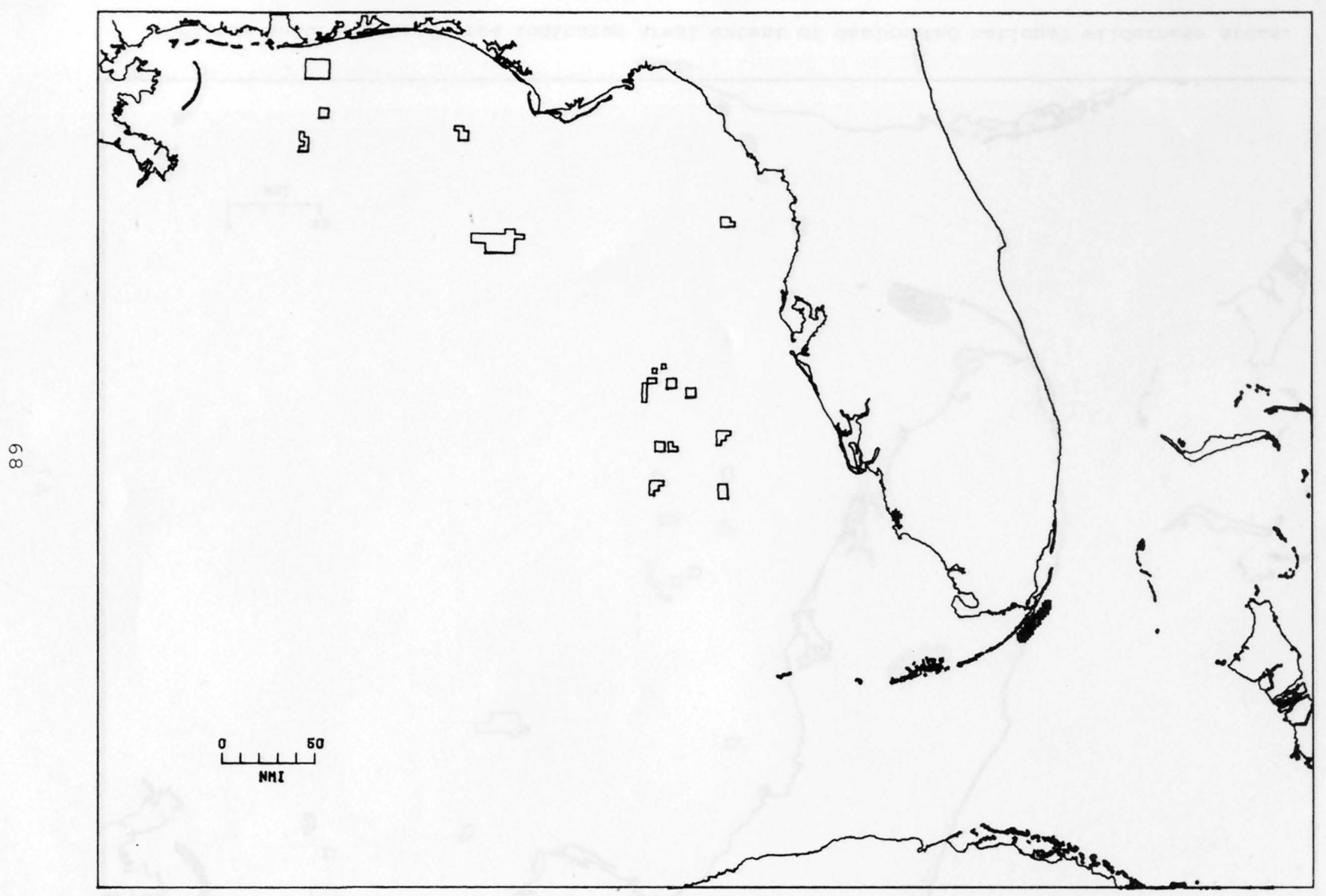

Figure A-26.--Hatched area indicates areal extent of national marine and estuarine sanctuaries. 


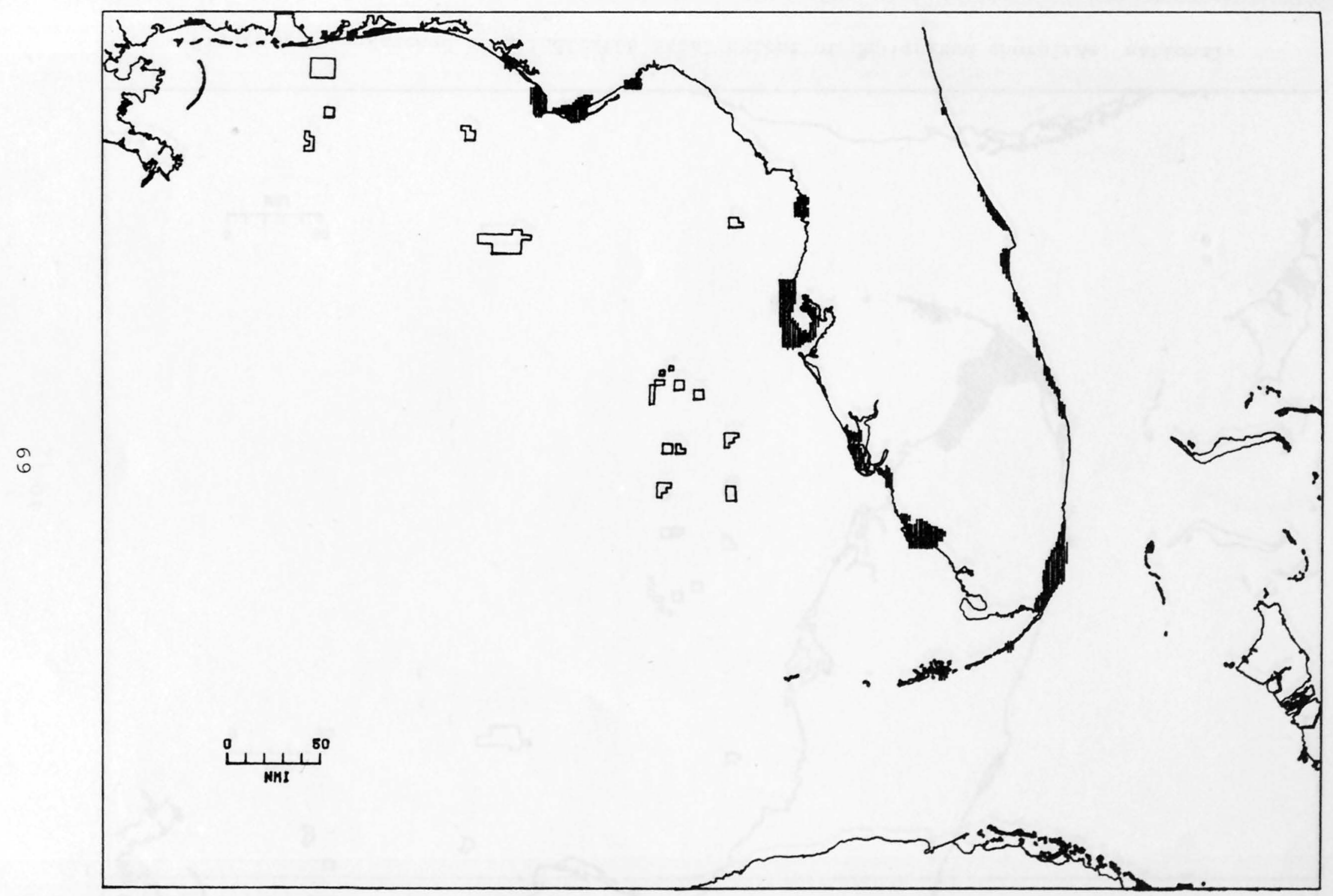

Figure A-27.--Hatched area indicates areal extent of Florida aquatic preserves. 


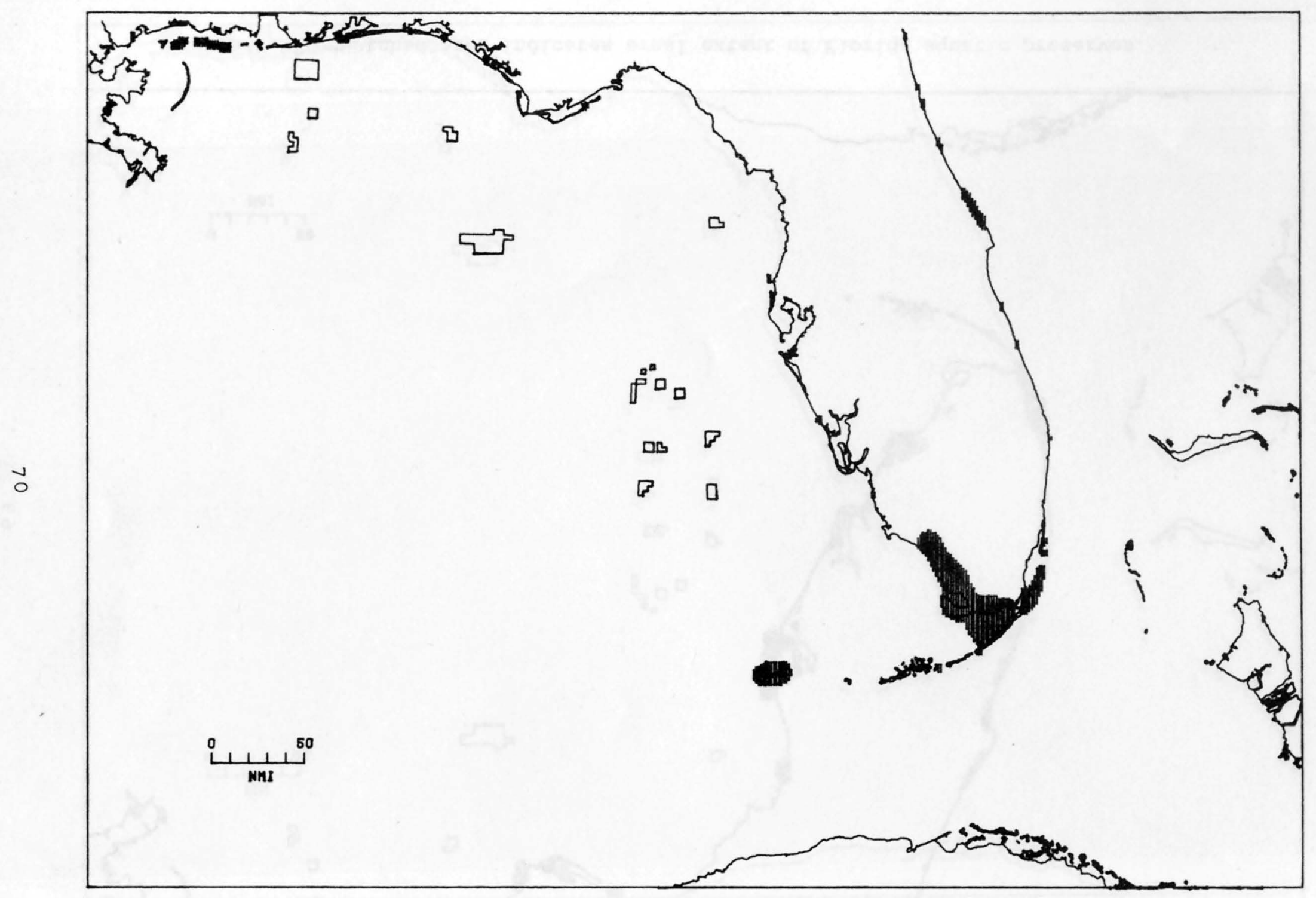

Figure A-28.--Hatched area indicates areal extent of designated shoreline, national, and state parks. 


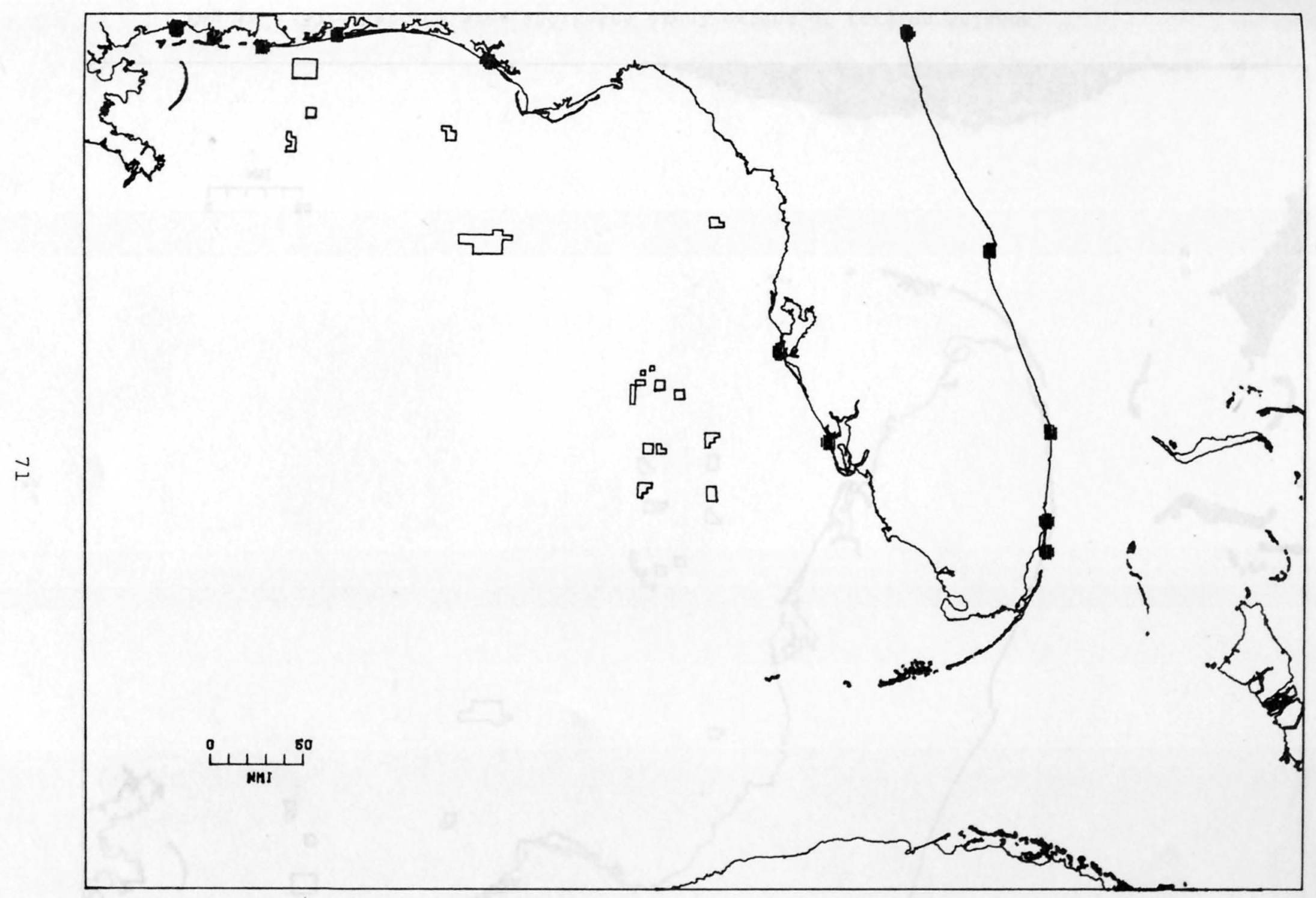

Figure A-29.--Hatched area indicates areal extent of ports. 


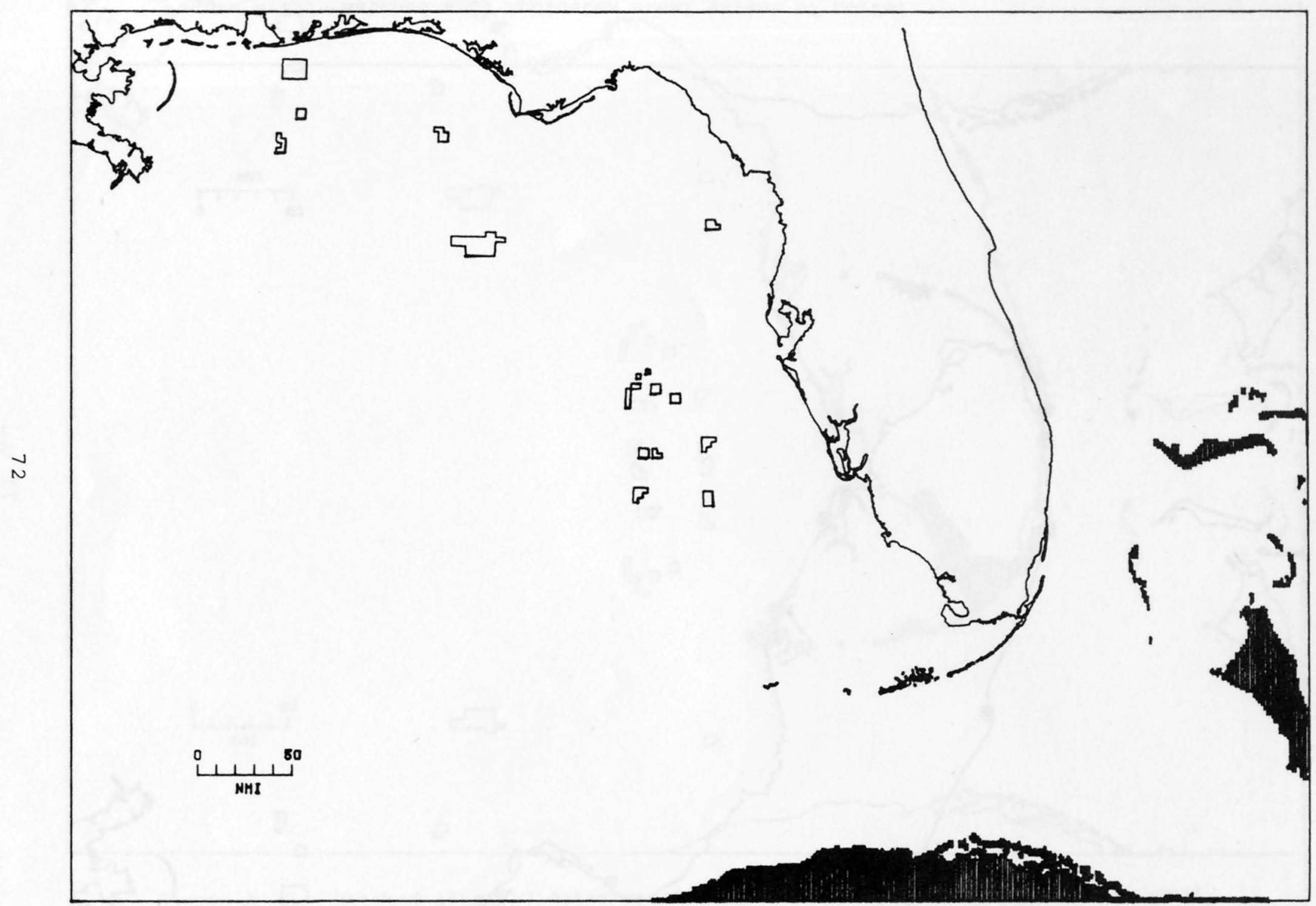

Figure A-30.--Hatched area indicates areal extent of foreign islands. 